\author{
UNIVERSIDADE DE SÃO PAULO \\ ESCOLA DE COMUNICAÇÕES E ARTES \\ PROGRAMA DE PÓS-GRADUAÇÃO EM CIÊNCIA DA INFORMAÇÃO
}

CÉLIA REGINA DE OLIVEIRA ROSA

Serviço de publicação por biblioteca universitária:

edição de livros digitais em acesso aberto 


\section{Serviço de publicação por biblioteca universitária: edição de livros digitais em acesso aberto}

Dissertação apresentada ao Programa de PósGraduação em Ciência da Informação da Escola de Comunicações e Artes da Universidade de São Paulo, como parte dos requisitos para obtenção do título de Mestre em Ciência da Informação.

Área de Concentração: Programa de PósGraduação em Ciência da Informação

Linha de pesquisa: Gestão de Unidades de Informação

Orientador: Prof. Dr. Marcos Luiz Mucheroni

São Paulo

2018 
Autorizo a reprodução e divulgação total ou parcial deste trabalho, por qualquer meio convencional ou eletrônico, para fins de estudo e pesquisa, desde que citada a fonte.

Ficha Catalográfica

Rosa, Célia Regina de Oliveira

Serviço de publicação por biblioteca universitária: edição de livros digitais em acesso aberto / Célia Regina de Oliveira Rosa. - 2018.

97 p.: il.

Dissertação (Mestrado Profissional) - Escola de Comunicações e Artes da Universidade de São Paulo, 2018.

Orientador: Marcos Luiz Mucheroni.

1. Biblioteca publicadora. 2. Serviço de publicação. 3. Livro digital. 4. Comunicação acadêmica. 5. Editora de universidade. I. Rosa, Célia Regina de Oliveira. II. Título.

CDD 027.7

Elaborada pela bibliotecária Célia Regina de Oliveira Rosa CRB 8/5653 
Nome: ROSA, Célia Regina de Oliveira

Título: Serviço de publicação por biblioteca universitária: edição de livros digitais em acesso aberto

Dissertação apresentada ao Programa de PósGraduação em Ciência da Informação da Escola de Comunicações e Artes da Universidade de São Paulo, como parte dos requisitos para obtenção do título de Mestre em Ciência da Informação.

Aprovado em:

BANCA EXAMINADORA

Prof ${ }^{\mathrm{a}}$. Dra .

Instituição:

Julgamento:

Prof ${ }^{\mathrm{a}}$. Dra .

Instituição:

Julgamento:

Prof. Dr.

Instituição:

Julgamento: 


\section{AGRADECIMENTOS}

Agradeço a Deus pelas benções concedidas em todos os momentos de minha vida.

Ao Prof. Dr. Marcos Luiz Mucheroni pela orientação recebida ao longo do período do Mestrado Profissional, que muito contribuiu para meu aperfeiçoamento.

Aos docentes da Universidade de São Paulo, Escola de Comunicações e Artes, integrantes das bancas de Qualificação e Defesa:

À Prof ${ }^{a}$. Drạ. Maria Laura Martinez pelo estímulo e instruções dadas acerca do tema desta dissertação, que muito enriqueceu o trabalho final.

Ao Prof. Dr. José Fernando Modesto da Silva que igualmente incentivou e apontou diretrizes para desenvolvimento deste estudo.

À Prof ${ }^{a}$. Dr ${ }^{\underline{a}}$. Teresa Cardoso, da Universidade Aberta de Lisboa, por estar presente em minha defesa e por transmitir parte de sua experiência e conhecimento sobre livros digitais.

Agradecimentos especiais a:

Jason Colman do Michigan Publishing Services, Universidade de Michigan, por fornecer informações para composição do estudo de caso.

Paulus Editora, nas pessoas de Guilherme César e Claudiano Avelino, pelo relato do que caracteriza o trabalho do editor e à Daniela Kovacs minha gratidão pela boa vontade em demonstrar e ensinar as rotinas para edição de um livro digital, contribuindo com meu aprendizado.

À minha família pelo carinho e palavras de incentivo a mim dedicados em todos os momentos para conclusão deste trabalho. 
"If nature has made any one thing less susceptible, than all others, of exclusive property, it is the action of the thinking power called an Idea; which an individual may exclusively possess as long as he keeps it to himself; but the moment it is divulged, it forces itself into the possession of every one, and the receiver cannot dispossess himself of it. It's peculiar character too is that no one possesses the less, because every other possesses the whole of it. $\mathrm{He}$ who receives an idea from me, receives instruction himself, without lessening mine; as he who lights his taper at mine, receives light without darkening me."

(Thomas Jefferson to Isaac McPherson, 13 August 1813) ${ }^{1}$

\footnotetext{
${ }^{1}$ Disponível em: <http://tjrs.monticello.org/letter/293>
} 


\section{RESUMO}

O foco deste estudo é a Biblioteca Publicadora, modelo difundido em biblioteca internacional universitária ou de pesquisa para designar a biblioteca que atua em serviços de edição de conteúdos acadêmicos. Discute a produção do livro digital pelo serviço de publicação, diferente do modelo de publicação tradicional nacional voltado normalmente à produção de revistas digitais. Ao expandir seu campo de atuação, a biblioteca reafirma sua missão de preservação e circulação da informação através da reformulação e acréscimo da atividade de publicação de conteúdos digitais acessíveis irrestritamente. $\mathrm{O}$ trabalho destaca também a parceria Biblioteca Publicadora/Editora Universitária na construção de um modelo de publicação para conteúdos digitais, ressaltando suas dificuldades e ações por subsistência no meio acadêmico; envolvendo a busca por novos autores, leitores. Descreve a contribuição de entidades e associações, como o Library Publishing Coalition, voltadas à divulgação de práticas da publicação em formatos acessíveis via web e difusão de cursos para contribuir na formação de pessoas envolvidas na área. Este trabalho trata também das dificuldades do acesso aberto pelas vias verde, dourada, bronze, modelos híbridos, black ou piratas, além da importância do conhecimento sobre licenças de uso pela comunidade acadêmica. Apresenta estudos de caso provenientes de biblioteca de pesquisa e por editora da iniciativa privada apresentando fluxo de criação do livro digital por aplicativo de edição de conteúdo. Aponta alguns desafios da biblioteca publicadora no mundo editorial, como a relação editor/bibliotecário e as perspectivas para implementação e continuidade destas atividades.

Palavras-chave: Biblioteca Publicadora. Serviço de publicação. Livro digital. Comunicação acadêmica. Editora de universidade. Plataforma de publicação. 


\begin{abstract}
The focus of this study is the library publishing model disseminated into international university or research libraries in order to designate the library which acts in services of academic content editions. It discusses the production of digital book by a publishing service which is different from the traditional national publication model usually aimed at the production of digital journals. By expanding its field of activity, the library reaffirms its mission of preserving and circulating information by reformulating and adding the activity of publishing freely accessible digital content. The work also highlights the partnership of the Library PublishingUniversity Press in the building of a model of publication for digital contents, highlighting their difficulties and actions for subsistence in the academic environment; involving the search for new authors and readers. It further describes the contribution of entities and associations, such as the Library Publishing Coalition, in order to propagate publishing practices in web-accessible formats and distribute courses to contribute to qualification for training people involved in the area. This work also deals with the difficulties of open access through green, gold, bronze, hybrid, black or pirate models, as well as the importance of knowledge about licenses for use by the academic community. It presents cases from a research library and a publishing house report as well as the workflow of production of digital books by content publishing software. In addition, it points out some challenges facing the library publishing world, such as the publisher/librarian relationship and perspectives for the implementation and continuity of these activities.
\end{abstract}

Keywords: Library publishing. Publishing service. Digital book. Scholarly communication. University press. Publishing platform. 


\section{LISTA DE FIGURAS}

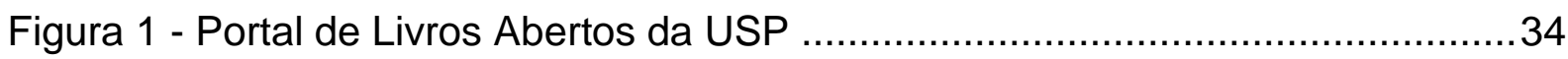

Figura 2 - Quadro comparativo das diferenças MPS e UMP .................................51

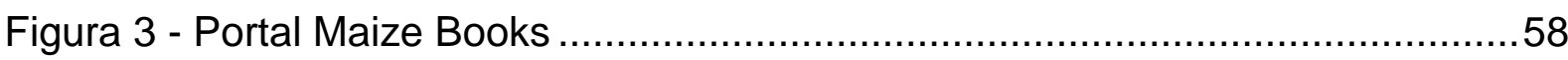

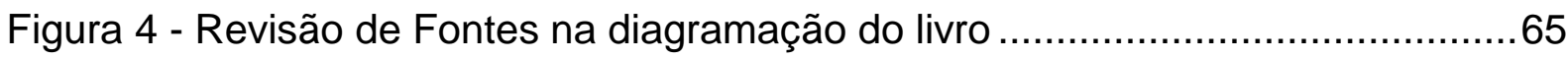

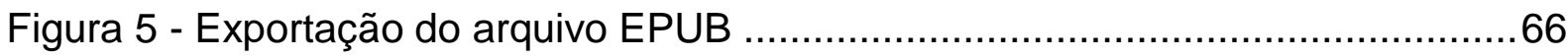

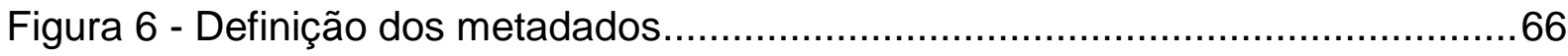

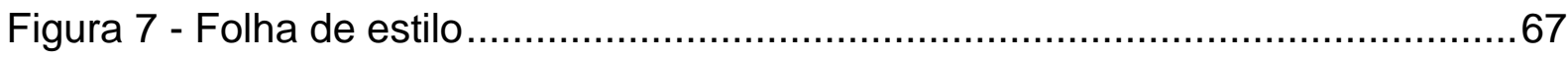

Figura 8 - HTML do livro digital com aplicação semântica na imagem de capa ........68

Figura 9 - Aplicação semântica no arquivo HTML da folha de rosto ........................69

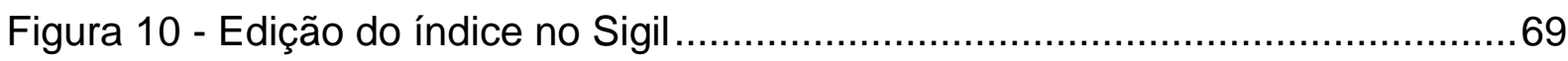

Figura 11 - Edição de metadados no Sigil.........................................................70 


\section{LISTA DE ABREVIATURAS E SIGLAS}
AA
Acesso Aberto
API
Application Programming Interface (Interface de Programação de Aplicativos)
BOAI
Budapest Open Access Initiative
$\mathrm{CC}$
Creative Commons
$\mathrm{CCO}$
Domínio Público
CC BY
Atribuição
CC BY-SA
Atribuição-Compartilhalgual
CC BY-ND
Atribuição-SemDerivações
CC BY-NC
Atribuição-NãoComercial
CC BY-NC-SA
Atribuição-NãoComercial-Compartilhalgual
CC BY-NC-ND
Atribuição-NãoComercial-SemDerivados
CSS
Cascading Style Sheets
DAISY
Digital Accessible Information System
$\mathrm{DL}$
Digital Library
DLXS
Digital Library Extension Service
$\mathrm{DOAB}$
Directory of Open Access Books
DOI
Digital Object Identifier
DRM
Digital Rights Management
EPUB
Electronic Publication
FTE
Full Time Equivalent
GNU/GPL
General Public License
HTML
Hyper Text Markup Language
IBICT
Instituto Brasileiro de Informação em Ciência e Tecnologia
IDPF
International Digital Publishing Forum
ISBN
International Standard Book Number
ISSN
International Standard Serial Number
JSTOR
Journal Storage
LIBGEN
Library Genesis
LPC
Library Publishing Coalition 


$\begin{array}{ll}\text { MARC } & \text { Machine-Readable Cataloging } \\ \text { MLP } & \text { Michigan Library Service } \\ \text { MPS } & \text { Michigan Publishing Services } \\ \text { NYU } & \text { New York University } \\ \text { OA } & \text { Open Access } \\ \text { OAPEN } & \text { Open Access Publishing in European Networks } \\ \text { OASPA } & \text { Open Access Scholarly Publishers Association } \\ \text { OMP } & \text { Open Monograph Press } \\ \text { OPAJE } & \text { Núcleo de Pesquisa e Extensão Observatório de Pesquisas } \\ & \text { Aplicadas ao Jornalismo e ao Ensino } \\ \text { PCRE } & \text { Perl Compatible Regular Expressions (Expressões Regulares } \\ & \text { compatíveis com Perl) } \\ \text { PDF } & \text { Portable Document Format } \\ \text { PKP } & \text { Public Knowledge Project } \\ \text { QS } & \text { Quacquarelli Symonds } \\ \text { RI } & \text { Repositório Institucional } \\ \text { SciELO Books } & \text { Scientific Electronic Library On-line } \\ \text { SGF } & \text { Smart Game Format } \\ \text { SIBi } & \text { Sistema Integrado de Bibliotecas } \\ \text { SIGIL } & \text { Multi-platform EPUB eBook Editor } \\ \text { SSRN } & \text { Social Science Research Network } \\ \text { SVG } & \text { Scalable Vector Graphics } \\ \text { THE } & \text { Times Higher Education } \\ \text { TI } & \text { Technology Information } \\ \text { TXT } & \text { Formato de Arquivo Simples } \\ \text { UMP } & \text { University of Michigan Press } \\ \text { URL } & \text { Uniform Resource Locator } \\ \text { USP } & \text { Universidade de São Paulo } \\ \text { WYSIWYG } & \text { What You See Is What You Get } \\ \text { XML } & \text { eXtensible Markup Language } \\ & \end{array}$




\section{Sumário}

1 INTRODUÇÃO

1.1 Justificativa

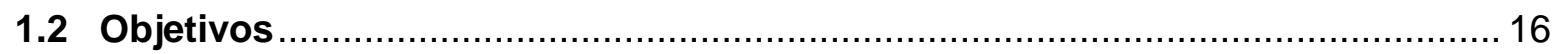

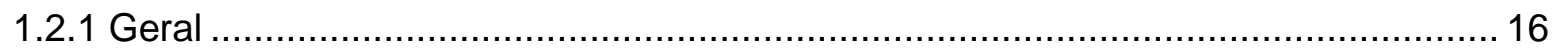

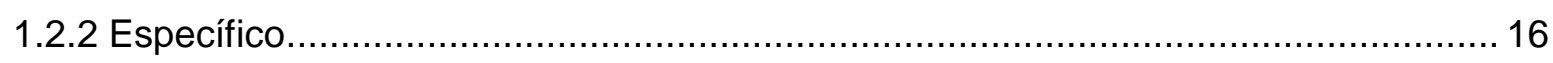

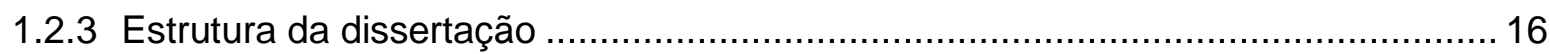

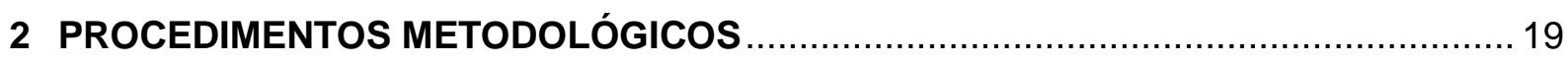

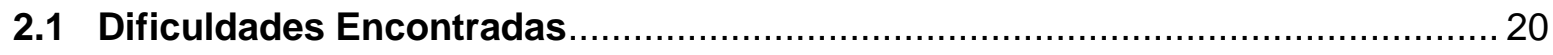

3 CONTEXTO

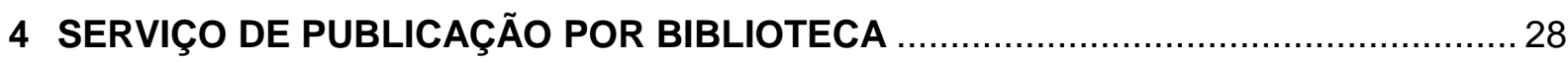

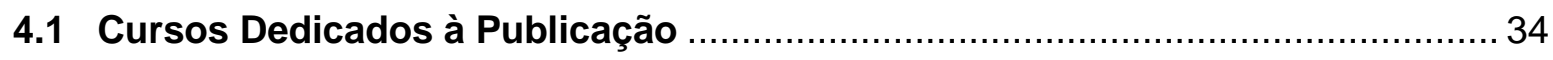

5 ACESSO ABERTO E IMPLICAÇÕES NO MERCADO EDITORIAL ………................. 38

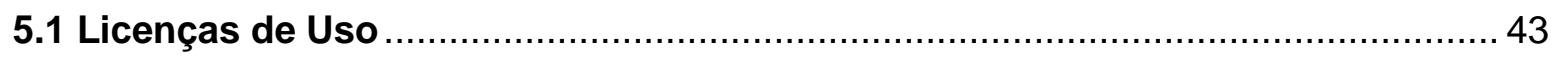

5.2 Formato Aberto EPUB

6 PRÁTICAS DE PUBLICAÇÃO DO LIVRO DIGITAL: ESTUDOS DE CASO …………....48

6.1 Estudo de Caso da Michigan Publishing of University of Michigan Library ...... 49

6.1.1 Software utilizado ................................................................................... 51

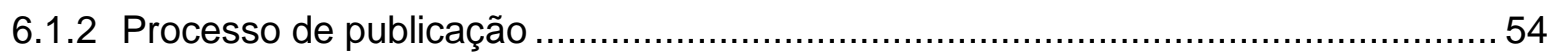

6.2 Estudo de Caso da Editora Comercial Paulus ………......................................60

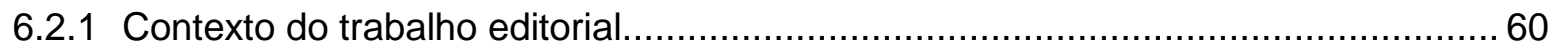

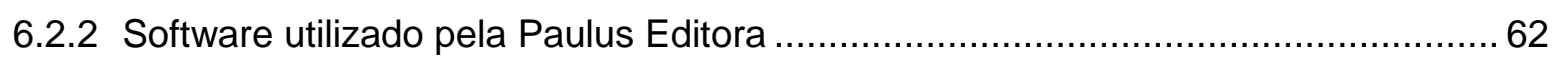

6.2.3 Processos de desenvolvimento do livro digital no editor Sigil ................................64

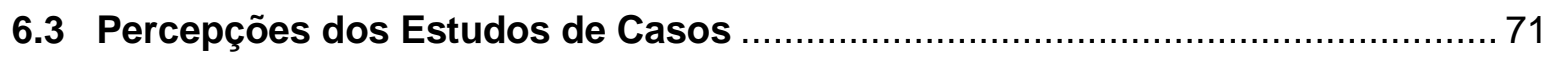

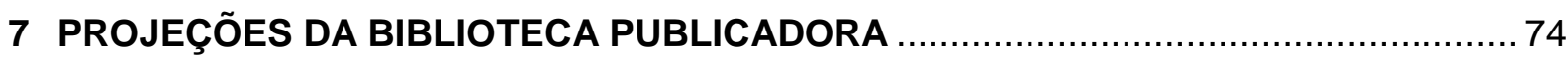

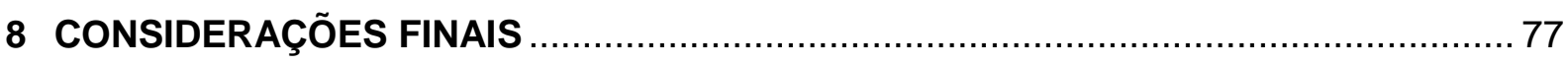

REFERÊNCIAS

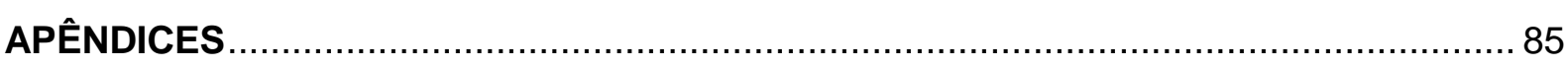

APÊNDICE A - Questões para Levantamento de Informações do MPS..................... 86

APÊNDICE B - Processos de Desenvolvimento do Livro Digital ............................... 89 


\section{INTRODUÇÃO}

O contexto desta pesquisa traz à tona experiências vividas no exercício profissional como bibliotecária encarregada de publicar livros digitais, em plataforma aberta, produzidos por docentes da Universidade de São Paulo. A prática diária contribuiu no aumento do interesse para investigar a produção de livros digitais proveniente do meio acadêmico, bem como a participação de editores, bibliotecários, pesquisadores e universitários no desenvolvimento desta atividade em benefício da disseminação e preservação da comunicação científica associada ao conceito de biblioteca publicadora².

As práticas da Biblioteca Publicadora vão de encontro ao entendimento da questão do trabalho editorial junto à visão do editor especialista somadas pelo trabalho cooperativo do bibliotecário em busca de uma visão interdisciplinar relativa à percepção e experiência de cada um em seus campos de conhecimento.

Para esta abordagem da biblioteca publicadora se considera:

I - A questão do trabalho editorial feito em parceria com a biblioteca: a atividade de publicar demanda que os conteúdos sigam uma norma culta, entre outros fatores, para alcance de padrões de qualidade. A curadoria deve estar presente na temática escolhida somado ao trabalho editorial, responsável por imprimir valor e credibilidade ao conteúdo digital através de processos como revisão do texto, revisão gramatical, revisão ortográfica, estilo.

II - As dificuldades: enumeram-se questões voltadas ao viés de inovação trazidas pela edição do livro acadêmico produzido pela biblioteca disseminadora da produção científica ao longo de sua existência; investiga as variáveis que influem no desenvolvimento deste trabalho, considerando que o conhecimento não se dá apenas pelo acesso à informação, mas pelo processamento desta, resultando em entendimento distinto e originando novo conhecimento.

O trabalho cooperativo entre bibliotecário e editor é necessário para constituir uma visão interdisciplinar em torno das diferenças de competências de cada um (percepção, experiência), pois o trabalho digital exige método e disciplina para que cada um entenda o próprio nível de contribuição no tocante à edição de livros digitais; além dos demais atores do processo como especialistas em publicação digital, estudantes de graduação atuando como estagiários, docentes, bibliotecários,

\footnotetext{
${ }^{2}$ Library-publishing (tradução nossa).
} 
editores, técnicos de outras formações.

O cenário de existência do livro em bibliotecas universitárias passa por coleções de acervos restritos e guardados, modificado posteriormente no momento em que o foco das universidades se tornou a pesquisa. A partir daí é necessário que as bibliotecas expandam as coleções e serviços para apoiar essa mudança (COURANT; JONES, 2014, p. 24).

Outro aspecto é a adversidade na conjuntura econômica que provoca e contribui para a desaceleração do consumo do livro em formato impresso, somado aos altos custos de criação, produção e comercialização.

A singularidade do processo de criação do livro convencional exige maior tempo do autor para sua composição o que faz aumentar o prazo até chegar às mãos do leitor, além de altos custos de produção editorial e distribuição. Depois de impresso, o livro segue inúmeras rotas de comercialização, dentre elas processos de aquisição por bibliotecas acadêmicas e sistemas de bibliotecas, lentos por inúmeras razões: verbas de aquisição institucionais, legislação, pregões, entre outros.

Esta sequência de etapas para compra do livro assegura o foco na consulta aos artigos de revista - mais acessíveis por seu alcance imediato - provenientes de repositórios institucionais, fontes de informação em acesso aberto, entre outros.

Outra dificuldade de acesso aos livros está na reforma trazida pela revolução digital, que impôs certa aceleração, em parte deste processo, pelos novos usos, formatos e acesso conectados em rede, exigindo maior agilidade nos estágios de composição do livro.

Além disso, editoras tradicionais são vendidas pelas dificuldades de mercado; fusões de capital são realizadas para constituição de grandes publicadores que, por sua vez, determinam grandes somas pelo direito ao acesso em bases de dados de produção científica para as universidades.

Empresas se estabelecem e mantêm parte de seus serviços voltados a disseminar conteúdos advindos da literatura, sem licenças, de modo a desenvolver políticas de uso e lucros extrativistas como o Google $^{3}$, que tem por missão declarada "organizar a informação mundial e torná-la universalmente acessível e útil" em mais de um milhão de servidores no planeta com solicitações de pesquisa que

\footnotetext{
${ }^{3}$ WIKIPÉDIA. A enciclopédia livre. Disponível em: <https://pt.wikipedia.org/wiki/Google>.
} 
ultrapassam a casa do bilhão, gerando maciço volume de dados que extrapolam a casa dos petabytes ( $10^{15}$ bytes).

Por volta de 2004, o Google ambicionou criar uma megabiblioteca digital, denominada Google Book Search, através da digitalização maciça dos acervos de livros da Universidade de Harvard de modo a permitir buscas em textos integrais de obras de domínio público disponíveis gratuitamente na Internet. Contudo, a empresa ambicionava vender assinaturas da base digital composta de livros protegidos por direito autoral e dividir os lucros entre autores e editores reclamantes por verem seu direito autoral infringido. O projeto não floresceu e o modelo Harvard de acesso livre vem sendo discutido no mundo acadêmico por apoiar o depósito da produção em repositório, gerenciado pela biblioteca, através do Office for Scholarly Communication e o comprometimento de difundir os resultados de pesquisas de forma livre a partir do acesso pela Internet (DARNTON, 2010, p.10).

Estes episódios não animam as bibliotecas universitárias ou de pesquisa, que tem de se adaptar às políticas de redução de custos impostas pela entidade em muitos segmentos, dentre eles o das aquisições.

Deste modo, novas diretrizes de trabalho são praticadas para garantir acesso aos conteúdos de livros: como assinaturas e contratação de pacotes de editoras com coleções didáticas para atendimento aos cursos de graduação, onde muitos títulos listados não são de interesse da comunidade universitária.

Além disso, os novos modelos de negócios difundidos por estas editoras priorizam a disseminação de conteúdos digitais em assinaturas de valores astronômicos, excluindo-se o direito da biblioteca ao acesso perpétuo da coleção.

Esta conjuntura leva a algumas soluções em rede pelas bibliotecas acadêmicas, de pesquisa, consórcios e associações sobre as práticas comuns relativas à produção de livros digitais oferecidos em acesso aberto: o chamado "library publishing" abordado neste estudo; o Library Publishing Coalition (LPC) ${ }^{4}$; The Academic Book of the Future ${ }^{5}$; OAPEN Library ${ }^{6}$ e o Directory of Open Access Books $(\mathrm{DOAB})^{7}$.

\footnotetext{
${ }^{4}$ Disponível em: <https://librarypublishing.org/>.

${ }^{5}$ Disponível em: <https://academicbookfuture.org/end-of-project-reports-2/>.

${ }^{6}$ Disponível em: <http://www.oapen.org/home>.

${ }^{7}$ Disponível em: <http://www.doabooks.org/doab?uiLanguage=en>.
} 
Para efeito de informação, o número de editoras do diretório DOAB cresceu para mais de 200 publicadores com mais de 8000 livros. Editoras universitárias do Brasil integram essa Fonte de livros digitais como: Editus, editora da Universidade Estadual de Santa Cruz (UESC, Ilhéus, BA), Editora da Universidade Estadual de Ponta Grossa (UEPG, Ponta Grossa, PR), Editora da Universidade estadual Paulista (UNESP), Editora FIOCRUZ da Fundação Oswaldo Cruz, entre outras por meio da SciELO Books.

Recentemente, o LPC através de seu blog, lançou o relatório Library Publishing Directory ${ }^{8} 2018$ enumerando atividades de biblioteca publicadora em 125 instituições de países como Estados Unidos, Canadá, Reino Unido, Austrália, Brasil, Alemanha, Irlanda e Suécia. Contudo, ainda muito trabalho precisa ser feito em prol da publicação para livros digitais oferecidos em acesso aberto.

Algumas iniciativas como workshops, treinamentos conduzidos por bibliotecários podem ser significativas para docentes e pesquisadores entenderem as formas de direito autoral e a importância de licenças de uso, seleção de fontes para publicação, comunicação acadêmica na universidade entre outras.

\subsection{Justificativa}

A pertinência deste estudo está voltada ao conceito de Biblioteca Publicadora $^{9}$ ainda sem conformidade ou entendimento no contexto brasileiro voltado à publicação de livros digitais, cujo conteúdo acadêmico e científico pode ser oferecido em acesso aberto por biblioteca universitária ou de pesquisa.

A biblioteca publicadora ou serviço de publicação tem por natureza sediar as operações de publicação, edição de formatos em plataforma tecnológica, gestão do conteúdo, atendimento à comunidade que não encontra um canal viável para editoração e lançamento de sua produção; diferente dos canais criados estabelecidos pela editora da Universidade com envolvimento e atuação de bibliotecários; pelo corpo docente responsável pela criação da demanda para publicação; pela participação ou não da editora universitária e recursos para difusão e fortalecimento da disseminação acadêmico-científica em acesso aberto.

\footnotetext{
${ }^{8}$ Disponível em: <http://librarypublishing.org/wp-ontent/uploads/2017/03/LPC_LPDirectory2018.pdf>.

${ }^{9}$ Library-publishing (tradução nossa).
} 
O desenvolvimento deste trabalho se dá pela identificação de iniciativas realizadas por universidades e organizações profissionais responsáveis por desenvolver e divulgar boas práticas acerca das dificuldades enfrentadas na publicação e difusão de conteúdos acadêmicos gerados pela comunidade acadêmica.

Para fins de análise prática, este trabalho apresenta dois estudos de caso: o primeiro proveniente de serviço de publicação por biblioteca com foco no livro digital e o segundo aborda a editoração do livro digital em editora comercial.

\subsection{Objetivos}

\subsubsection{Geral}

Contextualizar o trabalho da Biblioteca Publicadora destacando o livro digital produzido no meio acadêmico e oferecido em acesso aberto verificando a existência de cursos de base para aprimoramento dos diversos profissionais envolvidos (bibliotecários, editores de formação, técnicos especializados em publicação) para execução das tarefas práticas.

Tem por finalidade servir de suporte ao serviço de bibliotecas que já atua, coopera e pretende amadurecer suas atividades de publicação, ou àqueles que pretendem constituir a atividade a fim de aumentar sua contribuição na instituição. Destaca o acesso aberto e implicações do mesmo, além de problemas de licenças de uso para conteúdos digitais.

\subsubsection{Específico}

Conhecer parte da prática ou atividade editorial do livro digital pelo mapeamento de tarefas na apresentação de estudos de casos.

\subsubsection{Estrutura da dissertação}

A estrutura obedece a seguinte divisão:

A Introdução aponta a biblioteca universitária incumbida não somente da preservação e disseminação do acervo, mas a reformulação deste papel pelo 
acréscimo de atividades voltadas à publicação de conteúdos. Evidencia o conceito de biblioteca publicadora como alternativa para publicação em formatos acessíveis via rede, prática editorial, integração de novas rotinas no exercício diário e dificuldades na publicação de livros impressos.

A Justificativa apresenta o problema do trabalho que consiste na solução para composição de livros digitais pela atuação de biblioteca publicadora universitária ou de pesquisa, com vistas à disseminação da produção acadêmica e científica atrelada a baixo custo.

Os Objetivos contextualizam o trabalho de publicação de livros digitais abertos por parte de bibliotecas universitárias ou de pesquisa e a contribuição para a disseminação científica e a estruturação de novas rotinas de trabalhos.

A Metodologia investiga por meio de estudo exploratório descritivo, o mercado editorial do livro digital pelo conceito de biblioteca publicadora e análise de estudo de caso por serviço de publicação universitário e por editora comercial mostrando o processo de estruturação, políticas, a ocorrência de novas relações editoriais na comunidade universitária, o trabalho de editores comerciais, softwares e licenças utilizadas.

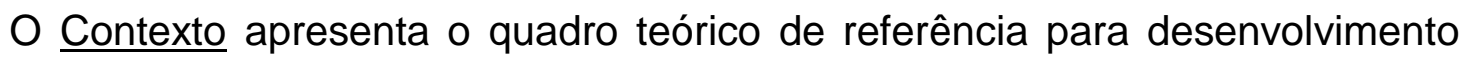
dos capítulos:

O Serviço de Publicação por Biblioteca apresenta o desenvolvimento do conjunto de questões que envolvem o tema publicação por library-publishing em universidade e formação educacionais oferecidas.

O Acesso Aberto apresenta as características e discussões em torno do modelo para disseminação imediata e irrestrita de conteúdos científicos publicados por editoras, enfatiza licenças de uso com destaque para o formato EPUB 3.

O capítulo Práticas de Publicação do Livro Digital relata os estudos de caso relativos à: Michigan Publishing Services e Paulus Editora.

Em Percepções dos Estudos de Casos são tratados os efeitos gerados pela publicação de conteúdos em benefício do acesso livre à comunicação científica, o trabalho prático envolvido evidencia pontos de sucesso para desenvolvimento da atividade em universidade e sugere mudanças na formação do bibliotecário.

Em Projeções da Biblioteca Publicadora apresentam-se ponderações sobre o 
estudo feito relacionando as dificuldades do meio.

As Considerações Finais destacam observações para continuidade do estudo. As Referências apresentam o elenco da literatura empregada na pesquisa. 


\section{PROCEDIMENTOS METODOLÓGICOS}

Análise exploratório-descritiva para apresentação de estudo de caso de serviço de publicação por biblioteca publicadora evidenciando aspectos de estrutura operacional, missão, plataforma, entre outros.

A coleta de informações se deu por meio de perguntas por e-mail, website institucional ao diretor do Michigan Publishing Service e ao grupo de trabalho da Paulus Editora que permitiu reuniões presenciais significativas e fundamentais para composição do estudo.

O primeiro estudo de caso, vinculado à Universidade de Michigan, foi construído segundo orientações do bibliotecário Jason Colman, diretor do Michigan Publishing Service.

O critério estabelecido para seleção foi o de conveniência por tratar-se de modelo de sucesso desenvolvido em uma grande universidade que reúne características semelhantes à Universidade de São Paulo: natureza coeducacional, reunião de campi principais e regionais, grandes complexos hospitalares, complexo estudantil, hospital acadêmico, museus e Sistema de Bibliotecas reunindo várias bibliotecas individuais.

Outro critério para seleção desta universidade se deu pela análise dos serviços existentes listados no diretório LPC.

O parâmetro de seleção para o segundo estudo de caso referente à editora comercial, se deu pela necessidade de conhecer o trabalho prático do editor voltado à publicação de livro digital.

O responsável pela área, Guilherme César, permitiu o desdobramento do estudo por meio de reuniões presenciais com Daniela Kovacs e equipe, além de muitas dúvidas esclarecidas pelos relatos do editor-chefe Claudiano Avelino.

A revisão bibliográfica na área da Ciência da Informação permitiu a recuperação de livros e artigos de revistas integrantes nas fontes indicadas abaixo.

O período de tempo pesquisado de 2007 a 2017 foi expandido para 2018 nas bases bibliográficas referenciais e de texto completo:

- Academic Search Premier: multidisciplinar; 
- Library and Information Science Abstracts (LISA): Biblioteconomia e Ciência da Informação;

- Information Science and Technology Abstracts: Biblioteconomia e Ciência da Informação;

- Web of Science: multidisciplinar;

- Scopus: multidisciplinar;

- blog sobre publicação acadêmica: "The Scholarly Kitchen";

Os termos de busca utilizados nas pesquisas em combinações por operadores booleanos foram: library publishing, publishing libraries, library publishing services, scholarly publishing, university press, open access, digital book(s), editorial publishing, digital formats, publishing platforms, scholarly communication.

\subsection{Dificuldades Encontradas}

A composição do relato do estudo de caso do Michigan Publishing Services da Michigan University apresentou maior dificuldade pelo levantamento de informações e esclarecimento de dúvidas por e-mail, considerando a distância envolvida por tratar-se de serviço desenvolvido internacionalmente.

A autorização para descrição do estudo foi concedida pelo próprio coordenador do serviço que atendeu prontamente, apesar de ser muito ocupado.

Outra instituição internacional permitiu o estudo, porém houve dificuldade pelo serviço possuir vários canais de publicação e não apresentar um coordenador geral responsável pelas atividades.

A natureza do estudo prático requer proximidade com a equipe envolvida no serviço de publicação da instituição, o que é fundamental para compreensão das adversidades do processo como um todo.

O entendimento de algumas questões foi facilitado, particularmente, por um artigo de autoria do coordenador da Michigan Publishing.

Publicado na revista The Journal of Electronic Publishing (JEP), o artigo trouxe a descrição da busca por solução de disseminação sustentável para os conteúdos digitais produzidos na instituição. 
A descrição valeu-se também de perguntas encaminhadas por e-mail ao coordenador do serviço (ver APÊNDICE A), além de informações coletadas no website da instituição entre outros artigos.

A caracterização do estudo sobre a editora comercial Paulus foi proveitosa pelo contato direto com o grupo, realizado por meio de encontros práticos na própria empresa localizada na cidade de São Paulo, Brasil. 


\section{CONTEXTO}

É preciso ressaltar que a atividade de Biblioteca Publicadora é um conceito partilhado e difundido entre bibliotecas de universidades internacionais; diferente do Brasil, onde este conceito e aplicação são incomuns para atividades de publicação de livros digitais. Neste sentido, se verifica ausência de cultura normalizada para atividades de edição e publicação de livros digitais provenientes de serviços de publicação por biblioteca em universidades.

Soma-se a esta questão, a falta de uma entidade ou organização nacional composta por associação, biblioteca ou instituição dedicada a fornecer capacitação/suporte na editoração de conteúdos para que os envolvidos (docentes, bibliotecários, editores, técnicos de outras formações, graduandos) alcancem melhor desempenho.

Historicamente, o livro é fonte fundamental do conhecimento ao longo dos séculos, daí o relato cronológico de acontecimentos ilustrando a importância da descoberta da Imprensa no século XV, onde consideram que a apresentação dos textos e o formato dos livros não sofreram grandes alterações neste início, evidenciando apenas as etapas significativas relacionadas à apresentação dos textos e a evolução percorrida relacionados no espaço de tempo (FEBVRE; MARTIN, 2017, p.157):

- Século XIV: gravura em madeira. Desde o final do século XIV, difusão das estampas xilográficas em grande número; a xilografia era mais importante que o texto em si; as imagens contavam a história para uma população iletrada;

- 1467: dois anos após o aparecimento do primeiro livro impresso na Itália, impressores alemães publicam “Meditationes” ilustrada com madeiras;

- 1474: livro ilustrado publicado em Lyon por um tipógrafo alemão;

- 1478: é publicado o primeiro livro ilustrado em Nápoles;

- Século XV: fólio, formato derivado por uma folha de papel dobrado uma só vez, cada folha origina quatro páginas. São comuns o "in-4" e o "in-8", usado para imprimir textos curtos; 
- 1520: encadernações de meio-luxo, técnica do forjamento em estampa à fabricação de encadernações comerciais;

- 1520: encadernações à la plaque;

- 1553: livro ilustrado de grande difusão artística, a "Bíblia". Em 1557 é publicado o livro ilustrado "Metamorfoses" de Ovídio;

- Século XVI (1 ${ }^{\text {a }}$ metade): surgem os "formatos portáteis", o livro deixa de ser visto como objeto precioso, sendo possível seu transporte e leitura a qualquer tempo;

- Século XVI (2‥ quartel): a paginação se torna usual por conta dos impressores humanistas e o livro assume seu aspecto atual;

- Século XVI (final): surgem os livros ilustrados para venda ambulante e, nesta época os livros ilustrados utilizam figuras gravadas em talho-doce (gravura sobre metal em côncavo);

- Século XVII: neste período as encadernações são decoradas com a "roleta" (pequeno cilindro de metal sobre o qual é gravado um motivo decorativo para ser repetido indefinidamente);

- Século XVIII: livros de luxo destinados à aristocracia do dinheiro; a bibliofilia se desenvolve e aparecem encadernações ornadas com mosaicos; encadernações policromas, "rendadas";

- Século XIX: aparecimento da prensa a vapor. É inventada a máquina de papel que permite produção rápida e barata de livros proporcionando um grande número de tiragens em brochuras.

O século XIX determina que, a partir deste momento, a democratização do livro diretamente ligada à apresentação comum, sem elementos de beleza e resistência que os séculos anteriores deixaram como herança, "[...] as encadernações simples perdem pouco a pouco sua beleza, depois sua solidez." (FEBVRE; MARTIN, 2017, p.189).

Neste século, em meio à corrente democratização, efervescência e penetração do livro na sociedade, surge a criação de métodos sistematizados de $P$. Otlet para organizar o conhecimento registrado e sua disseminação.

Otlet (1890, p.89), referindo-se ao livro microfotográfico, prenuncia algumas 
das facilidades que acompanham o livro digital, como a disponibilidade de acesso ilimitado, a facilidade de baixar o conteúdo, o baixo custo para disseminação do conteúdo publicado em plataformas abertas resultando em aumento da visibilidade, e acrescenta:

uma nova forma do livro deve ser encontrada, a qual eliminará os inconvenientes referidos e que, no futuro, produzirá livros que sejam: 1) menos pesados e menores, 2) uniformes em tamanho; 3) utilizem material permanente; 4) moderado no preço; 5) fácil de preservar; 6) fácil de consultar; e 7) produzido continuamente: ou seja, podem ser produzidas cópias ou duplicatas mediante solicitação.

Em 1945 o dispositivo Memex, concebido por Vanevar Bush, foi precursor do livro digital por agregar informações em diversos formatos como: texto, imagem e som (SERRA, 2015, p.32).

Em 1989, concebida por Tim Berners-Lee a web semântica se populariza pela invasão maciça, em todos os níveis da sociedade, de uma grande parte da população conectada à Internet em busca de uma rede de vantagens: informação, compras, relações pessoais, interconectividade, entre outros. Na década de 1990, concretiza-se a revolução digital pela existência da rede mundial World Wide Web (WWW).

Após toda esta evolução, Berners-Lee (2007) acredita que a web semântica ainda não atingiu todo o potencial e prevê seu crescimento,

[...] quando as pessoas começarem a colocar links públicos de dados na web, adicionando dados e arquivos pessoais. Mas acredito que ainda vai levar muitos anos, porque muita coisa terá que ser feita para torná-la realidade.

Neste contexto, a revolução digital dá destaque ao livro pela nova forma de leitura e consulta feita em trechos expressos de um dispositivo ou tela.

Desde a pedra, a pintura, o rolo, passando pelo códice até o livro tradicional, a escrita se dá em um objeto material: desenho, manuscrito ou tipos tipográficos. O conteúdo não sofreu qualquer desintegração de sua parte física, mas o momento é inusitado diante da transformação deste suporte da escrita e do modo de ler conforme descrito por Chartier (2010, p.8),

As mutações de nosso presente transformam, ao mesmo tempo, os suportes da escrita, a técnica de sua reprodução e disseminação, assim como os modos de ler. Tal simultaneidade é inédita na história da humanidade. A invenção da imprensa não modificou as estruturas 
fundamentais do livro, composto, depois como antes de Gutenberg, por cadernos, folhetos e páginas, reunidos em um mesmo objeto.

As diferentes variações do texto, descritas como mutações - de livro à adaptação cinematográfica; televisiva; CD; texto eletrônico tem características distintas e derivam de percepções, hábitos e técnicas de conhecimento diferentes que causam distorção ao que era inicialmente, a obra não é jamais a mesma quando inscrita em formas distintas, ela carrega, a cada vez, outro significado (CHARTIER, 1998, p.71).

Esse outro significado pode ocorrer pela leitura e as várias interpretações que ela expressa; contudo pode manifestar as variadas formas de interação com o livro digital a partir de dispositivos ou telas de apresentação do conteúdo.

A publicação digital remete ao sonho da biblioteca universal desde Alexandria, denominada "biblioteca sem paredes", que tem por finalidade congregar as inúmeras obras para leitura, nos mais variados lugares (CHARTIER, 1998, p.11).

Dentre as muitas dúvidas existentes frente à publicação do livro digital, desenvolvido a partir da aliança de bibliotecas publicadoras universitárias ou de pesquisa, fica a questão de quais métodos serão considerados para desenvolvimento com consequente adesão da comunidade (autores, pesquisadores e graduandos).

Os conflitos editoriais decorrentes dos altos custos impostos por grandes publicadores para os autores da comunidade universitária e bibliotecas universitárias remetem ao processo de publicação de livros digitais produzidos pela instituição, cujo propósito não é somente a disseminação de conteúdos, mas a constituição de um serviço pensado e estruturado para resolver os problemas de publicação criando alternativas para que os autores acadêmicos possam ser lidos.

Schmolling (2015, p.8) comenta a importância das bibliotecas universitárias na Alemanha como agentes publicadores e como a transição do impresso para o digital levou a mudanças na cadeia de publicação em prol do acesso ao conhecimento,

A variedade de tipos e formatos de mídia aumentou com o crescimento da informação digital. Não apenas textos, mas também imagens, áudio e dados de vídeo precisam de um acesso mais interativo. Com os novos requisitos das bibliotecas de e-science (grid computing, repositórios de dados primários), as bibliotecas ajudam 
os cientistas a arquivar, classificar e publicar dados brutos de pesquisa para a comunidade científica. Esta é uma grande questão futura para bibliotecas universitárias e de pesquisa. ${ }^{10}$ (tradução nossa).

O trabalho de publicação não pode ser visto como complemento às tarefas existentes na Biblioteca, segundo Gilman (2015, p.32) é preciso

[...] integrar intencionalmente fluxos de trabalho de publicação em áreas de serviço existentes, criando propriedade e investimento na publicação de serviços em toda a biblioteca. Cada função de publicação e fluxo de trabalho deve ser cuidadosamente mapeada para áreas com funções ou conjuntos de habilidades correspondentes ou semelhantes. (As pessoas podem ter habilidades fora dos requisitos de suas posições atuais e, portanto, podem contribuir para tarefas adicionais de publicação). ${ }^{11}$ (tradução nossa).

A integração do serviço de publicação na biblioteca vai exigir uma avaliação das atividades existentes, podendo ser reduzidas gradativamente, com prioridade para o núcleo de publicação. Inicialmente esta base de trabalho pode não ser adequada e algumas recomendações são necessárias para estruturar e dar suporte ao núcleo de publicação (GILMAN, 2015, p.32):

a) o diretor da biblioteca pode desempenhar função de "diretor do núcleo de publicação" para gerenciamento ou delegá-la;

b) a liderança editorial do serviço de publicação pode estar fora da biblioteca, é necessário um conselho editorial externo; os editores fazem a seleção avaliação por pares - e os autores são encarregados do desenvolvimento das edições;

c) o gerenciamento (produção, distribuição e marketing), deve ter por filosofia o foco em publicações únicas e não comerciais;

d) a gestão (produção e distribuição) e o fluxo de trabalho podem ser

\footnotetext{
${ }^{10}$ The variety of media type and format has augmented with the growth of digital information. Not only texts but also images, audio, and video data need a more interactive access. With new requirements of e-science (grid computing, primary data repositories) libraries help faculty to archive, classify and publish raw research data for the science community. This is a big future issue for university and research libraries.

${ }^{11}$ The best way to do this is to intentionally integrate publishing workflows into existing service areas, creating ownership and investment in publishing services across the library. Each publishing function and workflow should be carefully mapped to areas with corresponding or similar functions or skill sets. (Individual staff may also have skills outside the requirements of their current positions and so can contribute to additional publishing tasks).
} 
integrados em unidades de Bibliotecas. Este gerente é responsável por todos os processos e pode ser um bibliotecário envolvido na comunicação acadêmica;

e) os fluxos de trabalhos devem ser integrados nas atividades ou terceirizados com suporte do bibliotecário de sistemas ou da unidade;

f) a distribuição deve ser conduzida pelo gerente de publicação e envolve negociação de contrato com agregadores dos serviços de descoberta (OAPEN Biblioteca, JSTOR, entre outros), a criação de metadados e entrega dos mesmos com arquivos para distribuidores está dentro do escopo do fluxo de trabalho técnico;

g) o marketing deve dar visibilidade aos títulos publicados de diferentes formas (mídia social, dentre outros).

A configuração do núcleo de publicação se altera a medida do escopo, metas e limitações existentes na Instituição. 


\section{SERVIÇO DE PUBLICAÇÃO POR BIBLIOTECA}

O modelo para publicação de conteúdo por bibliotecas se fortalece gradativamente nas universidades em nível mundial. Difundido muito mais na Europa e América do Norte, os serviços de publicação por biblioteca podem estar fundamentados numa parceria com editoras universitárias (university press). Este padrão difere no Brasil, onde universidades públicas, em geral, possuem editoras que não mantêm o esforço de colaboração e uso de expertise dos serviços de biblioteca entre si.

A emergência de publicar conteúdos acadêmicos além dos padrões tradicionais - a baixo custo - seja revistas, monografias entre outros, faz com que essa necessidade seja aplicada em determinados segmentos de forma a cooperar com a expansão dos serviços de publicação por biblioteca em universidades que subsidiam os custos de publicações eletrônicas para resultar em produção de alta qualidade a baixos custos.

O propósito deste trabalho é oferecer um panorama bem restrito do serviço de publicação por biblioteca ou library publishing e algumas das implicações existentes em diferentes iniciativas para disseminar produção acadêmica, especialmente do livro digital envolvido pelo contorno do acesso aberto.

Recentemente, as atividades de publicação por biblioteca acadêmica ou de pesquisa caracterizam-se por uma notável expansão, apesar da prática da atividade ser pouco registrada e divulgada. O grande esforço empreendido para publicar revista ou livro digital é feito, na maioria das vezes, por uma equipe restrita ou por apenas um profissional bibliotecário incumbido de realizar múltiplas tarefas. Segundo Bonn; Furlough (2015):

O foco atual na publicação de bibliotecas começou em torno de vinte anos atrás. No final do século $\mathrm{XX}$, as possibilidades inspiradas por tecnologia digital e comunicação em rede, emparelhada com 0 aumento da insatisfação do consumidor com os custos e restrições de uso imposta por editores comerciais, levou algumas bibliotecas a explorar ativamente meios alternativos e modelos para publicação acadêmica. $^{12}$ (Tradução nossa)

\footnotetext{
${ }^{12}$ The current focus on library publishing began around twenty years ago. At the tail end of the twentieth century, the possibilities inspired by digital technology and networked communication, paired with increasing (library) consumer dissatisfaction with the costs and use constraints imposed by commercial publishers, led some libraries to actively explore alternative means and models for
} 
O mundo digital favoreceu a condução do fluxo de trabalho da publicação acadêmica, permitindo a edição dos múltiplos processos em plataformas que tornam visível o conteúdo restrito por proteção aos direitos autorais e limitação no acesso posteriormente disponível em repositórios - por se tratar de produção desenvolvida no contexto acadêmico-científico e/ou concebidos em livre acesso.

Uma das funções da biblioteca publicadora é proporcionar maior acesso a um número maior de publicações pela promoção e recuperação de conteúdos revisados e aumentados, transformados em novas edições ou produções inéditas que não encontram um canal de transmissão fora dos padrões convencionais, para tornar público temas ou pesquisas estudados e desenvolvidos durante tempo considerável de investigação do autor.

Neste contexto, surge em 2013 a associação independente Library Publishing Coalition (LPC ${ }^{13}$, liderada por bibliotecas acadêmicas, de pesquisa e consórcios de bibliotecas comprometidos com publicações acadêmicas, define o serviço de publicação por bibliotecas como o "o conjunto de atividades lideradas por bibliotecas de universidades para apoiar a criação, divulgação e curadoria de trabalhos acadêmicos, criativos e/ou educacionais" (LIBRARY PUBLISHING COALITION, 2013).

O LPC busca o compartilhamento de conhecimento, colaboração e formação de rede de trabalho entre bibliotecas publicadoras e entre bibliotecas e outros publicadores através do apoio e distribuição de práticas de publicação. A associação LPC aceita adesões de bibliotecas de pesquisa e acadêmicas de todo o mundo. Participam editoras universitárias, publicadores acadêmicos, fornecedores e associações profissionais. Possui comitês organizados, forças tarefas e atuação de grupos voluntários para estimular o trabalho.

Este novo conjunto de atividades, que o serviço de publicação por biblioteca precisa administrar, incentiva uma análise de prioridades das tarefas nas diferentes atividades, este é o momento em que o dirigente e sua equipe podem repensar os serviços existentes, as rotinas de trabalho e dispensar o que se tornou obsoleto para

${ }^{13}$ Library Publishing Coalition, disponível em: <https://librarypublishing.org/>. 
estabelecer ações inéditas como assumir a nova missão de colaborar com autores e editores na publicação de novos conteúdos digitais para proporcionar maior acesso às edições produzidas na universidade.

O serviço de publicação por biblioteca é considerado atividade definida como subcampo da publicação por ser executada em universidades, subsidiada pelo orçamento da biblioteca e por não ter fins lucrativos (SKINNER et al., 2014, p.1), transmitido em acesso aberto.

Bibliotecários, editores e a comunidade acadêmica poderão usufruir do conhecimento de cada um para dimensionar o trabalho dos serviços de publicação por biblioteca, aqui também denominado "biblioteca publicadora", considerando a natureza e diferenças do trabalho editorial, que também poderá se desenvolver com o suporte da editora da universidade voltada para publicação de conteúdos impressos e digitais.

Ferwerda (2010, p.92) define publicação em acesso aberto como "[...] validação e certificação dos resultados de pesquisa, incluindo todo o processo de revisão, edição, design, produção, marketing e distribuição".

As dificuldades na publicação de conteúdos impressos servem de incentivo para que bibliotecas de instituições universitárias se movimentem em torno da publicação digital de livros, revistas, entre outros disseminados por plataformas abertas a baixo custo, pela característica de cooperação existente neste modelo.

Tracy (2016, p.5) afirma que publicação no contexto da biblioteca é definida como um esforço intencional de capturar um conjunto amplo de atividades que envolvem seleção, revisão por pares, gerenciamento de workflow, edição, distribuição e marketing.

Este contexto estabelece rota alternativa para divulgação da comunicação científica e acadêmica sem a intermediação de editores profissionais, editoras poderosas responsáveis pelo desenvolvimento de novas soluções e modelos de negócios geradores de alta rentabilidade.

O serviço de publicação por biblioteca é requisitado pela comunidade em busca de orientação e ajuda prática para alguns aspectos de edição e composição de conteúdos derivados de pesquisas. É difícil para os autores encarregarem-se das inúmeras exigências do mercado profissional editorial altamente seletivo, que 
dificilmente atende às iniciativas destes autores de forma a disseminar sua produção intelectual em conteúdo digital indefinidamente, guardadas as devidas licenças de autoria e de publicação.

Outra dificuldade vai de encontro a editores que publicam autores e temas consagrados.

Ferwerda $^{14}$ (2010, p.91) descreve a impossibilidade dos editores em manter a sustentabilidade do modelo tradicional para publicação dos trabalhos por diversos motivos, o que os leva a adotar maior rigidez na seleção de obras disponíveis para publicação

[...] Os editores acadêmicos foram forçados a se tornar mais seletivos nos livros que publicam; autores, em particular jovens pesquisadores e autores iniciantes, acham difícil encontrar uma editora disposta a publicar seu trabalho. (tradução nossa) ${ }^{15}$

Tudo isso se soma às dificuldades dos editores com custos de produção de livro - em valores muito superiores se comparados aos artigos de revistas - por envolver arte-finalistas, especialistas em composição de capa, editores de conteúdo etc. Restrições econômicas impostas às bibliotecas universitárias obrigam-nas à reduzir novas aquisições de obras digitais e impressas.

O serviço de publicação por biblioteca se transforma em busca de um conjunto de soluções para viabilizar o acesso à comunicação acadêmica pela divulgação de conteúdos abertos, ao mesmo tempo em que agrega o novo papel em atribuições cotidianas. Porém existem outros programas que trabalham com assinaturas e modelos tradicionais (HAHN, 2008, p.24).

Os processos do novo modelo de publicação acadêmica digital podem diferenciar-se daqueles para impressão, pois poderão ser escolhidos pelos editores da biblioteca ou da editora da universidade conforme as necessidades dos autores: criação; seleção; avaliação; incluindo revisão por pares;; edição e marcação; design; composição; layout; produção de formatos específicos (on-line, impresso, digital, multiformato); marketing e descrição; distribuição e vendas (MCCORMICK, 2015, p.60).

\footnotetext{
${ }^{14}$ Eelco Ferwerda, coordenador do OAPEN (Open Access Publishing in European Networks) e publicador digital de conteúdos da Editora da Universidade de Amsterdam.

${ }_{15}$ "[...] Academic publishers have been forced to become more selective in the books they publish; authors, in particular young researchers and first-time authors, have found it harder to find a press willing to publish their work".
} 
Neste contexto o serviço de publicação por biblioteca tem muito a oferecer, podendo participar das fases de edição, produção, publicação, definição de metadados, operação em plataformas de publicação, disseminação de conteúdos, distribuição entre outras.

A biblioteca e a editora da universidade estão ligadas em suas missões: a primeira por oferecer informação e manter o acesso gratuito e em longo prazo; a segunda pela busca de autores e público além da universidade e a receita gerada pelo valor agregado dos serviços oferecidos (COURANT; JONES, 2015, p.35).

Os serviços de publicação por bibliotecas têm aumentado com base em informações divulgadas pelo diretório LPC Directory $2018^{16}$. O Diretório fornece o perfil resumido das iniciativas em andamento de programas de publicação em mais de 125 bibliotecas acadêmicas e de pesquisa no mundo anualmente, reunindo informações de interesse para criadores de conteúdo, bibliotecários, editores acadêmicos, desenvolvedores de plataformas, àqueles que pretendem instituir algum tipo de suporte de publicação de finalidade acadêmico-científico e agências de financiamento. As informações descrevem os serviços oferecidos aos autores, número e tipos de publicação, recursos financeiros, equipe envolvida, tipo de acesso.

Em 2018, o diretório mostra iniciativas nacionais da Universidade Federal do Tocantins através do Núcleo de Pesquisa e Extensão Observatório de Pesquisas Aplicadas ao Jornalismo e ao Ensino (OPAJE) e a Universidade de São Paulo pela atuação do Sistema Integrado de Bibliotecas (SIBiUSP) destacando os serviços de publicação desenvolvidos: Portal de Revistas USP e Portal de Livros Abertos da USP.

Dentre as inúmeras plataformas disponíveis para publicação de conteúdos de livros digitais destaca-se o Open Monograph Press (OMP-PKP), plataforma aberta para gerenciamento e publicação de monografias e volumes editados, utilizado pelo SIBiUSP.

O fluxo de trabalho permite a realização de avaliações internas e externas, edição do conteúdo, inserção de metadados e publicação do livro digital.

Em 2016, o lançamento do Portal de Livros Abertos da USP pelo SIBiUSP

\footnotetext{
${ }^{16}$ Library Publishing Coalition Directory, disponível em: <https://librarypublishing.org/wpcontent/uploads/2017/03/LPC_LPDirectory2018.pdf >.
} 
promoveu a reunião e divulgação dos livros digitais acadêmicos/científicos publicados em acesso aberto por docentes e/ou funcionários técnico-administrativos da Universidade de São Paulo.

Somando-se a esta iniciativa, a Pró-Reitoria de Cultura e Extensão Universitária da USP deliberou proposta permitindo que as Comissões de Cultura e Extensão das Unidades USP indiquem e confirmem as obras para publicação no Portal.

Os conteúdos divulgados no Portal recebem atribuição do identificador digital DOI que permite acesso permanente ao livro digital em formatos PDF $^{17}$, ePUB ${ }^{18}$ e Daisy ${ }^{19}$ em caso de retirada da plataforma do ar. Ele também fornece diretrizes para submissão de livros e manuais como:

- A obra de caráter científico deve apresentar autoria do todo ou parte por professor, funcionário ou técnico-administrativo da Universidade;

- O autor deve permitir a divulgação/reprodução da obra licenciada;

- O ISBN digital deve ser registrado na Agência Brasileira do ISBN em nome da faculdade ou instituto da USP.

\footnotetext{
${ }^{17}$ Portable Document Format (Formato Portátil de Documento).

${ }^{18}$ Electronic Publication (Publicação Eletrônica): formato de arquivo digital padrão específico para livros digitais.

${ }^{19}$ Formato Daisy proporciona acessibilidade a deficientes visuais ou pessoas com pouca visão e disléxicos.
} 
O Portal apresenta dados estatísticos de download distribuídos pelos meses do ano e desde seu lançamento percebe-se um aumento no número dos livros digitais disseminados pela comunidade USP ao público-leitor.

Figura 1 - Portal de Livros Abertos da USP

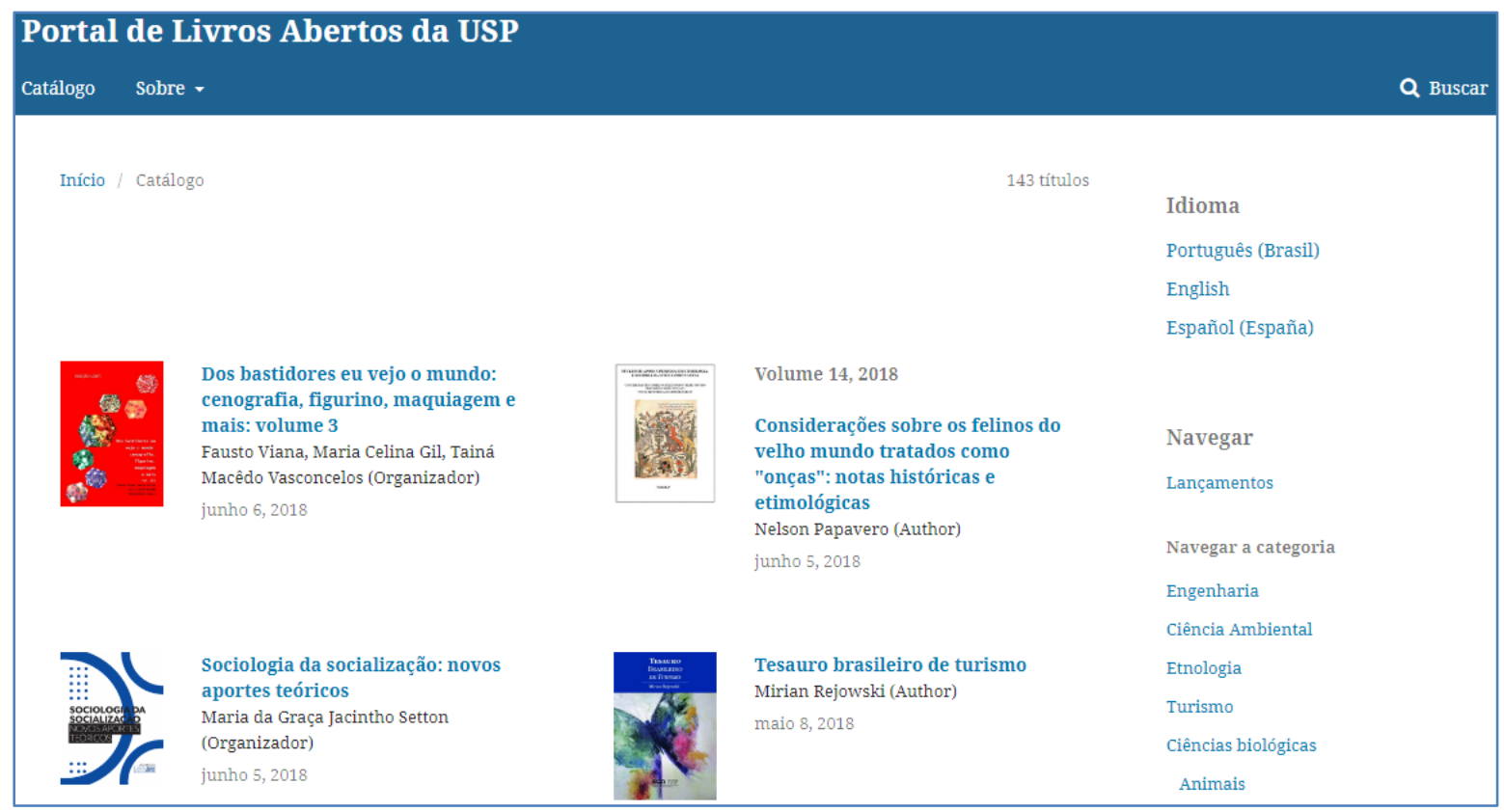

Fonte: Sistema Integrado de Bibliotecas da Universidade de São Paulo ${ }^{20}$

\subsection{Cursos Dedicados à Publicação}

Para o sucesso dos serviços de publicação por biblioteca é fundamental o envolvimento dos parceiros: biblioteca, editora da universidade, bibliotecários, editores entre outros. Skinner et al. (2014, p.3) enumeram cursos existentes no exterior, de pós-graduação ou não, oferecidos por profissionais do meio que proporcionam aprendizado neste trabalho colaborativo em países como Austrália, Reino Unido, Estados Unidos e Canadá por Escolas de Biblioteconomia e Ciência da Informação e outros programas ${ }^{21}$, alguns exemplos:

- Programa de Grau Acadêmico: programa abrangente sobre fundamentação editorial e informação sobre publicação: Center of Publishing of New York

\footnotetext{
${ }^{20}$ Disponível em: <http://www.sibi.usp.br/>, <http://www.livrosabertos.sibi.usp.br/portaldelivrosUSP>.

${ }^{21}$ Society for Scholarly Publishing, disponível em: <https://www.sspnet.org/careers/publishing-andlibrary-programs/\#PublishingPrograms>.
} 
University, St. John's University (Division of Library and Information Science), University of Michigan Ann Arbor (School of Information - Library and Information sciences Specialization) entre outros;

- Institutos de verão: conta com profissionais de alto nível no mercado que oferecem capacitação para este trabalho gratuitamente: NYU Summer Publishing Institute;

- Workshops de Desenvolvimento Profissional: cursos de longa duração que favorecem o avanço de profissionais em nível de gerenciamento e posições editoriais;

- Programas on-line ou à distância: programas on-line de educação continuada (webinars): Library Publishing Coalition Webinars;

- Programas de treinamento na empresa: grandes editoras que desenvolvem seus próprios programas corporativos;

- Programas de estágio: editoras de universidade e publicadores comerciais que oferecem estágios para profissionais. Ex.: The New Press Internship Program.

É essencial a integração do profissional nos mais diferentes cursos, para melhor qualificação, considerando as diferenças e buscas por novos contextos ligados à publicação de livros digitais.

Entidades como Open Access Scholarly Publishing Association - OASPA ${ }^{22}$ promovem eventos sobre acesso aberto e sobre a indústria da publicação buscando soluções em torno desta temática.

O Public Knowledge Project oferece a PKP School ${ }^{23}$, ambiente de cursos online disponíveis para melhorar a qualidade da publicação acadêmica, especialmente o programa de publicação por biblioteca.

Outras iniciativas de aprendizagem são fortalecidas pela organização iSchools ${ }^{24}$, constituída em 2005 por um coletivo de escolas de informação dedicadas ao avanço deste campo em disciplinas como: tecnologia da informação,

\footnotetext{
22 Disponível em:< https://oaspa.org/>.

${ }^{23}$ Disponível em: < http://pkpschool.sfu.ca/>.

24 Disponível em: < https://ischools.org/about/>.
} 
biblioteconomia, informática e ciência da informação.

O trabalho realizado pelos variados serviços de publicação por bibliotecas ocorre desde a preparação e orientação dos estudantes ao longo da vida acadêmica, enfocando a importância de torná-los parceiros para expansão das atividades pela agregação de valor maior que vai além do recurso oferecido. Oficinas acadêmicas podem contribuir para compreensão de conceitos-chaves como: revisão por pares, direitos de autor, plágio, licenças de uso e suas implicações, políticas mandatórias de repositórios, análise de diferentes ambientes que dissemina a informação, publicação em revistas de acesso aberto para favorecer o universo da comunicação acadêmico-científica e seus desdobramentos (BUCKLAND, 2015, p.124).

A participação das bibliotecas universitárias ou de pesquisa na produção e gestão de conteúdos digitais é altamente relevante e promissora pelo alcance exercido na comunidade e pela oferta de suporte para edição de livros digitais oferecidos em acesso aberto para um público-leitor desejoso de obter conhecimento e um autor que deseja ser lido.

O momento é de entender as questões referentes aos modelos de publicação, conhecer a diversificação de atividades existentes nas universidades em torno dos mesmos e buscar soluções para maior difusão destes procedimentos.

Conhecer as etapas práticas deste trabalho implica em contribuir com análises e redimensionar tarefas, encargos ou fatores ligados à publicação pela agregação de conhecimento dos diversos participantes interessados na promoção da comunicação científica (docentes, bibliotecários, editores, técnicos de outras formações, graduandos).

No primeiro trimestre do século XXI, Keener (2014) defende uma mudança de identidade da publicação acadêmica com mudança de valores, as editoras não escolhem mais os manuscritos e projetos que venderão melhor por estarem mais preocupadas com a nova scholarship que trata da disseminação ampla dos livros digitais, repositórios, trabalhos on-line interativos e sua rápida adoção favorecida pelas tecnologias.

É importante que bibliotecários e editores pensem um modo de atuação compartilhada, permitindo melhor produção na área, respeitando-se as diferenças de 
formação.

Existem lacunas a ser completadas no que se refere à educação para publicação, como por exemplo, a criação de cursos voltados este tema e estudos dirigidos sobre permissões legais existentes no país para orientação dos autores de forma a ampliar a cultura do serviço de publicação por biblioteca.

É interessante que, os cursos de formação para bibliotecários promovam a integração nos currículos de serviços voltados à publicação, de modo a expandir a área, incrementando o número de publicações em ambiente digital.

A demanda por publicações de baixo custo cresce rapidamente entre os serviços oferecidos pelas universidades, provavelmente esta demanda resultará em diferentes interesses para a comunidade acadêmica e, muitas mudanças apontam nesta direção com o surgimento de novo conjunto de serviços relacionados.

Além disso, existe a carência estudantil por um número maior de textos de acesso fácil e rápido permitido pelo meio digital em acesso aberto.

É necessário clarificar que a Biblioteca Publicadora pode suprir esta carência por oferecer a publicação acadêmica disponibilizada em rede de forma gratuita somada a uma licença aberta que promova a proteção ao autor. 


\section{ACESSO ABERTO E IMPLICAÇÕES NO MERCADO EDITORIAL}

Historicamente, a definição de acesso aberto proveniente das declarações de Budapeste (BOAI) em fevereiro de 2002 ${ }^{25}$; a declaração de Bethesda em junho de $2003^{26}$ e a Declaração de Berlim sobre Acesso Aberto ao Conhecimento nas Ciências e Humanidades em outubro de $2003^{27}$ ratificam o movimento difundido mundialmente que provê acesso livre sobre a ciência e os resultados de pesquisa para qualquer pessoa com acesso à Internet.

A importância do acesso aberto é indiscutível por favorecer o acesso à extensa informação científica desenvolvida após a II Guerra Mundial por uma extensa cadeia de produtores: universidades, centros de pesquisa, pesquisadores, editoras, editores, bibliotecas.

Em 1971, iniciada por Michael Hart, a biblioteca digital Projeto Gutenberg disponibiliza textos completos de livros em domínio-público.

Stevan Harnad ${ }^{28}$ lança em 1989 a revista de acesso livre Psycoloquy.

Em 1990 Tim Berners-Lee, criador da internet mundial, lança a WWW.

Em 1991 é lançado o repositório de preprints ArXiv e Paul Ginsparg garante aos físicos, destaque e reconhecimento pela disponibilização dos artigos de produção científica.

Em 1994, o World Wide Consortium (W3C) é instituído no Instituto de Tecnologia de Massachusetts - MIT com suporte da Organização Européia para a Pesquisa Nuclear (CERN), Agência de Projetos de Pesquisa Avançada de Defesa (ARPA) e da Comissão Europeia ${ }^{29}$.

Em 1994 com o acesso aberto em crescimento, Stevan Harnad propõe o autoarquivamento (self-archiving) em repositórios institucionais de acesso aberto.

A Iniciativa de Acesso Aberto (BOAI) definiu diferentes composições de acesso à Via Verde (Green Road) e à Via Dourada (Golden Road).

A via verde resulta em alcance direto à ciência desenvolvida e disseminada

\footnotetext{
${ }^{25}$ Budapest Open Access Initiative. Disponível em: $<$ http://www.budapestopenaccessinitiative.org/boai-10-translations/portuguese-brazilian-translation>.

${ }^{26}$ Bethesda Declaration. Disponível em: <http://legacy.earlham.edu/ peters/fos/bethesda.htm>.

${ }_{27}^{27}$ Berlin declaration. Disponível em: <https://openaccess.mpg.de/Berlin-Declaration>.

${ }^{28}$ Wikipedia. Disponível em: <https://en.wikipedia.org/wiki/Stevan_Harnad>.

${ }^{29}$ BandTec Digital School. Disponível em: < http://tecnologia.bandtec.com.br/a-evolucao-dos-20-anosda-world-wide-web/>.
} 
abertamente, favorecendo o autoarquivamento pelo autor em repositórios institucionais e o retorno para a sociedade como um todo dos investimentos públicos confiados ao autor para desenvolvimento da pesquisa.

A via dourada, onde o acesso à produção acadêmica se dá em revistas científicas comerciais restritas a grandes editores, é responsável por divulgar novos resultados de pesquisa a um público específico via modelo de negócio de acesso pago por meio dos portais das diferentes bases de dados.

Os repositórios vem afirmar o direito de acesso à informação acadêmica pela via verde, onde pesquisadores depositam a cópia digital de sua produção que, dependendo da política da revista, pode obedecer a um período de embargo de seis meses até liberação para leitura.

Com o avanço do acesso aberto, as editoras criaram modelos de negócios que são denominados de acesso aberto híbrido.

Neste modelo, autores pagam para publicar em títulos de revistas específicas para dar visibilidade aos conteúdos em acesso aberto, favorecendo aumento dos lucros e realce às políticas econômicas dos grandes editores. Aqui se caracteriza total inversão de valor, pois quem ganha é o publicador sobre o trabalho do autor / pesquisador que não ganhou notabilidade e benefícios resultantes do tempo dedicado ao estudo e experimentos pela publicação dos resultados científicos.

Guédon (2004, p.325) considera que a visão de mandatos defendidos para integrar as políticas de repositórios da universidade, no sentido de aumentar a visibilidade da produção científica em acesso aberto é, de certo modo, simplista e que as vias dourada e verde podem se complementar no futuro para afirmar o acesso aberto.

O não cumprimento do depósito da produção científica em Repositório Institucional (RI) pode estar associado a outros motivos: como obrigação entendida como algum tipo de dever moral imposto aos pesquisadores que não agradou, somado ao fato de que bibliotecários falharam em tornar os repositórios interessantes, ou até mesmo por pesquisadores poderem estar sujeitos a monitoramento pode ser algumas das razões de falha dos repositórios (POYNDER, 2018).

Piwowar et al. (2018) denomina outra forma de acesso aberto "Bronze", onde 
a produção científica é publicada apenas para leitura no site do editor sem especificação de licença e sem permitir download. Neste caso o conteúdo fica restrito, sem permitir reuso e a editora inviabiliza o acesso por meio de cobrança no website. Estes documentos disponíveis para leitura temporária no site do editor foram observados anteriormente e denominados como "peek-a-boo" (HARNAD, 2006).

A imposição de compra de artigos por meio de assinatura não os torna mais citados, ainda assim, os artigos de acesso aberto podem ser compartilhados e, ser mais citados do que os que estão por trás de paywall (PIWOWAR et al, 2018).

Dúvidas com relação ao crescimento da via verde podem não ser verídicas, pois, sistematicamente, são adicionados documentos de acesso híbrido, dourado e bronze em Rl, chamados de "cópias sombreadas em verde" somado ao autoarquivamento de conteúdos retrospectivos de anos ou décadas atrás, o que contribui para seu desenvolvimento (PIWOWAR et al., 2018).

Questionado sobre a perspectiva do acesso aberto, o pioneiro Harnard (2015) destaca:

Nós não chegamos tão longe quanto poderíamos, se tivéssemos depositado todos os nossos artigos. Eu e muitos outros ainda estamos trabalhando para que o autoarquivamento aconteça. Os obstáculos são o lobby de publicação de periódicos por assinatura, a prematura "febre dourada" e a demanda prematura por CC-BYantes mesmo de termos o acesso aberto na via verde. ${ }^{30}$ (tradução nossa)

Se, de um lado existe a dificuldade em torno do acesso aberto para torná-lo imediato e irrestrito, as grandes editoras também estão preocupadas em criar fórmulas que mantenham seu controle sobre a produção científica. Este fato pode ser ilustrado pela aquisição de repositórios e empresas de modelo de rede social, voltados para a academia, por editoras para estabelecimento de novos modelos de negócios como o Social Science Research Network (SSRN) e o Mendeley.

Sabe-se que a publicação digital goza de preferência junto aos leitores acadêmicos e pesquisadores, mas o futuro é indefinido quanto à sua manutenção e

\footnotetext{
${ }^{30}$ We have not gotten nearly as far as we could have done if we had all self-archives our articles.

$\mathrm{I}$, and many others, are still working on getting self-archiving to happen. The obstacles are the subscription journal publishing lobby, premature "Gold Fever", and premature demand for CC-BY (libre $\mathrm{OA})$ even before we have Green OA.
} 
viabilização de recursos. No que se refere às bibliotecas publicadoras, o quadro começou a ser delineado e o caminho, embora longo, projeta grandes desenvolvimentos para o futuro por sua participação na edição de conteúdos acadêmicos e missão pautada pela difusão do mesmo.

Quanto aos artigos compartilhados em sites - denominados piratas - como Sci-Hub e LibGen não existe consenso entre pesquisadores para encaixar este grupo em acesso aberto (PIWOWAR et al., 2018), contudo esses domínios se popularizaram e, mesmo que seus objetivos não estejam claramente definidos, na prática estão entre as preferências de leitores que buscam pela literatura a qual não possuem acesso.

Rodrigues (2015) há tempos trata da relação entre acesso aberto e o modelo de construção e difusão do conhecimento. Com respeito aos novos rumos do movimento Acesso Aberto, considera que o momento atual é de transição e questionamento:

Essa transição será liderada pela comunidade científica e suas instituições (as universidades e os financiadores da pesquisa)? Ou, pelo contrário, será conduzida em função dos interesses e dos pontos de vista da indústria da informação científica e dos grandes grupos editoriais, mantendo o domínio estabelecido nas últimas décadas?

No Brasil, o movimento do acesso aberto se constitui pela participação ampla de pesquisadores e instituições brasileiras em ações de apoio e manifestos publicados. Atualmente, tramita o Projeto de Lei 387, de 2011 sobre a criação e manutenção de repositórios institucionais no Brasil. As declarações aprovadas são:

- 2005: Declaração de Salvador Sobre Acesso Aberto: a perspectiva dos países em desenvolvimento ${ }^{31}$;

- 2005: Manifesto Brasileiro de Apoio ao Acesso Livre à Informação Científica ${ }^{32}$;

- 2005: Carta de São Paulo - defende o acesso livre à informação ${ }^{33}$;

- 2006: Declaração de Florianópolis ${ }^{34}$;

\footnotetext{
${ }^{31}$ Declaração de Salvador. Disponível em: <http://www.icml9.org/public/documents/pdf/pt/DclSalvador-AcessoAberto-pt.pdf>.

${ }^{32}$ Manifesto Brasileiro de Apoio ao Acesso Livre à Informação Científica. Disponível em: $<$ http://livroaberto.ibict.br/Manifesto.pdf>.

${ }^{33}$ Carta de São Paulo. Disponível em: <http://www.ibict.br/Sala-de-Imprensa/noticias/2005/carta-desao-paulo-defende-o-acesso-livre-a/impressao>.
} 
- 2007: Submetido para aprovação o Projeto de lei n.1120 sobre Política de Acesso livre $^{35}$, arquivado em 2012.

O movimento nacional contou com a forte ação exercida pelo Instituto Brasileiro de Informação em Ciência e Tecnologia (IBICT), em 2009, pelo desenvolvimento de papel fundamental junto a universidades e institutos de pesquisa para disseminação do seu programa de acesso aberto revelando o papel fundamental dos bibliotecários ao trabalhar em parceria com editores de revistas científicas e, por participar das atividades de desenvolvimento de repositórios institucionais a fim de promover a visibilidade da produção científica brasileira (COSTA; KURAMOTO; LEITE, 2013) resultando na continuidade e progresso das atividades de desenvolvimento da biblioteca publicadora.

Estudiosos da comunicação científica fazem previsões dos desdobramentos do acesso aberto onde, cada vez mais, novas ações confirmam seu valor na ciência, porém este capítulo pertence ao futuro.

Ações por parte de bibliotecas universitárias e de pesquisa internacionais demonstram, claramente, sua importância ao romper contratos de big deal mesmo que a comunidade universitária se revolte ou as editoras ofereçam novos termos para as assinaturas. O aumento de valores dos pacotes como Springer, Wiley, Elsevier, Taylor e Francis, SAGE, Oxford University Press, e Cambridge University Press fez com que as universidades, dentro de nova conjuntura envolvendo orçamentos restritos, precisassem rever suas possibilidades de arcar com tais custos aumentando, portanto, o número de cancelamentos (ANDERSON, 2017).

O cenário constituído pelo acesso aberto imediato e irrestrito à Ciência se dá pela confirmação de um padrão de benefícios propagados, a despeito de inúmeras proposições muitas vezes oportunistas, formatadas por publicadores influentes no processo da comunicação científica.

\footnotetext{
${ }^{34}$ Declaração de Florianópolis. Disponível em: $<$ http://www.ibict.br/Sala-deImprensa/noticias/2006/declaracao-de-florianopolis >.

${ }_{35}$ Projeto de lei n.1120. Disponível em: < http://www.camara.gov.br/sileg/integras/461698.pdf>.
} 


\subsection{Licenças de Uso}

Novas adesões em torno do acesso aberto se confirmam pela criação de licenças de uso denominadas Creative Commons ${ }^{36}$ (CC), fundado em 2001 com apoio do Centro para o Domínio Público, se constitui como organização não governamental, sem fins lucrativos, liderado por um Conselho de Administração composto por líderes de pensamento, especialistas em educação, tecnólogos, juristas, investidores, empresários e filantropos.

A criação das licenças CC são influenciadas pela General Public License (GNU/GPL) da Free Software Foundation em conjunto com uma plataforma de aplicativos Web.

A versão 4.0 publicada em 2013 estipula diferentes tipos de uso e restrições sobre o produto intelectual relacionado à cópia, compartilhamento de conteúdo e comercialização, aqueles que desejam reservar todos os direitos de acordo com a lei de direitos autorais não devem usar licenças CC. A notação CCO se destina a marcar o trabalho no Domínio Público antes da prescrição dos direitos autorais.

Para casos de trabalhos com licença CC atribuída sem autorização do autor, este deve pedir imediata remoção para o responsável por sua concessão.

As Licenças CC derivam do copyright menos adaptável e proibitivo, porém, flexibilizam os diferentes acessos a produções acadêmicas somados à mudança de cultura indicada por bibliotecas com relação ao acesso aberto. Neste contexto, a Universidade de Oxford obteve aumento de depósitos em serviços de repositórios ultrapassando mais de $1000 \%$ por mês de cópias de publicações de pesquisa, somados à disposição de bibliotecários em promover o acesso aberto para acadêmicos e cientistas que, a partir de sua aceitação, passam a utilizar terminologias como "verde", "ouro", "CC-BY" e SHERPA-Romeo ${ }^{37}$ (RUMSEY, 2017).

As licenças representadas pelo Creative Commons Brasil ${ }^{38}$ caracterizam-se pelas notações relacionadas:

\footnotetext{
${ }_{37}^{36}$ Disponível em: <https://creativecommons.org/>.

${ }^{37}$ Contém políticas do editor sobre autoarquivamento de artigos de periódicos na web em acesso aberto. Disponível em: <http://www.sherpa.ac.uk/romeo/faq.php?la=pt\&flDnum=|\&mode=simple $>$.

${ }_{38}$ Disponível em: <https://br.creativecommons.org/licencas/>.
} 
- CC BY: os licenciados têm o direito de copiar, distribuir, exibir e executar a obra e fazer trabalhos derivados dela, com créditos para o autor ou licenciador;

- CC BY-SA: Share Alike (SA): os licenciados devem distribuir obras derivadas somente sob uma licença idêntica à que governa a obra original;

- CC BY-ND: esta licença permite a redistribuição, comercial e não comercial, desde que o trabalho seja distribuído sem alteração no seu todo;

- CC BY-NC: uso não Comercial (NC), os licenciados podem copiar, distribuir, exibir e executar a obra, além de fazer trabalhos derivados dela, desde que para fins não comerciais;

- CC BY-NC-AS (Share Alike SA): os licenciados devem distribuir obras derivadas somente sob uma licença idêntica à que governa a obra original, estritamente para fins não comerciais;

- CC BY-NC-ND: esta é a mais restritiva de todas as outras e alguns entendem como a melhor para adoção. Permite download, compartilhamento por terceiros dos trabalhos desde que os créditos sejam atribuídos ao autor sem uma única alteração e com proibição para fins comerciais.

Nota-se pouco entendimento dos usuários de biblioteca com relação às subdivisões de licenças dos direitos autorais no acesso aos conteúdos digitais. Explicado, em parte, pela implantação da tecnologia digital em rede, que permite a cada indivíduo conectado ao computador, usar as funções de impressão, reimpressão, publicação e comércio - tornando a lei de direitos autorais desnecessária por não cumprimento - e pelo indivíduo acreditar no uso sem permissão em virtude da lei estar focada nas relações autor /editor (LITMAN, 2017).

Capacitações, treinamentos, workshops temáticos promovidos por bibliotecários em torno dos direitos autorais contribuem para a compreensão das licenças de uso e consecutiva propagação de modo preciso por seus usuários. 


\subsection{Formato Aberto EPUB}

Padrões de formato aberto (open source) para edição, como HTML5, Open Office, PDF são usados nas publicações digitais, dentre eles o EPUB (Electronic Publication) comumente usado para composição de livros digitais, revistas, publicações educacionais, profissionais e científicas.

Esta seção apresenta apenas o formato EPUB, excluindo-se o formato PDF por este manter a formatação e diagramação não permitindo alteração no tamanho da fonte, reordenação de páginas e leitura confortável em dispositivos de telas pequenas como celulares ou leitores (e-readers).

O formato EPUB foi concebido pelo Fórum Internacional de Publicação Digital $^{1}$ (International Digital Publishing Forum - IDPF) para revolucionar o mundo editorial com a possibilidade deste se tornar o padrão global para conteúdos nascidos digitalmente.

A missão do Fórum Internacional de Publicação, como organização global de comércio e normas, é voltada ao desenvolvimento e promoção da publicação eletrônica e do consumo de conteúdo.

A atuação do IDPF é global por perseguir os objetivos relacionados:

- Desenvolver a adoção de publicações eletrônicas por meio de tecnologia comprovada, difusão de melhores práticas;

- Aprimorar e difundir a utilização das especificações e padrões comuns;

- Fomentar a interoperabilidade em aplicativos de publicações e sistemas de leitura EPUB e obter adesões de membros da comunidade para resolução dos trabalhos no fórum;

- Reconhecer, analisar e indicar padrões criados por outros órgãos referentes a conteúdos eletrônicos;

- Apresentar e congregar fórum para discussão de questões técnicas concernentes à publicação eletrônica;

- Agregar as diferenças culturais das diferentes nações, idioma, leitura, diferenças de aprendizagem e habilidades naturais.

O histórico do formato EPUB passa pelo desenvolvimento do EPUB 2, inicialmente padronizado em 2007 como um formato sucessor da Open eBook Publication Structure ou OEB, originalmente desenvolvido em 1999. A versão de 
manutenção EPUB 2.0.1, aprovada em 2010, foi a versão ramal final no EPUB 2 (INTERNATIONAL DIGITAL PUBLISHING FORUM, s.d.).

O EPUB 2.0.1 foi substituído pela versão EPUB 3.0, já atualizado para 3.0.1 do mesmo padrão. O projeto EPUB $3.0^{39}$ foi desenvolvido e aprovado como especificação final em 2011 por um grupo de representantes do IDPF e especialistas que tornaram público e acessível um repositório de código fonte e uma página WiKi para registro dos requisitos, apontamentos sobre reuniões, soluções entre outros.

Aplicativos como o Sigil, que será abordado no capítulo posterior, oferecem suporte ao formato EPUB com uma variedade de recursos que o livro impresso não reúne.

O EPUB 3 proporciona um meio de descrever, acondicionar e escrever em código o conteúdo da web organizado e semanticamente aperfeiçoado, incluindo $\mathrm{HTML}^{40}, \mathrm{CSS}^{41}, \mathrm{SVG}^{42}$; além de outros recursos dispostos em arquivo único (IDPF, 2018).

O EPUB 3 tem documentos de layout fixo para permitir a definição de metadados para publicações EPUB.

A versão 3 do EPUB transpõe algumas barreiras e oferece estruturação do conteúdo e recursos para layout, interatividade, animações, áudio, vídeo, tipografia avançada, suporte a fórmulas matemáticas, narração de texto em voz alta, acessibilidade. Os recursos avançados podem ser de animação, educacionais, inserção de simulações, jogos no texto (baixados sob demanda), idiomas de caracteres especiais, ilustrações animadas, narração em áudio, streaming de vídeo, entre outros (DUARTE, 2012).

A vantagem do EPUB 3 é agregar a apresentação de novas soluções de recursos avançados com o objetivo de proporcionar ao leitor conforto e animação na leitura.

A adesão ao EPUB de empresas de peso, como a Amazon que começou a

\footnotetext{
${ }^{39} \mathrm{http}: / /$ idpf.org/epub.

${ }^{40}$ HyperText Markup Language ou Linguagem de Marcação de Hipertexto.

${ }^{41}$ Cascading Style Sheets é um mecanismo para adicionar estilo (cores, fontes, espaçamento, etc.).

${ }^{42}$ Scalable Vector Graphics: Gráficos Vetoriais Escaláveis. Linguagem XML para descrever de forma vetorial desenhos e gráficos bidimensionais, quer de forma estática, quer dinâmica ou animada, https://pt.wikipedia.org/wiki/SVG.
} 
utilizá-lo em 2013 e a Apple ${ }^{43}$, mostra a força do padrão para edição digital e fortalecimento do conceito "Lightweight Content Protection" ${ }^{\text {"44 }}$ (Proteção "Leve" de Conteúdo) que, ao mesmo tempo, garante a proteção dos conteúdos com uso do $\mathrm{DRM}^{45}$ e favorece o acesso aberto sob diversos tipos de licenças, dentre elas as licenças Creative Commons abordadas no subitem anterior.

\footnotetext{
${ }_{44}^{43}$ https://support.apple.com/en-us/HT202066.

${ }^{44} \mathrm{http}: / /$ idpf.org/epub-content-protection.

${ }^{45}$ Digital Rights Management ou Gerenciamento de Direitos Digitais: impede a cópia ilimitada ou a cópia pirata de um arquivo eletrônico. Utilizado por editoras ou empresas que comercializam livros digitais.
} 


\section{PRÁTICAS DE PUBLICAÇÃO DO LIVRO DIGITAL: ESTUDOS DE CASO}

A implantação dos serviços de biblioteca publicadora universitária está ligada a fatores como: política da instituição, equipe envolvida para realização do trabalho (como bibliotecários, profissionais com forte base em $\mathrm{TI}$, editores envolvidos nas questões do universo de publicação), condições estruturais de ambiente (equipamentos, softwares), ações educativas voltadas para integrar e qualificar membros da comunidade (como graduandos com interesse voltado às práticas de publicação do livro digital e docentes).

As apresentações dos estudos de casos se constituem em eventos de sucesso de naturezas diferentes, pois são provenientes do meio acadêmico e da iniciativa privada, respectivamente.

São importantes por transmitir o conhecimento da prática empregada, fomentar a discussão e promover incentivos em torno das operações de publicação fundamentada na biblioteca.

O relato destas experiências traz significados, bem como questionamentos à publicação digital de conteúdos acadêmicos e científicos produzidos na universidade para oferecimento à sociedade de forma aberta e irrestrita.

O primeiro estudo de caso vincula-se à Universidade de Michigan, que advoga pelo acesso ao conhecimento acadêmico-científico proveniente das atividades de publicação difundidas pelo bem sucedido Michigan Publishing Services (MPS) e pela larga experiência deste serviço nesta importante universidade americana.

A descrição deste estudo enfoca a estrutura de publicação para livros digitais em acesso aberto, os procedimentos adotados na execução das tarefas para divulgação dos conteúdos, buscando destacar aspectos da política institucional para contribuir, expandir e aperfeiçoar esta atividade.

O segundo estudo de caso demonstra parte do processo de desenvolvimento prático do trabalho editorial voltado à publicação do livro digital pela editora comercial Paulus. Neste contexto, desvinculada da prática de disseminação da comunicação acadêmico-científica proveniente de biblioteca publicadora na Universidade. 
A descrição desta prática se realizou por meio da observação das etapas de trabalho apresentada pela equipe encarregada em unir esforços para aperfeiçoamento do trabalho editorial.

\subsection{Estudo de Caso da Michigan Publishing of University of Michigan Library ${ }^{46}$}

A Universidade de Michigan ocupa a $21^{a}$ posição mundial segundo o QS Top Universities $^{47}$ no ano de 2017 e a $27^{\mathrm{a}}$ no Times Higher Education College Ranking ${ }^{48}$ ( $T H E$ ), entre as universidades da América do Norte, no período de 2017 a 2018.

O estudo de caso foi realizado com base em perguntas encaminhadas por email ao diretor e bibliotecário Jason Colman, responsável pela Michigan Publishing Services (MPS), daqui em diante referido apenas como MPS.

O MPS iniciou suas atividades em 2001 como unidade/departamento de publicação de biblioteca centralizada. Em 2018, conforme descrição do Library Publishing Directory, o serviço possui um total FTE (Full Time Equivalent) para suporte das atividades de publicação de: equipe profissional (16); estudantes de graduação (1).

O MPS conta com serviços adicionais como: design gráfico (impressão ou web); impressão sob demanda; composição; cópia de edição; marketing; divulgação; treinamento; catalogação; metadados; registro ISSN; registro ISBN; atribuição/alocação de identificadores $\mathrm{DOI}^{49}$; contrato/preparação de licença; autor copyright; outro autor consultivo; hospedagem de conteúdo suplementar; streaming de áudio/vídeo.

A missão do MPS é: publicar conteúdos acadêmicos e educacionais em uma variedade de formatos para ampla disseminação e preservação permanente; fornecer serviços de publicação para a comunidade da Universidade de Michigan e defender o acesso ao conhecimento acadêmico da forma mais ampla possível.

\footnotetext{
${ }^{46}$ Disponível em: <www.publishing.umich.edu>.

47 QS World University Rankings: Classificação Internacional de Universidades, publicada pela Quacquarelli Symonds (QS), <https://www.topuniversities.com/university-rankings>.

48 Times Higher Education (THE) College Ranking: Fundado em 2004, o THE fornece a lista das melhores universidades no mundo pelos resultados de avaliação de ensino, pesquisa, perspectivas internacionais entre outros, <https://www.timeshighereducation.com/world-university-rankings > .

49 Digital Object Identifier: Código numérico que identifica o item digital para que ele fique permanentemente na web mesmo que sua localização ou metadados sejam modificados.
} 
As atividades do MPS incluem:

- Publicar monografias em formulários impressos e eletrônicos;

- Hospedar e publicar revistas em acesso aberto;

- Desenvolver novos modelos de publicação digital para compartilhamento de conhecimento;

- Criar versões permanentes e acessíveis de publicações do corpo docente;

- Consultar sobre direitos autorais e publicação;

- Defender direitos de autores da Universidade de Michigan;

- Reeditar itens de coleções e do corpo docente em novas formas (reedições, edições digitais).

O MPS é estruturado para publicar livros digitais em acesso aberto pela operação da editora University of Michigan Press (UMP) e pelo Michigan Publishing Services (MPS) de modo distinto.

A editora UMP publica apenas alguns livros digitais em acesso aberto por ano, enquanto o MPS prioriza o movimento mundial em prol da ciência aberta publicando quase todos os itens abertamente.

Os livros digitais da editora UMP, abertos ou não, são adquiridos por editores, especialistas em campos específicos. Estes trabalham com os autores para desenvolver propostas e trazê-las para a revisão docente, com foco particular nas expectativas de receita de vendas.

No MPS, o bibliotecário atua também como editor por trabalhar diretamente com o corpo docente da Universidade e atender às necessidades de publicação destes. O bibliotecário não conduz uma revisão por pares independente, mas traz todos os livros publicados pelo MPS para um comitê de revisão interno.

$\mathrm{Na}$ UMP todos os livros sob o selo da editora passam pela curadoria, entendida aqui como revisão por pares, ao passo que no MPS muitos títulos não passam por esta revisão.

O MPS pode ser entendido como um modelo de autopublicação assistida, no qual não existe um processo editorial. Aqui, os custos provenientes dos trabalhos de edição e editoração de texto são repassados para o corpo docente.

O MPS também preserva publicações sobre a infraestrutura da biblioteca, por 
entender que esta seja uma forma mais sustentável de execução na universidade (Figura 2).

Figura 2 - Quadro comparativo das diferenças MPS e UMP

\begin{tabular}{|c|c|}
\hline Michigan Publishing Service (MPS) & University of Michigan Press (UMP) \\
\hline $\begin{array}{l}\text { Publica a maioria dos livros digitais em acesso } \\
\text { aberto/ano }\end{array}$ & $\begin{array}{l}\text { Publica apenas alguns livros digitais } \\
\text { em acesso aberto/ano }\end{array}$ \\
\hline $\begin{array}{l}\text { Bibliotecário atua como editor, trabalho direto com o } \\
\text { corpo docente da Universidade }\end{array}$ & $\begin{array}{l}\text { Livros digitais, abertos ou não, são } \\
\text { adquiridos por editores especialistas em } \\
\text { campos específicos }\end{array}$ \\
\hline $\begin{array}{l}\text { Bibliotecário não conduz revisão por pares } \\
\text { independente, todos os livros publicados } \\
\text { são trazidos para um comitê de revisão interno }\end{array}$ & Curadoria "revisão por pares" \\
\hline $\begin{array}{l}\text { Modelo de auto-publicação assistida, } \\
\text { não existe um processo editorial }\end{array}$ & $\begin{array}{l}\text { Equipe trabalha com os autores para } \\
\text { desenvolvimento de propostas com } \\
\text { vistas para revisão docente }\end{array}$ \\
\hline $\begin{array}{l}\text { Custos de edição / editoração são repassados para } \\
\text { o corpo docente. Recebe verba anual da reitoria } \\
(\$ 178,000 / a n o)\end{array}$ & Foco nas receitas de vendas \\
\hline $\begin{array}{l}\text { Preserva publicações sob a infraestrutura } \\
\text { da Biblioteca }\end{array}$ & \\
\hline
\end{tabular}

Fonte: Michigan Publishing Service (MPS)

\subsubsection{Software utilizado}

A plataforma utilizada para publicações digitais é a Digital Library Extension Service (DLXS), aplicativo desenvolvido internamente na Universidade de Michigan, responsável por hospedar e preservar livros em formato $\mathrm{XML}^{50}$, sua vantagem é apresentar maior agilidade para a busca e auxiliar nos aspectos de catalogação e

${ }^{50}$ eXtensible Markup Language: linguagem de marcação recomendada pela W3C para a criação de documentos com dados organizados hierarquicamente, tais como textos, banco de dados ou desenhos vetoriais. A linguagem XML é extensível porque permite definir os elementos de marcação.: $<$ https://www.tecmundo.com.br/programacao/1762-o-que-e-xml-.htm>. 
indexação de livros.

O DLXS ${ }^{51}$ é uma ferramenta gratuita de open source DL com foco em quatro amplas "classes" de materiais:

- Classe de texto: conversão retrospectiva, projetos de codificação de texto;

- Classe de imagem: Torre de Babel, muitas formas de metadados reunidas ou mantidas distintamente, grau crescente de suporte para ferramentas;

- Classe bibliográfica: ferramentas para sistemas bibliográficos; escalabilidade (por ex., 17 milhões de citações no índice de tempo), simplicidade (menos de uma hora para colocar uma coleção on-line);

- Ajuda (pré-classe).

Algumas funcionalidades devem ser consideradas ao analisar a escolha de plataforma para livros digitais, como: busca do texto completo, busca de palavrachave, opções de copiar/colar, opções de impressão, opções para baixar conteúdo, busca em nível da coleção, busca avançada, marcador de página, ferramentas de citação, ferramentas de anotação, leitura off-line, disponibilidade de relatório de uso, URLs persistentes para livros e capítulos, impressão sob demanda, modelos de personalização e disponibilidade de registros MARC (RONCEVIC, 2013, p.12).

Elliot (2015) destaca no estudo publicado do relatório para Andrew W. Mellon Foundation, a necessidade do desenvolvimento de novo modelo de transição digital em apoio à publicação e divulgação de monografias digitais para as Humanidades, baseado na experiência da Emory University. O estudo feito por um grupo de trabalho especificou a necessidade da existência da publicação digital de acesso aberto e de outra física impressa sob demanda, para disseminação complementar da publicação acadêmica de longo prazo. O estudo concluiu que a monografia precisa ter os recursos de qualidade descritos abaixo, alguns deles comuns para publicação de livros digitais:

1. Revisão por pares intensiva por especialistas de conteúdo;

\footnotetext{
${ }^{51}$ DLXS. <https://www.cni.org/wp-content/uploads/2013/05/DLXS-JWilkin2001Stfppt.pdf>.
} 
2. Novas formas de marketing para atrair leitores, além da parceria dos autores na questão com o compartilhamento do livro aberto em redes sociais e profissionais;

3. Design que garanta uma experiência de leitura de alta qualidade garantindo navegação e acessibilidade que permitam o acesso de leitores de diferentes habilidades visuais;

4. Licença de uso que permita a reutilização e circulação do trabalho para fins não comerciais;

5. Sustentabilidade e preservação pelo armazenamento, permanência e durabilidade - são as áreas de maior preocupação referentes à publicação digital - e apoio ao desenvolvimento de uma plataforma para o repositório de publicações digitais;

6. Impressão - item importante a se considerar, uma vez que as Humanidades levam em conta esta característica, considerando a restrição ou inexistência ao acesso digital em muitos ambientes;

7. Anotações, uma vez que se trata de um recurso primordial existente nas novas plataformas de publicação digital e, os conteúdos anotados devem ser exportados;

8. Busca de conteúdo por índice de assunto, sem o qual a monografia deve ser toda examinada para se encontrar a informação necessária;

9. Potencial de rede, as publicações digitais devem fornecer links, incorporados ao texto ou em apêndices, para Fontes primárias que estão publicamente disponíveis na Internet.

Em 2016 o MPS, apoiado pela Andrew W. Mellon Foundation lança a versão beta de outra plataforma denominada Fulcrum $^{52}$ que utiliza estrutura dos softwares abertos Hydra/Fedora para melhor representar os resultados de comunicação científica e oferecer suporte aos livros em acesso aberto.

Ainda em desenvolvimento, a plataforma Fulcrum permite flexibilidade, descoberta e durabilidade pela característica de interoperabilidade com outras ferramentas de publicação, integrada à cadeia de fornecimento de informações com

\footnotetext{
${ }^{52}$ Blog do Fulcrum. Disponível em: <www.fulcrum.org/blog/2016/10/24/fulcrum-beta-launch/>.
} 
descoberta de conteúdo pelos leitores, rastreamento do impacto para itens pesquisados, além de estar direcionada para curadoria de objetos digitais.

Alguns autores como Geyer (2016) descrevem as facilidades que a plataforma reúne para disseminação de objetos digitais,

O foco do Fulcrum é a apresentação de Fontes digitais e materiais suplementares que não podem ser representados adequadamente em formato impresso. A plataforma permite uma experiência mais rica e um entendimento mais profundo para o leitor e permite que os autores criem argumentos melhores e multifacetados, oferecendo suporte a conteúdo multimídia, incluindo reprodução de arquivos de áudio e vídeo e capacidade de zoom panorâmico para imagens de alta resolução. Todo o conteúdo é detectável e preservado através de URLs duráveis; metadados estruturados e resultados de pesquisa facetada que também permitem uma exploração mais aprofundada dos materiais ${ }^{53}$. (tradução nossa)

O livro digital "A Mid-Republican House From Gabil" (2018 $\left.{ }^{54}\right)$, exemplo de apresentação na Fulcrum está disponível pela Editora da Universidade de Michigan para consulta, com dados quantitativos detalhados que são referenciados no texto e no conteúdo em $3 D^{55}$.

\subsubsection{Processo de publicação}

A produção de livro no MPS segue mais ou menos um processo tradicional, exceto por ser mais rápido comparado a muitas editoras acadêmicas. Normalmente é possível produzir um livro no prazo de três a quatro meses, diferente do período de um ano normalmente utilizado.

A equipe da MPS conta com dois bibliotecários e uma equipe regular de quatro funcionários (dois coordenadores de publicação digital sênior e dois coordenadores de publicação digital) com habilidades variadas, todos, porém, com boa experiência unificada em gerenciamento de projetos ${ }^{56}$.

\footnotetext{
${ }^{53}(\ldots)$ the focus of Fulcrum is the presentation of digital source and supplemental materials that cannot be represented adequately in print form. The platform allows for a richer experience and deeper understanding for the reader and enables authors to make better, multi-faceted arguments by supporting multimedia content, including playback for audio and video files, and pan-zoom capability for high resolution images. All content is discoverable and preserved via durable URLs; structured metadata and faceted search results also allow for further exploration of the materials.

${ }_{54} \mathrm{https}: / / \mathrm{www}$.fulcrum.org/gabii.

${ }^{55} \mathrm{http}: / / \mathrm{dx}$.doi.org/10.3998/mpub.9231782.

${ }^{56}$ Lista de funcionários https://www.publishing.umich.edu/directory/.
} 
Em geral, os bibliotecários não possuem habilidades de editor e é necessário um trabalho cooperativo entre estes dois profissionais no contexto do trabalho conjunto em biblioteca publicadora para sua evolução.

Como formação incentivadora, a Biblioteconomia poderia incluir em sua grade curricular parte do conhecimento desenvolvido pelos cursos de editoração para que bibliotecários possam ter acesso à vivência do editor; não implicando na conversão do bibliotecário em editor. Colman comenta a necessidade de conhecer as habilidades do editor em sua experiência no MPS,

como bibliotecário de aquisição de livros, tive que aprender mais sobre o conjunto de habilidades do editor. Eu diria que a maneira típica como os outros bibliotecários interagem com os editores do UMP é conectando-se com professores em suas disciplinas que podem ter projetos interessantes ${ }^{57}$. (tradução nossa)

O processo de publicação da MPS conta com as atividades:

1. Aquisição e Consulta: conversa com o autor para desenvolvimento da proposta e configuração do orçamento e serviços necessários;

2. Edição de texto: o manuscrito é editado em conformidade com guia de estilo, geralmente o Chicago Manual of Style, e toda alteração deve ser aprovada pelo autor;

3. Tipografia: no caso de produção de versão impressa e/ou PDF do livro, é projetada e esquematizada a composição tipográfica. O processo conta com a aprovação do autor;

4. Conversão $X M L / E P U B^{58}$ : uma versão $X M L$ ou EPUB do livro é criada para hospedagem na plataforma digital;

5. Impressão de provas: uma cópia do livro por demanda é impressa para garantir que o conteúdo passe nas verificações de qualidade;

6. Publicação: são lançados todos os formatos do livro para leitura e venda (eletrônico, impresso, Kindle / iBook);

\footnotetext{
${ }^{57}$ Comentário de Jason Colman disponível no Apêndice A.

${ }^{58}$ Electronic Publication: formato de arquivo digital padrão específico para eBook.
} 
7. Avaliação: as vendas oferecidas pela Amazon são monitoradas pelo MPS, além da análise da web e impacto das métricas para verificar se o livro está atingindo o público direcionado.

Normalmente o MLP publica apenas conteúdo acadêmico, porém recentemente, foi editado o livro para colorir "Colour Me Michigan" em celebração aos 200 anos de história da Universidade ${ }^{59}$.

Hawkins (2014) comenta a evolução dos serviços de publicação da Michigan passando de escritório de publicação acadêmica (Scholarly Publishing Office) para uma equipe multidepartamental (Michigan Publishing) e progredindo para uma operação totalmente integrada com a editora University of Michigan Press (Michigan Publishing) relacionando a operação de publicação na Universidade às diferentes configurações do direito autoral, vantagens e alterações destes modelos e a gestão entre autores e editores evoluindo de acordo com o pensamento da organização.

O modelo de licenças escolhido pelo MPS é o Creative Commons em razão dos principais integrantes do acesso aberto, como a associação Open Access Scholarly Publishers Association ${ }^{60}$ (OASPA), utilizarem a licença CC BY conforme a definição de acesso aberto proveniente da Iniciativa de Acesso Aberto de Budapeste $^{61}$, sendo a licença CC-BY-NC-ND mais comum para livros digitais abertos, seguida pela CC-BY.

Segundo Kahn (2013) o contrato para novos autores da Michigan estabelece que a adoção de licença CC pelos autores garante recebimento de ganhos nos três primeiros anos,

"Na Michigan Publishing, publicamos muitos trabalhos com licenças CC. Notavelmente, na Editora da Universidade de Michigan publicamos uma série de sucesso financeiro onde uma licença CC é

\footnotetext{
${ }^{59}$ Disponível em: <https://www.publishing.umich.edu/publications/color-me-michigan/>.

${ }^{60}$ Open Access Scholarly Publishers Association: <https://oaspa.org/about/mission-and-purpose/>.

${ }^{61}$ Uma antiga tradição e uma nova tecnologia convergiram para tornar possível um avanço histórico. A antiga tradição é a disposição de cientistas e acadêmicos em publicar o fruto de suas pesquisas, sem remuneração, em nome da transparência e democratização do conhecimento. A nova tecnologia é a internet. $O$ avanço histórico que eles possibilitam é a distribuição da literatura acadêmica arbitrada por toda a extensão do globo e o acesso totalmente irrestrito e gratuito por parte de qualquer cientista, acadêmico, professor, estudante ou outro interessado. Desfazer as barreiras que impedem o acesso a esta literatura irá acelerar a pesquisa, fortalecer a educação e difundir o conhecimento de maneira geral, assentando as bases para a união da humanidade em uma ampla e inédita conversação intelectual comum em sua marcha pelo conhecimento. Disponível em: $<\mathrm{http}: / /$ www.budapestopenaccessinitiative.org/translations/portuguese-translation>.
} 
aplicada a uma versão on-line quando o trabalho é publicado impresso. Embora cada livro seja abertamente acessível on-line assim que é impresso, as vendas da impressão são fortes. [...], nossos autores terão a oportunidade de aplicar uma licença CC, imediatamente ou em três anos após a publicação. Na verdade, eles também podem recusar uma licença CC. Os autores que publicam com o selo da Editora da Universidade de Michigan e que optam por uma licença CC imediata receberão um adiantamento sobre os royalties consistentes com os ganhos alcançados nos primeiros três anos $^{62}$. (tradução nossa)

Este contrato permite que os autores retenham os direitos autorais dos trabalhos criados por eles

A Michigan Publishing manterá direitos de publicação em vez de direitos autorais e trabalhará de forma agressiva em apoio aos nossos autores para comercializar e distribuir seus trabalhos. Acreditamos que essa nova posição seja um passo importante por uma série de razões; o mais importante é alinhar nossas práticas de publicação com a política da Universidade de Michigan (SPG 601.28) que mantém os direitos autorais de obras escritas por professores em nome do autor ${ }^{63}$. (tradução nossa)

É importante ressaltar que o MPS recebe da reitoria da Universidade de Michigan a verba de $\$ 178,000 /$ ano para oferecer suporte à publicação de acesso aberto para professores, alunos e funcionários da Universidade.

Para a publicação de livros digitais e impressos foi criada a Maize Books, editora da Michigan Publishing, voltada à publicação de conteúdos acadêmicos que não se ajustam às categorias de monografia ou artigo de revista. Este novo modelo, oferece processos simplificados de seleção, produção e distribuição para diversas áreas disciplinares contribuindo com a missão do MPS: aumentar o impacto dos programas de publicação em uma universidade descentralizada garantindo redução de custos; defender novas ambições de publicação da comunidade da Michigan

\footnotetext{
${ }^{62}$ At Michigan Publishing, we publish many works with CC licenses. Notably, at the University of Michigan Press we publish a financially successful series where a CC license is applied to an online version when the work is published in print. Although each book is openly accessible online as soon as it is printed, sales of the print have been strong. Henceforth, our authors will be given an opportunity to apply a CC license, either immediately or in three years after publication. In fact, they may also refuse a CC license. Those authors who publish under our University of Michigan Press imprint and who opt for an immediate CC license will be offered an advance on royalties consistent with earnings that we typically see in the first three years.

${ }^{63}$ Michigan Publishing will retain publishing rights rather than copyright, and will work aggressively in support of our authors to market and distribute their works. We believe this new position to be an important step for a variety of reasons; most significantly, it aligns our publishing practices with policy at the University of Michigan (SPG 601.28), which keeps copyright for faculty-authored works in the author's name.
} 
além de criação de espaço para experimentação na publicação acadêmica como acesso aberto, acessibilidade, diversidade e aprendizado dos alunos por meio da publicação (COLMAN, 2017).

Figura 3 - Portal Maize Books

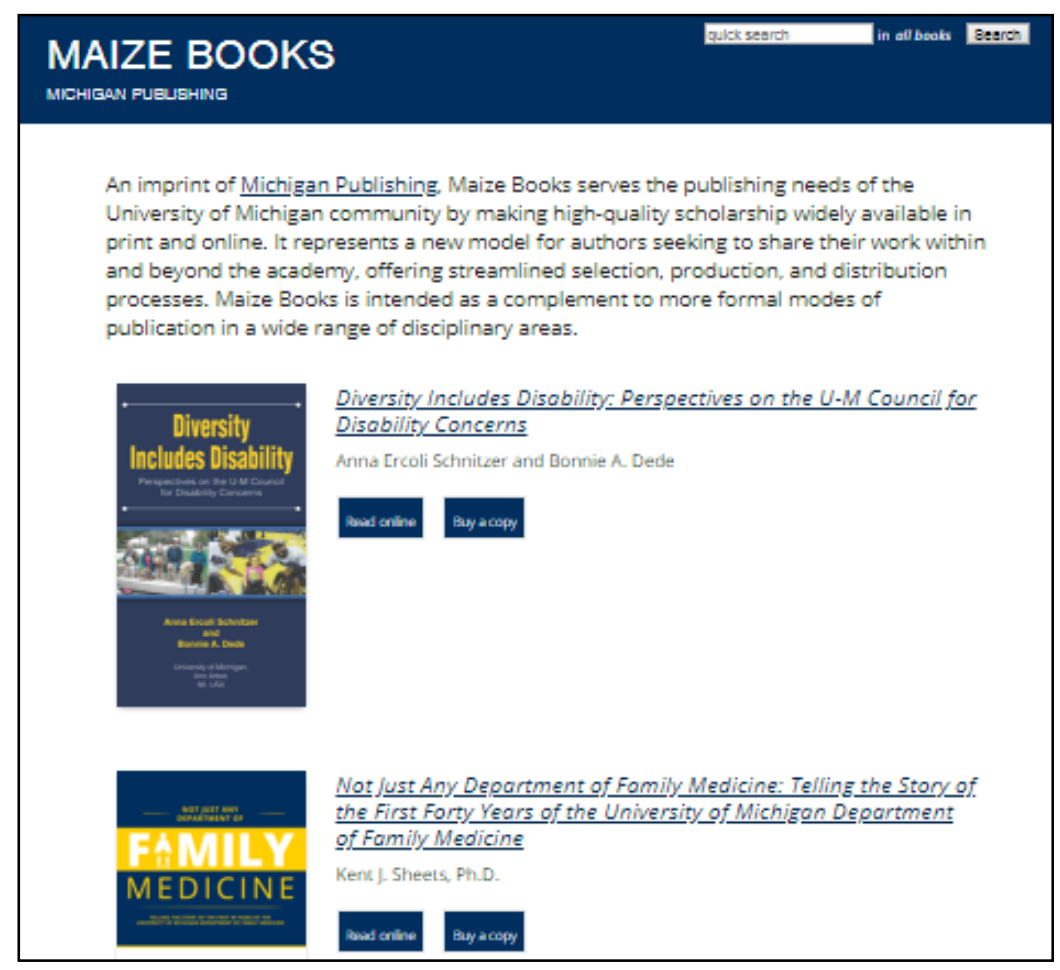

Fonte: Michigan Publishing - University of Michigan Library ${ }^{64}$

Reunindo diferentes temas em versão on-line de acesso aberto, somado às versões impressa e digital, o Maize Books é uma solução para conteúdos que não seriam aceitos por editoras tradicionais, mas de acordo com Colman (2017) por passarem por processos de edição de texto, design e composição, ajudam os autores a transmitir suas ideias com mais facilidade.

O programa de publicação da Michigan edita publicações de valor acadêmico como: volumes editados, textos de ensino, relatórios de financiamentos, histórias institucionais, manuais técnicos, relatórios e literatura cinzenta.

No dia-a-dia da biblioteca universitária nos deparamos com a perda de textos acadêmicos e científicos provenientes de eventos que nem sempre são armazenados satisfatoriamente nos sites de eventos promovidos por associações

\footnotetext{
${ }^{64}$ Disponível em: <https://www.maizebooks.org/>.
} 
entre outros e, apesar desta literatura cinzenta ser solicitada por estudiosos, sua recuperação e reuso não ocorre pela falha no armazenamento.

Neste sentido, o trabalho realizado pela MPS fornece destino garantido a toda literatura cinzenta que poderá ser consultada, não somente pela comunidade universitária, mas pela sociedade além de ser armazenada e disposta digitalmente, impondo assim um alto valor no trabalho desempenhado pelo MPS sem interferir na missão da editora UMP.

Os livros da Michigan são convertidos na versão XML para acesso aberto além de contar com versões impressa e digital geradas para consumo em comércio eletrônico como Amazon, Apple iBooks e por meio de publicação sob demanda como Ingram Content Group.

Outras publicações em acesso aberto provenientes da UMP são subsidiadas por outros programas como o Knowledge Unlatched ${ }^{65}$.

A sustentação do modelo de publicação de livros digitais não é fácil quando se pensa em equacionar a verba de recursos provenientes da universidade: número de integrantes de equipe, horas trabalhadas, recursos provenientes de e-commerce, equipamentos, softwares, entre outros.

Porém, pode-se claramente identificar que a MPS consegue desenvolver atividades de publicação de modo diferente do trabalho realizado pela editora UMP.

Ambos os serviços coexistem MPS e UMP mantêm suas peculiaridades no atendimento às necessidades de publicação da comunidade universitária de forma satisfatória e carregam as atribuições exatas dos papéis de cada um.

O grau de importância dos serviços do MPS e da UMP são igualmente relevantes no tocante à produção editorial de livros digitais e à disseminação dos conteúdos.

O trabalho do MPS feito por bibliotecários por formação soma-se ao dos editores por formação de modo alinhado para garantir aplicabilidade e eficiência no trabalho realizado e na disseminação dos livros digitais produzidos.

\footnotetext{
${ }^{65}$ Disponível em: <http://www.knowledgeunlatched.org/>.
} 


\subsection{Estudo de Caso da Editora Comercial Paulus}

Este é um estudo exploratório-descritivo das atividades e etapas de trabalho que caracterizam o processo de edição e publicação do livro digital em editora comercial.

$\mathrm{Na}$ presente seção será apresentada a descrição do fluxo de trabalho da Paulus Editora para entendimento de procedimentos adotados e possíveis diferenças com relação àqueles praticados pelas universidades.

Este estudo foi elaborado por visitas à editora, mediante observação do trabalho conduzido pela equipe encarregada nas diferentes fases em busca de aperfeiçoamento da rotina de suas atividades com aplicação de exercício prático no software utilizado.

A Pia Sociedade de São Paulo, por meio da Paulus Editora, oferece um catálogo de livros digitais com pouco mais de 400 títulos em formato EPUB para venda com licença de copyright reservada à editora. Os temas de livros digitais oferecidos pela editora são ligados às Ciências humanas e Sociais, Comunicação, Educação, Filosofia, Literatura Infantil, Psicologia, Saúde, Teologia, entre outros.

A área editorial da Paulus integra o setor de Multimídia responsável pelos projetos gráficos dos livros, composto por seis funcionários:

- Um gerente, que coordena a divisão de tarefas entre a equipe e contato com ilustradores contratados para produção de ilustrações para livros infanto-juvenis;

- Quatro designers, responsáveis pela produção dos livros (projeto gráfico, diagramação e capa);

- Uma web designer, encarregada da produção dos livros digitais. Para a produção dos livros são utilizados os softwares do pacote Adobe, como Photoshop, InDesign, Illustrator, além do uso do Sigil para os livros digitais.

\subsubsection{Contexto do trabalho editorial}

Os livros para publicação na editora chegam por duas vias: enviados espontaneamente pelos autores ou encomendados pela editora. 
No caso dos livros enviados espontaneamente, a editora recebe quase sempre por e-mail. Estes são encaminhados ao diretor editorial que, após rápida verificação, decide se o livro deve ser recusado ou encaminhado para análise. Se recusado, uma mensagem padrão é encaminhada ao autor. Caso o livro seja considerado apto para análise, o conteúdo é enviado, pelo menos, a dois pareceristas responsáveis por decidir se a obra pode ser publicada ou não, levando em consideração o conteúdo e as condições atuais do mercado editorial.

Os pareceres são encaminhados ao diretor editorial, responsável por apresentá-los na reunião mensal do conselho editorial onde, após comentários dos conselheiros, toma a decisão de publicar ou não, estabelecendo o prazo e a coleção mais adequada para o livro.

Ao editor compete avaliar a obra, sugerindo ou não a publicação. Em caso positivo, compete a ele dialogar com o autor, sugerindo modificações que possam tornar o texto mais claro, além de sugerir ao departamento de designer o layout da obra, imagens a ser inseridas, entre outros.

Para livro encomendado pela editora, o diretor editorial ou editor assistente verificam o conteúdo após recebimento. Algumas vezes, o diretor editorial entra em contato com o autor para sugerir modificações por motivos de clareza ou linha editorial. Feito isto, o livro é apresentado ao Conselho apenas para dar conhecimento e não para ser submetido à aprovação.

A editora segue padrão de qualidade estabelecido por norma culta, mas não de maneira estrita, procurando levar em consideração a natureza da cada obra e o público a que se destina.

Sendo livro encomendado ou não, depois de apresentado ou aprovado no conselho, ele passa para a preparação que se constitui em leitura feita por um revisor mais experiente, que pode sugerir modificações de estilo, além da correção de erros.

Após esta preparação, o livro é paginado e passa por duas revisões, nas quais os revisores só devem corrigir erros de digitação ou falhas graves, sem interferir no estilo da obra. Normalmente após esta etapa, a obra paginada é devolvida ao autor, para que faça suas últimas observações antes do livro ser enviado à gráfica. 
A editora tem como padrão conciliar a publicação simultânea em formato digital após o lançamento da versão impressa; é feita nova seleção dos títulos publicados para lançamento digital.

Tão logo, os títulos sejam selecionados, inicia-se a produção dos livros digitais simultaneamente ao pedido de ISBN digital para cada título.

Após a conclusão destas duas etapas, os conteúdos dos livros digitais são inseridos na plataforma de distribuição detalhada no subitem Processos de Desenvolvimento do Livro Digital.

A distribuição é feita em plataforma própria onde, após o fornecimento dos dados do livro e carregamento do arquivo EPUB original, os livros são enviados para lojas parceiras. Na plataforma é possível acompanhar as vendas por período (dia, mês, ano).

Para efeitos de preservação o arquivo original de cada livro digital é armazenado em um diretório na rede interna da Editora e na plataforma de distribuição, os arquivos ficam salvos para eventuais alterações.

\subsubsection{Software utilizado na Paulus Editora}

A editora utiliza o software Sigil (Sigil Ebook, 2017), que foi criado em 2009, com desenvolvimento e manutenção de mudanças feitas entre diferentes desenvolvedores.

O software foi desenvolvido por Strahinja Val Marković. De 2011 a 2015 John Schember assumiu os trabalhos e, em 2015 a atualização do software ficou a cargo dos desenvolvedores Kevin Hendricks e Doug Massay.

O Sigil é um aplicativo novo e indispensável de produção aberto destinado à criação e manutenção de livros digitais, editor de EPUB que suporta WYSIWYG (What You See Is What You Get) (DEMARCO, 2014), por exibir na tela do computador informações (textos, diagramas, imagens etc.) com aspecto semelhante ao da impressão, facilitando a visualização prévia do trabalho antes de sua finalização.

A edição é baseada em código de arquivos EPUB, bem como a importação de arquivos HTML e texto sem formatação. 
A versão 0.9.9 de 2017 traz novos recursos e correções para EPUB2 e EPUB3 descritas na documentação do GitHub ${ }^{66}$ :

- Preferências gerais: o histórico pode ser desabilitado da área de transferência enquanto o Sigil estiver em processo/execução, qualquer coisa adicionada à área de transferência estará disponível para colagem;

- Nova configuração de preferências do dicionário ortográfico permitindo ao usuário incluir palavras com números;

- Foram adicionados ao menu principal, dois novos ícones de inicialização rápida para plug-ins, disponibilizando um total de cinco;

- Interface melhorada com menus distribuídos harmonicamente;

- Múltiplas visões: livro, código e visualização (edição WYSIWYG);

- Gerador de índice com suporte de cabeçalho multinível;

- Editor de metadados com suporte total para todas as entradas de metadados;

- Verificação ortográfica baseada no corretor e analisador morfológico Hunspell com dicionários padrão e configuráveis pelo usuário;

- Suporte de expressão regular completa (PCRE) para localizar e substituir;

- Prevê a importação de arquivos EPUB e HTML, imagens e folhas de estilo;

- API integrada para HTML externo e editores gráficos;

A versão Sigil 0.9.9, assim como as anteriores oferecem suporte para ePUB 3: iframe, img, audio, video, mathml, svg (exceto para suporte a svg na coluna), armazenamento local em javascript e exibição de PDFs incorporados, além de reconhecer e permitir tags específicas para html5 como seção.

A vantagem do programa disponibilizado em código aberto no github permite e facilita que outros usuários cadastrados possam contribuir com melhorias e aperfeiçoamento do Sigil, construir uma comunidade de desenvolvedores para trabalho conjunto com outros desenvolvimentos - Wikipedia, por exemplo e ambientes de repositórios abertos.

Outra vantagem é o editor de metadados, que armazena informação sobre

\footnotetext{
${ }^{66} \mathrm{O}$ GitHub é uma plataforma de hospedagem de código fonte com sistema de controle de versão pelo Git, possibilitando que qualquer usuário cadastrado na plataforma colabore em projetos abertos ou privados. Fonte consultada: <https://sigil-ebook.com/>.
} 
outros dados do EPUB possibilitando a catalogação e recuperação dos mesmos registrados sob todas as formas.

6.2.3 Processos de desenvolvimento do livro digital no editor Sigil

Considera-se o arquivo final do livro impresso como arquivo base para o livro digital, por este arquivo estar formatado com todos os estilos de texto: família de Fontes, estilo de parágrafos, recuos, citações, entre outros. Além de imagens, tabelas e gráficos, quando for o caso.

A editora utiliza, para esta atividade específica (profissional de edição de livros digitais), o editor de plataforma aberta SIGIL, versão 0.8.7, que possibilita a importação de arquivos $\mathrm{TXT}^{67}, \mathrm{HTML}^{68}$, EPUB ${ }^{69}$ e exportação do formato SGF.

Por permitir a edição do formato EPUB, este software oferece acesso aos arquivos de texto (HTML), imagem e estilo (CSS), à configuração de índice e inserção de metadados.

A edição final do livro físico dá origem ao desenvolvimento do livro digital diagramado, revisado e salvo em formato arquivo do InDesign com extensão ".indd".

Após recebimento do arquivo em InDesign, são feitas formatações sempre preservando ao máximo o projeto gráfico original como: estilos do texto, organização de ficha de créditos, link do sumário e, para cada um desses estilos ao exportar para EPUB será gerada uma tag para edição do HTML e CSS no Sigil (Figura 03) ${ }^{70}$.

\footnotetext{
${ }^{67}$ TXT: Arquivo de texto com pouca formatação.

${ }^{68}$ HTML: Arquivo de páginas na web, documentos HTML (Hyper Text Markup Language) executados por navegadores.

69 EPUB: International Digital Publishing Forum. É livre e aberto para dispositivos de leitura, abreviação de Electronic Publication é uma compactação de vários arquivos (HTML, CSS, imagens, fontes entre outros).

${ }^{70}$ As figuras no Apêndice tem numeração sequencial conforme a descrição do texto sobre desenvolvimento do livro digital no Sigil.
} 
Figura 4 - Revisão de Fontes na diagramação do livro

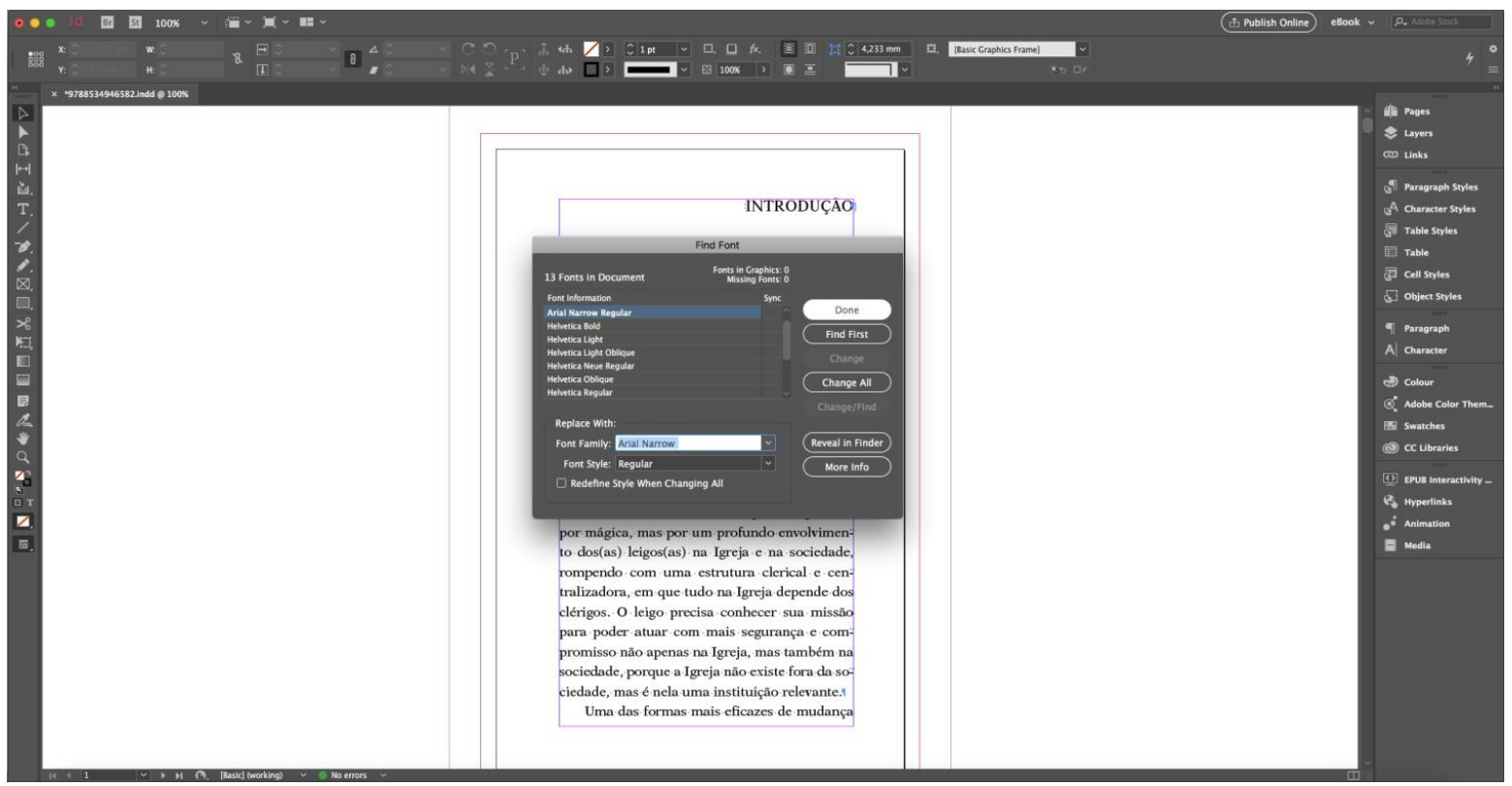

Fonte: A autora.

A seguir, é criado o estilo de parágrafo que será aplicado para todos os estilos iguais, no exemplo abaixo se pode identificar o estilo para o texto corrido do livro (APÊNDICE B, figura B-4). A configuração da tag que será exportada para o CSS do livro digital. No exemplo para o texto corrido foi utilizada a tag $\mathrm{P}$, empregada para parágrafos e outros textos simples (APÊNDICE B, figura B-5). A seguir, é criado um estilo para o título dos capítulos, da mesma forma que foi feito o estilo do texto corrido (APÊNDICE B, figura B-6).

Etapa de criação do estilo de caractere, utilizado nas variações do estilo de texto quando há trechos em itálico, negrito, sublinhado, sobrescrito, entre outros (APÊNDICE B, figura B-7).

Configurações utilizadas para os números das notas de rodapé: a configuração adotada numera as notas a partir do número 1 a cada seção (capítulo), os números são identificados entre colchetes [] e posicionados sobrescritos na marcação do texto e no parágrafo de nota (APÊNDICE B, Figura B-8).

Após formatação de todo o conteúdo, o arquivo é exportado em formato EPUB (APÊNDICE B, figura B-9), configurando-se as informações dos metadados de título, nome da editora e ISBN (APÊNDICE B, figura B-10). 
Figura 5 - Exportação do arquivo EPUB

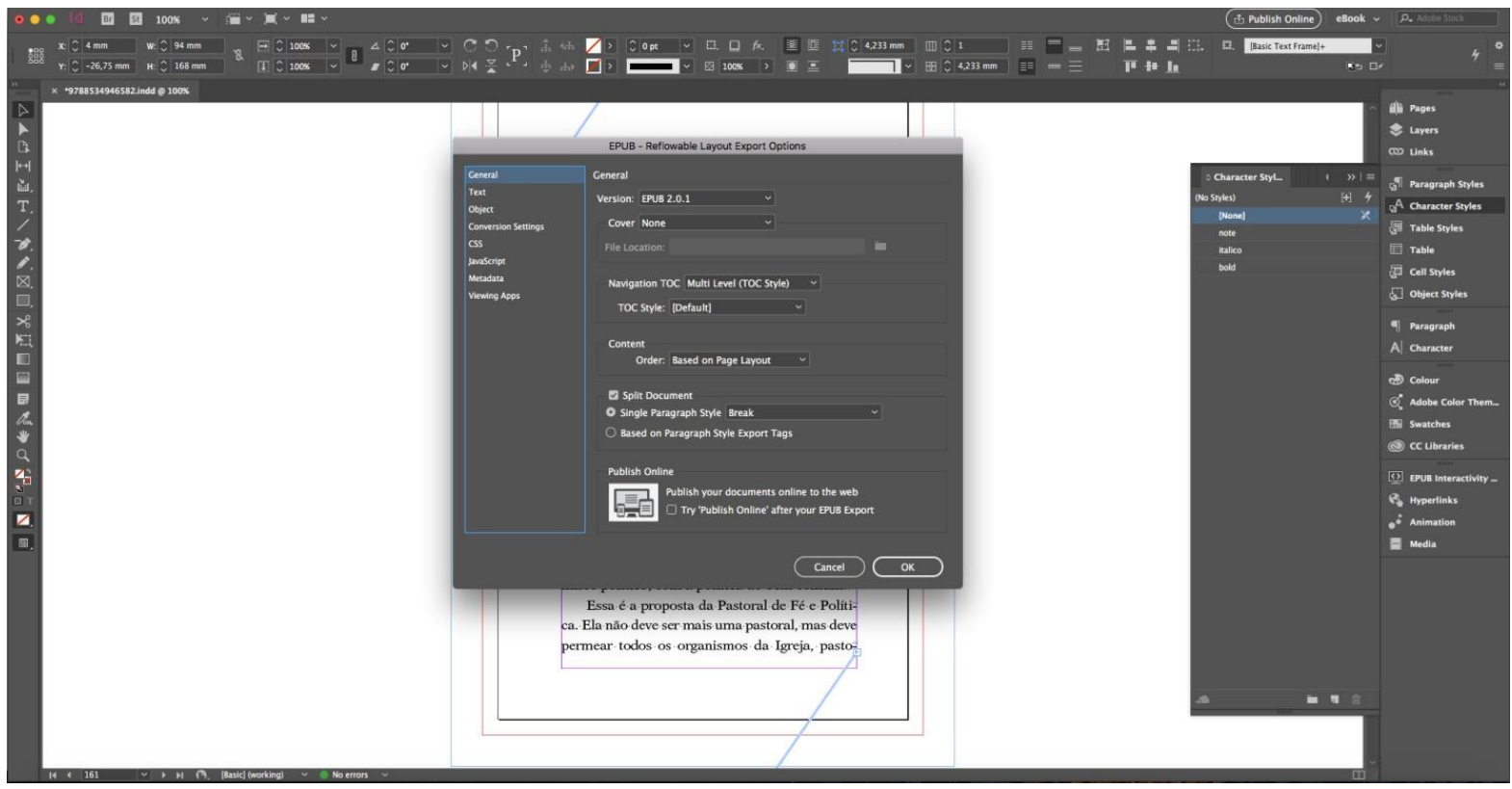

Fonte: A autora.

Os metadados descritos no aplicativo para o livro digital são os de título, autor, editora, palavras-chave escolhidas a partir do tema do livro e uma pequena sinopse da obra.

Figura 6 - Definição dos metadados

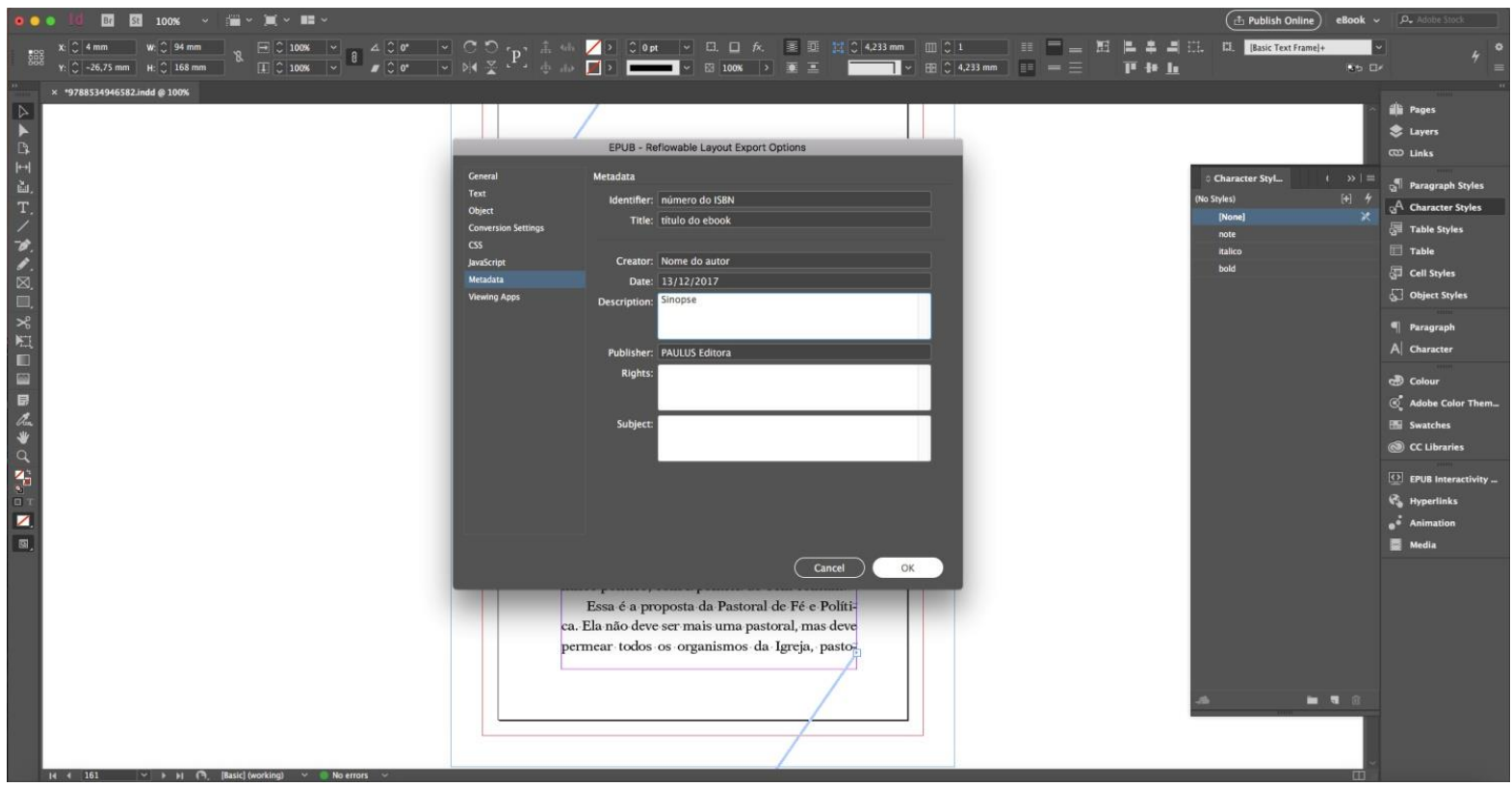

Fonte: A autora. 
É utilizada a versão 2.0 para configuração do arquivo EPUB pela compatibilidade com a maior parte dos leitores eletrônicos e aplicativos de leitura de livros digitais.

A imagem de capa é inserida manualmente e não é incluída na exportação, conforme descrição da utilização do Sigil. A navegação se dá pelo índice multinível ${ }^{71}$ interno, com conteúdo baseado no layout do arquivo formatado, com quebra de capítulo a cada ocorrência de estilo de parágrafo break, localizado sempre ao final de cada capítulo.

Inicialmente, é feita uma revisão para verificar se as páginas não apresentam erros de quebra, espaçamentos, funcionamento de fontes, exibição de imagens, etc. Caso apresente algum problema, as correções podem ser feitas diretamente na folha de estilo (APÊNDICE B, figura B-11)

Figura 7 - Folha de estilo

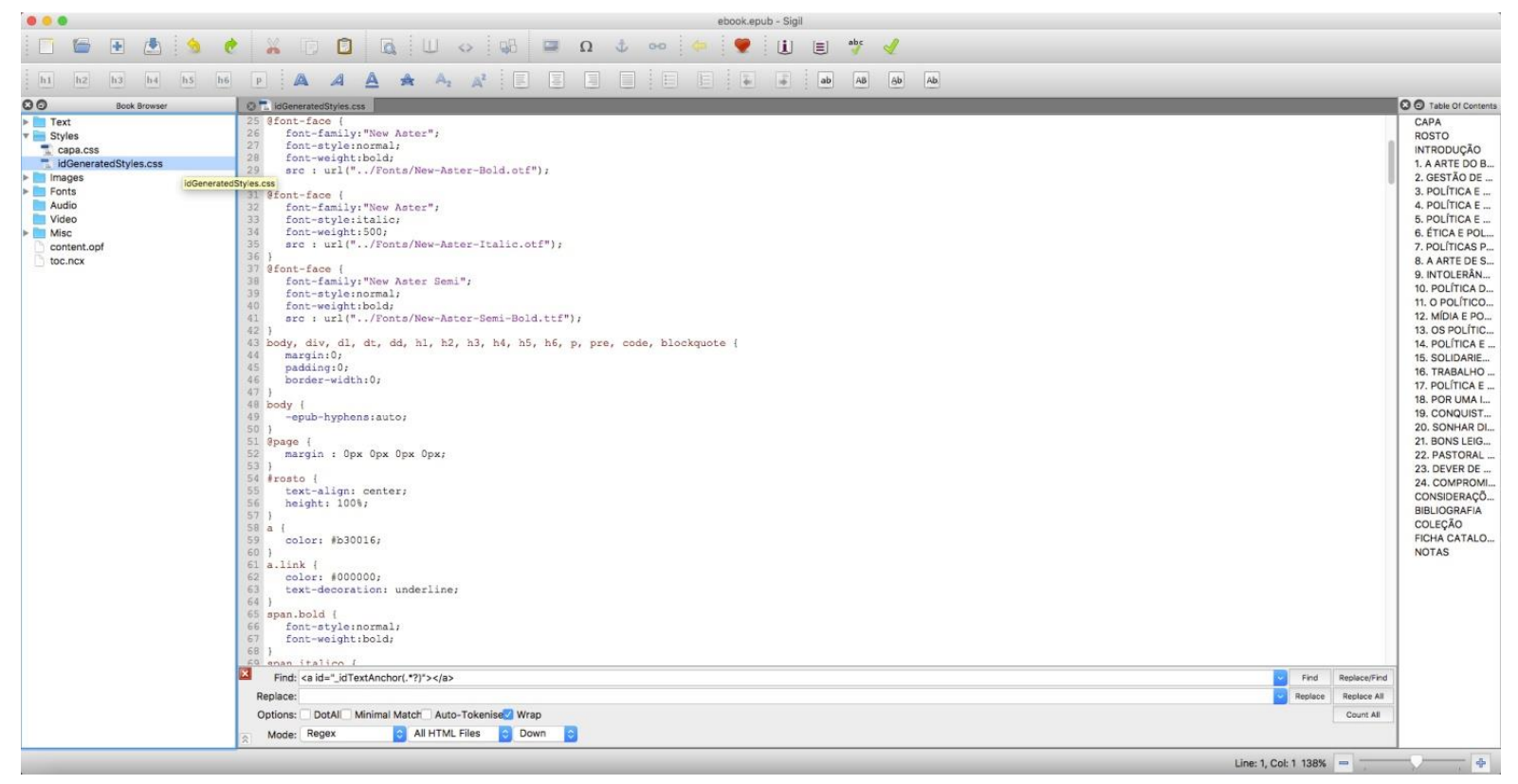

Fonte: A autora.

As imagens de capa e folha de rosto são incluídas manualmente, adicionando novos arquivos HTML e estilo CSS. A imagem de capa deve ser identificada com a

\footnotetext{
${ }^{71}$ Fonte: < http://www.inf.unioeste.br/ clodis/BDI/BDI_2007_Modulo5_1.pdf >.
} 
semântica "cover", essa configuração é fundamental para a visualização do thumbnail $^{72}$ (APÊNDICE B, figura B-11).

Figura 8 - HTML do livro digital com aplicação semântica na imagem de capa

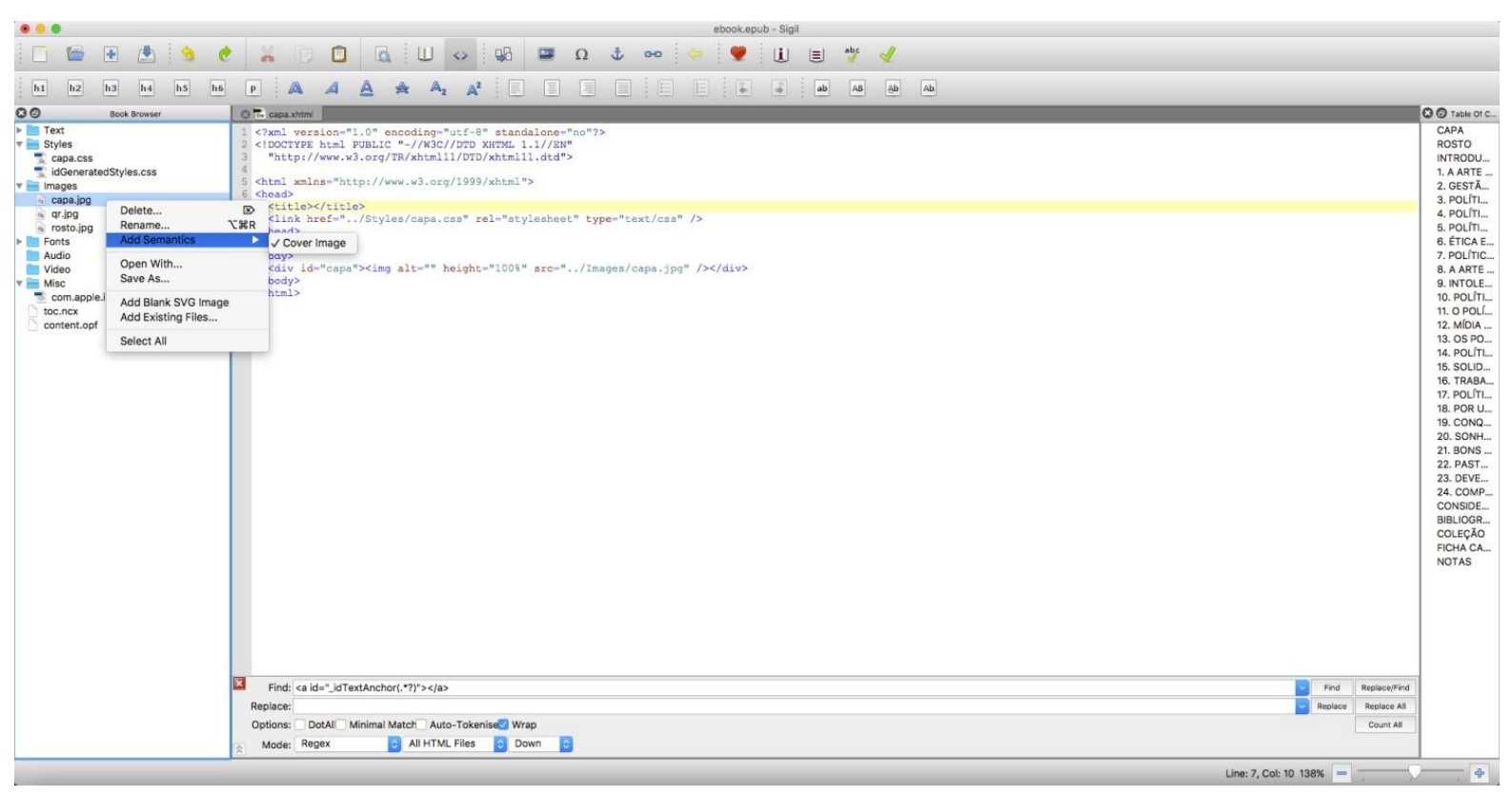

Fonte: A autora.

A semântica também deve ser utilizada nos arquivos HTML para identificar cada arquivo: capa, folha de rosto, ficha de créditos, prefácio, dedicatória entre outros (APÊNDICE B, figura B-12).

\footnotetext{
${ }^{72}$ Thumbnail é uma miniatura de uma imagem usada para despertar atenção e fazer uma prévia do conteúdo original.
} 
Figura 9 - Aplicação semântica no arquivo HTML da folha de rosto

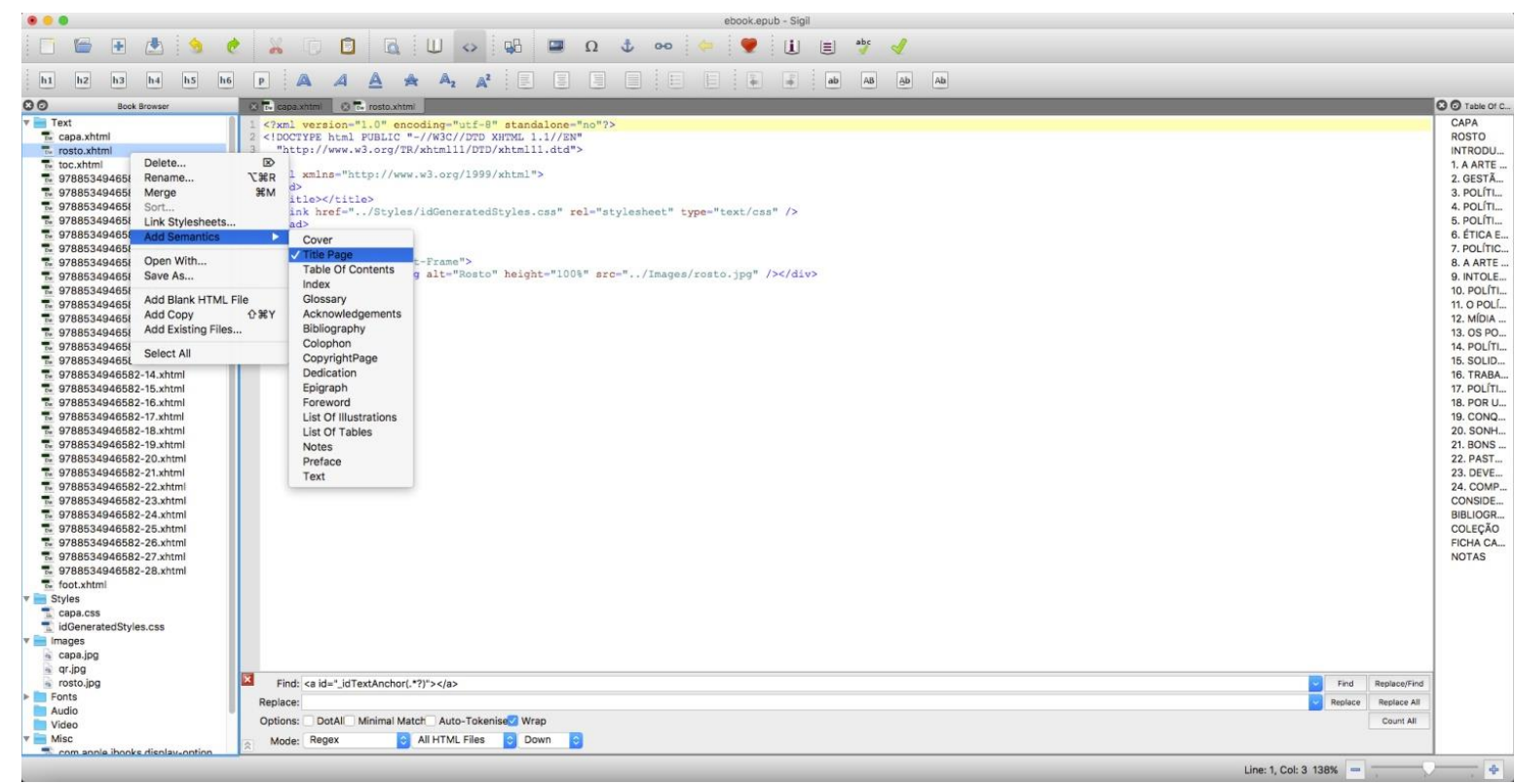

Fonte: A Autora.

O índice interno é gerado automaticamente na exportação do arquivo EPUB sendo possível editá-lo e alterá-lo no Sigil de forma que fique adequado para a navegação e o mais próximo possível do apresentado no livro físico (APÊNDICE B, figura B-14).

Figura 10 - Edição do índice no Sigil

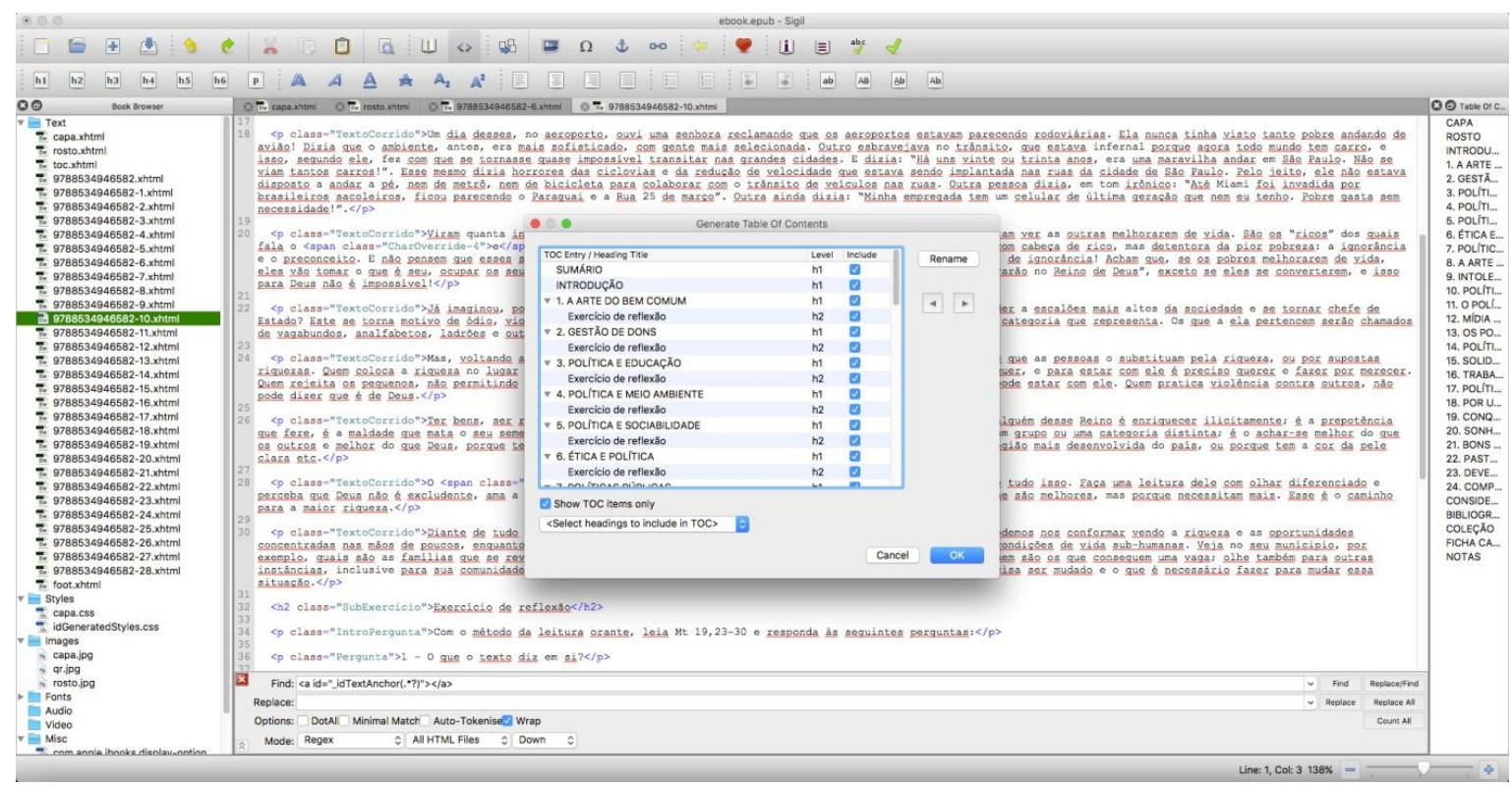

Fonte: A autora. 
É recomendável incluir um índice externo, em arquivo HTML, que será utilizado pelos leitores eletrônicos ou aplicativos que não suportam o recurso do índice interno (APÊNDICE B, figura B-15).

Para otimização da leitura, as notas de rodapé são reunidas em capítulo único posicionado após a ficha catalográfica (APÊNDICE B, figura B-16).

Os metadados são fundamentais para a identificação do livro digital podendo ser editados e/ou alterados (APÊNDICE B, figura B-17). O código exportado pelo InDesign possui algumas $\operatorname{tags}^{73}$ que não serão utilizadas, é importante fazer algumas correções para deixar o código limpo para um bom funcionamento do livro digital.

Figura 11 - Edição de metadados no Sigil

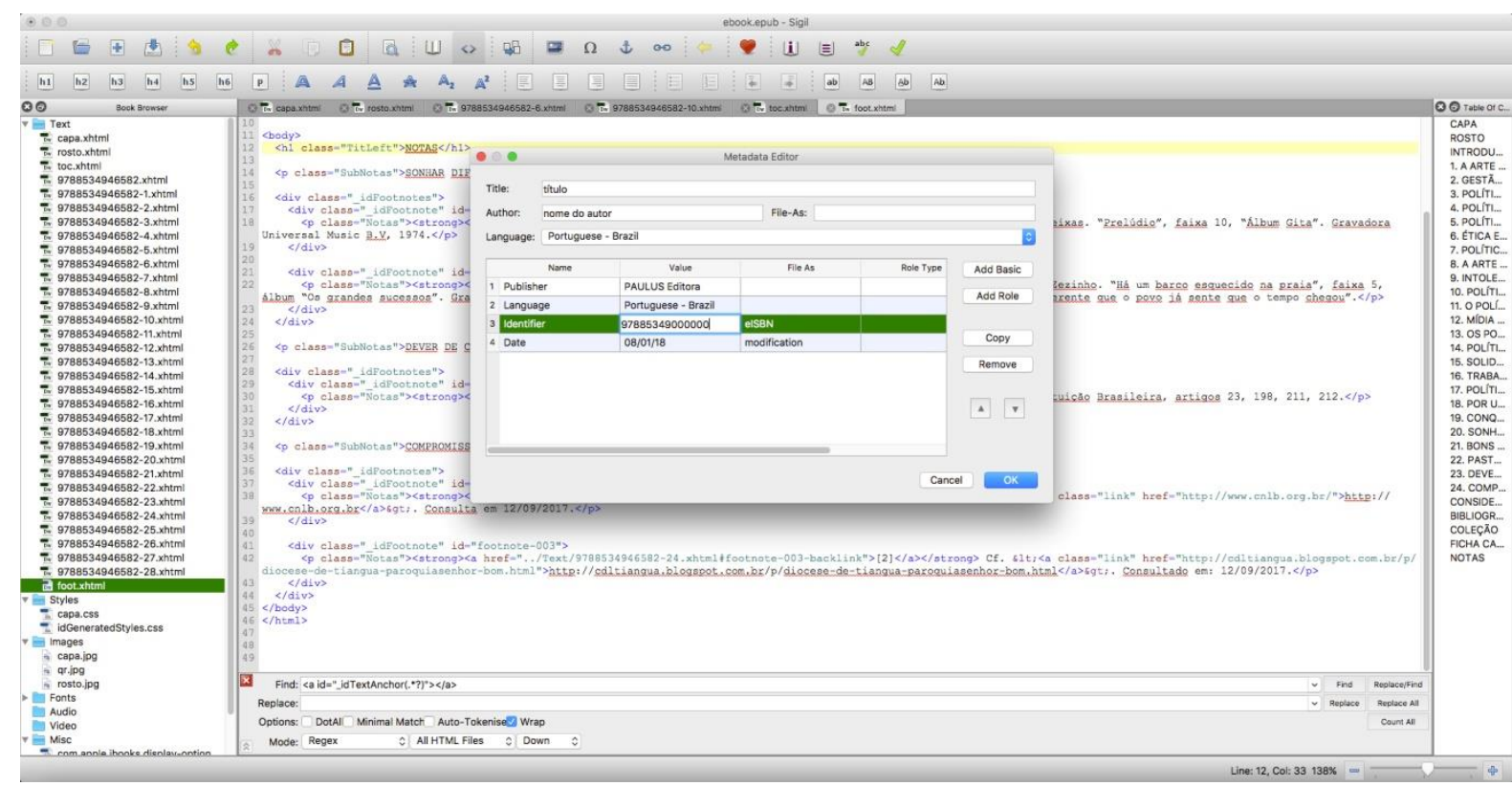

Fonte: A autora.

A última etapa de uso do Sigil consiste na verificação de possíveis erros utilizando recurso do software que identifica qualquer problema no código, podendo ser corrigido prontamente para que o livro digital fique pronto para a distribuição (APÊNDICE B, figura B-18).

A distribuição do livro digital é feita pelo sistema MACS da empresa de publicação digital Bookwire onde são importados o arquivo EPUB, imagem de capa

\footnotetext{
${ }^{73}$ Tag: metadado ou palavra-chave são termos usados para descrever, classificar e organizar arquivos, páginas, imagens.
} 
e todas as informações e metadados do livro digital a partir dos arquivos base. Finalizada esta etapa, a empresa distribui os arquivos para as lojas parceiras responsáveis pela comercialização do livro digital (APÊNDICE $B$, figura B-19).

A plataforma Bookwire promove a distribuição do produto digital para livrarias virtuais com conversão rápida de diversos formatos para livros digitais $\mathrm{MOBI}^{74}$, $\mathrm{FLAC}^{75}$ para áudio livros e KF8 ${ }^{76}$. A plataforma verifica a qualidade dos metadados e dos arquivos com proteção anticópia $\mathrm{DRM}^{77}$ para venda posterior dos produtos. A Paulus Editora não publica áudio livros até a data de finalização deste estudo em fevereiro de 2018.

\subsection{Percepções dos Estudos de Casos}

Os estudos de casos evidenciaram o trabalho dispendioso face às peculiaridades na produção de conteúdos digitais por parte da biblioteca publicadora e da editora comercial.

A biblioteca publicadora volta-se para sua missão de oferecer acesso e a editora universitária para o lucro necessitando de recursos para sua sobrevivência (COURANT; JONES, 2015, p.23). Diferente da editora comercial que atua em ambiente econômico convencional e materializa sua aplicação em serviços para obtenção de lucro.

Os livros digitais da editora comercial estudada são oferecidos na loja virtual e o acesso as primeiras 11(onze) páginas é dado a partir do "download degustação". A editora não promove o acesso aberto e não foi possível determinar os motivos somente que alguns autores não permitem que o livro impresso seja transformado em digital.

O foco do estudo de caso da editora Paulus foi vivenciar o que o editor faz em todas as fases de desenvolvimento do livro digital.

\footnotetext{
${ }^{74}$ Formato Mobi de arquivo de dados baseado no padrão Open eBook em formato XHTML, $<$ https://www.reviversoft.com/pt/file-extensions/mobi>.

${ }^{75}$ O FLAC é um formato de música que oferece uma qualidade de CD real e possibilita que seja tocado no sistema operacional da Apple iOS.

${ }^{76}$ O KF8 (também chamado de AZW3) é basicamente um EPUB que foi compilado usando um banco de dados Palm e o esquema DRM da Amazon. Fonte:<https://wiki.mobileread.com/wiki/KF8>.

77 Digital Rights Management (DRM): empregado nos livros digitais com o intuito de controlar sua utilização por meio de cópias, é a etapa final para permitir ou restringir o acesso ao conteúdo digital assegurando e administrando os direitos autorais.
} 
A missão da biblioteca universitária é fornecer aos usuários acesso confiável à informação por longos períodos de tempo, enquanto a editora universitária está associada ao exterior por disponibilizar o trabalho acadêmico para além dos muros da Universidade (COURANT; JONES, 2015, p.21).

Neste contexto a biblioteca publicadora outorga um novo modelo de apoio à biblioteca universitária ou de pesquisa por aumentar a disseminação de conteúdo acadêmico-científico aberto em rede extrapolando as divisas da universidade.

O estudo do MPS revela a inovação representada pela biblioteca publicadora no campo de trabalho do bibliotecário, delegando a ele desenvolvimento de competências para aprimoramento do serviço como: conhecimento em tecnologia de informação para viabilização de estratégias de negócios; conhecimento em sistemas de hardware/software; habilidade multitarefa para trabalhos com data limite restrita; instrução em editoração; gestão de equipe de formações diversas; cooperação no desenvolvimento de novos modelos de publicação por meio de sua experiência e descoberta do novo usuário interessado nos conteúdos digitais de produção acadêmico-científica para reflexão de outras inovações.

O aumento do impacto do programa MPS ocorreu pela extensa atividade de publicação existente possibilitando a vigência do baixo custo, por encontrar soluções diferentes através de esforço conjunto entre a instituição, a equipe de publicadores e estudantes aprendizes e por fornecer um espaço de experimentação em publicação acadêmica (COLMAN, 2017).

A atividade de publicação pode aumentar a influência dos profissionais da informação, imersos no ambiente intelectual, na busca por novas soluções para composição de diferentes conteúdos acadêmicos e sua dinamização pelas áreas disciplinares.

Wittenberg (2008, p.39) afirma a importância da descoberta de novos modelos acadêmicos de publicação, considerando as transformações do ambiente digital vigente; sem definir se serão os mediadores convencionais (editores acadêmicos, bibliotecas) responsáveis por outorgar qualidade ao conteúdo ou se os próprios estudiosos determinarão sistemas para avaliar e divulgar sua produção.

O estudo da biblioteca publicadora não trata de discussões sobre bibliotecários se apropriarem do trabalho de editores, mas da redefinição da força de 
trabalho do bibliotecário pelo desenvolvimento de recursos em ambiente web que permita pesquisar dados, percorrer os recursos em biblioteca digital pela mediação colaborativa virtual deste profissional ou pela comunicação direta com autores para organizar e fornecer conteúdo à medida da necessidade dos usuários, além de conhecer ambientes de metadados, busca, descoberta, preservação, acesso e transformar preceitos para qualidade e confiabilidade do conteúdo (WITTENBERG, 2008, p.40).

Bibliotecários de perfil transformador são necessários para a rotina diária e para a produção de novos serviços. As bibliotecas devem pensar sobre novas contratações, não considerando apenas o mérito do grau advindo por pósgraduação, mas deve-se considerar a abrangência de experiência e habilidades preciosas deste indivíduo para prosperidade dos trabalhos da biblioteca de pesquisa (COUNCIL ON LIBRARY AND INFORMATION RESOURCES, 2008, p.3).

O estudo de caso do MPS demonstra pleno crescimento das atividades de publicação com foco no desenvolvimento autosustentável. Estas conquistas têm como objetivo: aceitar todos os projetos mesmo que haja dificuldade em relação à capacidade; administrar recursos da universidade (fundos departamentais, de pesquisa e verbas da universidade) usando as habilidades existentes e relacionamentos com fornecedores para atendimento eficiente às necessidades do corpo docente. Projetos recusados deste público, faz com que eles busquem soluções mais caras ou optem por autopublicação (self-publishing) implicando em maiores gastos para a instituição (COLMAN, 2017).

As discussões apresentadas aqui demonstram a importância da Biblioteca Publicadora, também denominado neste trabalho como serviço de publicação e traz como consequência direta à instituição, visibilidade e fortalecimento pelo atendimento à sua comunidade. 


\section{PROJEÇÕES DA BIBLIOTECA PUBLICADORA}

Este capítulo espelha observações e questionamentos sobre o conjunto de serviços da biblioteca publicadora apresentados no estudo.

A publicação por bibliotecas tem acontecido de muitas formas ao longo do tempo, mais recentemente na última década, pela materialização e execução de uma variedade de serviços empreendidos por bibliotecários variando de relação, instrução de tecnologia, disseminação mais abrangente de informações, gerenciamento de digitalização etc. (KEENER, 2014).

O bibliotecário é agente integrante na disseminação de conteúdos por sua proximidade com leitores agora e desde sempre.

Esta aproximação se traduz em fator de sucesso e ponto positivo para firmar o desenvolvimento das atividades de publicação pela descoberta de hábitos específicos deste público, e descobertas de necessidades não exploradas, mas de alguma forma desejadas por esta coletividade.

Também é necessário ponderar sobre o espaço dos novos modelos de publicação considerando o ambiente fechado do pesquisador e o ambiente aberto da web. Por compartilhar informação em espaços colaborativos com colegas, o pesquisador precisa se certificar se o crédito acadêmico pelo trabalho partilhado lhe será atribuído e refletir sobre o acompanhamento do conteúdo por editores, procurando tornar este meio social produtivo para pesquisa acadêmica e sua disseminação (WITTENBERG, 2008, p.38).

Considerando o alto volume de conteúdo digital disposto na web, como a biblioteca publicadora fará a diferença pela composição e propagação de livros digitais?

A biblioteca publicadora não sobrevive sem recursos externos, o que traz algumas incertezas a respeito da base econômica sobre a qual este modelo será estabelecido.

Editores tradicionais desenvolveram metodologia própria de procedimentos de trabalho para edição de livros e, bibliotecários se defrontam com os desafios do mundo editorial na biblioteca publicadora. Como se estabelecem as relações entre editores e bibliotecários dispostos a participar desta atividade? 
Em outros países, a biblioteca publicadora pode contar com novos profissionais de publicação oferecidos por meio de consórcio de Escolas de Informação denominadas iSchools, dedicadas ao avanço do campo da informação e em evolução com programas anteriormente focados em áreas como tecnologia da informação, biblioteconomia, informática, ciência da informação partilhando interesse fundamental nas relações entre informação, pessoas e tecnologia.

A realidade brasileira se diferencia pela existência dos cursos de informação em nível muito mais acadêmico do que prático. Keener (2015) adverte que cursos de biblioteconomia e iSchools vão oferecer ao mercado profissionais de publicação que saibam "pensar" relacionando fatores positivos como:

1. Missões dos cursos em acordo com as necessidades de mudança dos editores $;{ }^{78}$

2. Os currículos das iSchools valorizam a experiência prática através de técnicas sobre seminários baseados na teoria; ${ }^{79}$

3. Os editores acadêmicos precisam de pensadores novos e avançados. Embora nem todos os futuros editores vão atuar nos serviços de publicação de bibliotecas, o envolvimento crítico e o questionamento das formas tradicionais de publicação serão valiosos para qualquer que pretenda trabalhar na indústria de publicação; ${ }^{80}$

4. O curso de graduação também é importante para a aprendizagem da teoria, além da prática, bem como para o desenvolvimento da comunicação acadêmica. O tempo gasto no ensino superior é útil para trabalhar ao lado de pesquisadores. Acadêmicos e editores funcionam melhor quando cada um tem uma boa compreensão de como é o fluxo de trabalho do outro. ${ }^{81}$ (tradução nossa)

\footnotetext{
${ }^{78}$ There are many reasons why iSchools and MLIS programs are prime places for aspiring publishing professionals. First, their missions are in keeping with the changing needs of publishers. The iSchool organization declares that iSchools address the "fundamental issue of harnessing the incredible flow of information for the betterment of humanity...The iField also empowers people in other fields to create, find, store, manipulate, and share information in useful forms... The iField's most visible and viable outcome is the delivery of the right information at the right time to the right people in the right form." [3] Sounds like publishing!

${ }^{79}$ Second, iSchool and library school curricula generally value practical experience through practicums over theory-based seminars.

80 Third, because they are in a state of experimentation, academic publishers need fresh, forward thinkers. How will the curricula of library science and iSchools help shape future publishing professionals? The Library Publishing Coalition (an organization that champions the library publishing movement) describes library publishing as "based on core library values and building on the traditional skills of librarians, it is distinguished from other publishing fields by a preference for Open Access dissemination and a willingness to embrace informal and experimental forms of scholarly communication and to challenge the status quo." $[4]$ While not all future publishing hopefuls will go into library publishing, that critical engagement with and questioning of traditional forms of publishing will be valuable for any and all who aim to enter the industry.

${ }^{81}$ Finally, coursework in graduate school is also important for learning theory in addition to practice, as
} 
Cursos de inovação em publicação serão bem recebidos pelos envolvidos na área, com domínio técnico necessário à prática diária da biblioteca publicadora em aplicações / plataformas para gestão de conteúdo digital, linguagens de marcação, linguagens de script, metadados para descrição dos livros digitais, preservação digital para estes trabalhos concebidos digitalmente.

Considera-se que apenas o desenvolvimento técnico do bibliotecário não é suficiente para alcançar um bom resultado na prática de publicação, mas a proximidade do bibliotecário com pesquisadores facilita o entendimento do mundo acadêmico aproximando-o dos trabalhos da biblioteca publicadora.

Num primeiro momento, estas questões parecem causar preocupação e estranhamento pela aproximação das atividades de publicação e editores de formação no universo de bibliotecários, contudo este novo panorama de trabalho se traduz em novas perspectivas neste conjunto de diferentes propostas de publicação acadêmico-científica e seu decorrente enriquecimento.

well as for the development of long-term views on scholarship and scholarly communication. Time spent in higher education is useful for working alongside scholars, in order to better understand the research process side of the equation. Scholars and publishers work best when each has a good understanding of what the others' workflow is like. 


\section{CONSIDERAÇÕES FINAIS}

As dificuldades para publicar livros impressos e o caráter cooperativo do modelo de publicação digital incentivam bibliotecas universitárias ou de pesquisa a se movimentarem em torno da publicação e distribuição de livros digitais em acesso aberto a partir da biblioteca publicadora.

A publicação de livros digitais criados por docentes, técnicos ou pósgraduandos no ambiente acadêmico e oferecidos em acesso aberto, estabelece nova rota para divulgação da comunicação científica independente da intermediação de grandes publicadores comumente voltados ao desenvolvimento de soluções, modelos de negócios de alta rentabilidade e autores consagrados nas mais diferentes disciplinas do conhecimento.

A prática em torno do serviço da Biblioteca publicadora evidencia a demanda da comunidade acadêmica em busca de orientação e ajuda na composição de conteúdo acadêmico produzido a partir de pesquisas financiadas por instituições de fomento e por verbas institucionais.

Órgãos da universidade, editora universitária e biblioteca publicadora podem atuar em conjunto para aumentar a acessibilidade, benefício e estabilidade do conteúdo acadêmico pelas oportunidades significativas criadas pelo ambiente digital, como o desaparecimento de parte de custos associados à produção, armazenamento e distribuição do livro acadêmico em papel / impresso produzido com subsídio da universidade (COURANT; JONES, 2015, p.33).

Esta prática é essencial para a formação de profissionais de publicação. Neste sentido, os currículos dos cursos de biblioteconomia poderiam oferecer cursos práticos de publicação de livros digitais.

Para garantir a qualidade na seleção de conteúdos, os requisitos podem ser discutidos e descritos pela comunidade acadêmica e, então, repassados à biblioteca publicadora que, por sua vez, se encarrega da composição e disseminação na rede mundial considerando suas estreitas conexões com autores e leitores.

Os esforços voltados para este tipo de operação e criação da biblioteca publicadora ainda são incipientes nas universidades brasileiras.

Apesar do envolvimento de bibliotecas na produção de revistas científicas e parcerias com docentes editores, ainda não se considera a inserção da atividade de 
publicação de livros digitais como um serviço parceiro ou não da editora universitária na instituição, mesmo com toda a extensão de oportunidades e benefícios para todas as áreas disciplinares que a biblioteca publicadora pode significar.

O serviço de biblioteca publicadora deve ser constituído de forma centralizada na universidade, como unidade autônoma, configurada para agregar e atender as necessidades de publicação da comunidade universitária em sua totalidade, portanto, não deve ser constituída por cada biblioteca existente nos diferentes campi.

Por não existir consenso quanto ao conceito de Biblioteca Publicadora em português, considera-se neste trabalho como: modelo difundido pela biblioteca universitária ou de pesquisa para designar o conjunto de operações criado em colaboração pelo serviço de bibliotecas; editora da universidade; docentes; pela participação dos cursos de graduação de biblioteconomia e editoração com finalidade de atuação legítima referente às práticas de publicação de conteúdos acadêmicos e científicos relevantes para a comunidade universitária e publicados em meio digital, preferencialmente em acesso aberto.

O estudo em torno da biblioteca publicadora não se esgota, este serviço está em estado de efervescência aguardando por execução, desenvolvimento e evolução.

A argumentação do tema fica em aberto, à espera de novas complementações e trabalhos futuros.

A discussão a respeito da Biblioteca Publicadora destaca alguns pontos para desenvolvimento em pesquisas futuras como:

- aproximação e promoção de parceria entre docentes e bibliotecários da universidade;

- reavaliação da grade curricular do curso de biblioteconomia em proveito da promoção e integração de serviços voltados à publicação;

- aplicação do modelo MPS da Universidade de Michigan, por este ir além de um modelo de sucesso e por tratar-se de universidade que trabalha orientada para diminuição das diferenças, em busca de equidade e inclusão de melhorias na vida acadêmica e profissional 
para todos aqueles que participam de seu crescimento, desdobramento e progresso. 


\section{REFERÊNCIAS}

ANDERSON, R. The forbidden forecast: thinking about open access and library subscriptions. The Scholarly Kitchen. 2017. Disponível em:

$<$ https://scholarlykitchen.sspnet.org/2017/02/21/forbidden-forecast-thinking-openaccess-library-subscriptions/ $\geq$. Acesso em: 28 jan. 2018.

BONN, M.; FURLOUGH, M. Getting the Word Out: academic libraries as scholarly publishers. Chicago: The Association of College \& Research Libraries, 2015.

Disponível em:

<http://www.ala.org/acrl/sites/ala.org.acr//files/content/publications/booksanddigitalre sources/digital/9780838986981_getting_OA.pdf >. Acesso em: 07 maio 2017.

BUCKLAND, A. More than Consumers: students as content creators. In: BONN, M.; FURLOUGH, M. Getting the Word Out: academic libraries as scholarly publishers. Chicago: The Association of College and Research Libraries, 2015. p.33. Disponível em:

$<$ https://atrium.lib.uoguelph.ca/xmlui/bitstream/handle/10214/12087/Buckland_ACRL chapter.pdf?sequence=1\&isAllowed=y >. Acesso em: 13 jun. 2017.

. More than Consumers: students as content creators. In: BONN, M.;

FURLOUGH, M. Getting the Word Out: academic libraries as scholarly publishers. Chicago: The Association of College and Research Libraries, 2015. p.124. Disponível em: <

https://atrium.lib.uoguelph.ca/xmlui/bitstream/handle/10214/12087/Buckland_ACRLc hapter. pdf?sequence=1\&isAllowed=y >. Acesso em: 24 maio 2018.

CHARTIER, R. A aventura do livro: do leitor ao navegador: conversações com Jean Lebrun. São Paulo: Imprensa Oficial do Estado de São Paulo: Editora UNESP, 1998. Disponível em:

<https://intelectuaisculturaepoltica.files.wordpress.com/2016/02/roger-chartier-aaventura-do-livro-do-leitor-ao-navegador-editora-da-unesp-1988.pdf>. Acesso em: 14 jun. 2017.

. Escutar os mortos com os olhos. Estudos Avançados, São Paulo, v. 24, n. 69, p. 6-30, jan. 2010. Disponível em:

<http://www.revistas.usp.br/eav/article/view/10510/12252>. Acesso em: 20 jun. 2017. doi:10.1590/SO10340142010000200002.

COLMAN, J. Sustainable Book Publishing as a Service at the University of Michigan. The Journal of Electronic Publishing, v. 20, n. 2, 1 ago. 2017. Disponível em: <http://hdl.handle.net/2027/spo.3336451.0020.214>. Acesso em:

COSTA, S. M. S.; KURAMOTO, H.; Leite, Fernando César Lima. Acesso aberto no 
Brasil: aspetos históricos, ações institucionais e panorama atual. In: RODRIGUES, E.; SWAN, A.; BAPTISTA, A. A. (Org.). Uma década de acesso aberto na UMinho e no mundo. Braga: Universidade do Minho, Serviços de Documentação, 2013, p. 133-150. Disponível em:

<http://repositorium.sdum.uminho.pt/bitstream/1822/26144/3/RepositoriUM_10anos.p df>. Acesso em: 11 jan. 2018.

COUNCIL ON LIBRARY AND INFORMATION RESOURCES. Part I, A Continuing Discussion on Research Libraries in the 21st Century. In: No brief candle: reconceiving research libraries for the 21st century. Washington: CLIR, 2008. Disponível em: <http://www.clir.org/wp-content/uploads/sites/6/pub142.pdf.>. Acesso em: 24 set. 2017.

COURANT, P.; JONES, E. A. Scholarly Publishing as an Economic Public Good. In: BONN, M.; FURLOUGH, M. (Ed.). Getting the Word Out: academic libraries as scholarly publishers. Chicago: Association of College and research Libraries, 2015. Disponível em:

$<$ http://www.ala.org/acrl/sites/ala.org.acrl/files/content/publications/booksanddigitalre sources/digital/9780838986981_getting_OA.pdf >. Acesso em: 13 jun. 2017.

DARNTON, R. A Questão dos Livros: passado, presente e futuro. São Paulo: Companhia das Letras, 2010. p.10.

DEMARCO, T. Sigil, BlueGriffon, and the Evolving Software Market. IEEE Software, v. 31, n. 4, p. 97-99, 2014. Disponível em:

$<$ https://pdfs.semanticscholar.org/1e55/f29e3cbd331ee0d2a5c9bf9408e8507c5f4f.pd f>. Acesso em: 20 jan. 2018.

DUARTE, M. Page Lab blog. Disponível em: <www.pagelab.com.br/2012/epub3-aevolucao-das-publicacoes-digitais/>. Acesso em: 25 abr. 2018.

ELLIOTT, M. A. The Future of the Monograph in the Digital Era: a report to the Andrew W. Mellon Foundation. The Journal of Electronic Publishing , v.18, n. 4, fall 2015. doi:10.3998/3336451.0018.407. Acesso em: 05 Jun. 2017.

FEBVRE, L. \&; MARTIN, H. J. O aparecimento do livro. $2^{\text {a }}$.ed. São Paulo: Editora da Universidade de São Paulo, 2017. p. 157-189.

FERWERDA, E. New models for monographs. Serials: The Journal for the Serials Community. v. 23, n. 2, Jul. 2010. Disponível em: <serials.uksg.org/articles/10.1629/2391/galley/1354/download>. Acesso em: 20 fev. 2017. 
GEYER, J. Throw Back to the Future" AAUP Blog Tour: Special University Press Week Post. University of Michigan Press blog, 17 nov. 2016. Disponível em: $<$ http://blog.press.umich.edu/2016/11/throw-back-to-the-future-aaup-blog-tourspecial-university-press-week-post/>. Acesso em: 5 nov. 2017.

GILMAN, I. Adjunct no more: promoting scholarly publishing as a core service of academic libraries. Against the Grain, v. 26, n. 6, 2015. Disponível em:

$<$ https://commons.pacificu.edu/cgi/viewcontent.cgi referer $=\&$ httpsredir $=1 \&$ article $=10$ 26\&context=libfac>. Acesso em: 19 jun. 2017.

GUEDÓN, J.C. The "Green" and "Gold" Roads to Open Access: The Case for Mixing and Matching, Serials Review, 30:4, 2004. p.315-328. doi:

10.1080/00987913.2004.10764931.

HAHN, K. L. Research Library Publishing Services: new options for university publishing. Wachington D.C., Association of Research Libraries, mar. 2008. 41 p. Disponível em: <http://www.arl.org/storage/documents/publications/research-librarypublishing-services-mar08.pdf>. Acesso em: 22 mar. 2018.

HARNAD, S. The Open Access Stories: Stevan Harnad, OA pioneer. [S.I.], 19 out. 2015. Disponível em: <https://blog.scholasticahq.com/post/the-open-access-storiesstevan-harnad-oa-pioneer/>. Acesso em: 19 jun 2017.

Re: When is a Journal Open Access? 2006, Disponível em: $<$ http://users.ecs.soton.ac.uk/harnad/Hypermail/Amsci/5881.html>. Acesso em: 14 mar. 2018.

HAWKINS, K. S. The Evolution of Publishing Agreements at the University of Michigan Library. Journal of Librarianship and Scholarly Communication, v. 2, n. 4, 2014. . Disponível em: <http://jlsc-pub.org/articles/10.7710/2162-3309.1175>. Acesso em: 07 maio 2018.

INTERNATIONAL DIGITAL PUBLISHING FORUM. EPUB. Disponível em: <http://idpf.org/epub>. Acesso em: 23 abr. 2018.

. EPUB 3.1 Recommended Specification 5 January 2017. Disponível em: <http://www.idpf.org/epub/31/spec/epub-spec.html>. Acesso em: 25 abr. 2018.

KAHN, M. New author's agreement from Michigan Publishing. University of Michigan Press blog, [S.I.], 7. jun. 2013. Disponível em: <https://blog.press.umich.edu/2013/06/new-authors-agreement/>. Acesso em: 18 jan. 2018.

KEENER, A. Library (Publishing) School: training and competencies for the new publishing. Professional. Education and Training for 21st Century Publishers, v.17, n.12, Spring 2014. Disponível em: < https://quod.lib.umich.edu/j/jep/3336451.0017.206?view=text;rgn=main>. doi:10.3998/3336451.0017.206. Acesso em: 24 abr .2018. 
. Library (Publishing) School: training and competencies for the new

publishing. Professional. Education and Training for 21st Century Publishers, [S.I], v.17, n.12, Spring 2014. p.67. Disponível em: < https://quod.lib.umich.edu/j/jep/3336451.0017.206?view=text;rgn=main>. doi:10.3998/3336451.0017.206. Acesso em: 24 abr .2018.

LEE, T.B. Qual é o futuro da web, segundo Tim Berners-Lee. Computerworld, 09 jul. 2007. Disponível em:

$<$ http://computerworld.com.br/negocios/2007/07/09/idgnoticia.2007-07-

09.9970442373>. Acesso em: 08 jun. 2017.

LIBRARY PUBLISHING COALITION. What is Library Publishing? Disponível em: $<$ https://librarypublishing.org/>. Acesso em: 13 jan. 2018.

LIPPINCOTT, S. K. The Library Publishing Coalition: organizing libraries to enhance scholarly publishing. Insights, v.29, n.2, Jul 2016. doi:10.1629/uksg.296. Acesso em: 15 Mar. 2017.

LITMAN, J. Chapter eight: "Just Say Yes to Licensing!" In: Copyright digital. Ann Arbor, MI: Michigan Publishing, University of Michigan Library, 2017. doi: 10.3998/mpub.9798641. Acesso em: 20 maio 2018.

MCCORMICK, M. Toward New-Model Scholarly Publishing : uniting the skills of publishers and libraries. In: BONN, M; FURLOUGH, M. Getting the word out academic libraries as scholarly publishers. Chicago: The Association of College and Research Libraries, 2015. Disponível em:

$<$ http://www.ala.org/acrl/sites/ala.org.acrl/files/content/publications/booksanddigitalre sources/digital/9780838986981_getting_OA.pdf>. Acesso em: 23 nov. 2017.

OTLET, P. International organisation and dissemination of knowledge: Selected Essays of Paul Otlet. Translated and edited by Rayward, W. B. Ed. Amsterdam: Elsevier for the International Federation of Documentation, 1990. Disponível em: <www.ideals.illinois.edu/handle/2142/4004>. Acesso em: 06 Jun. 2017.

PIWOWAR H; PRIEM J; LARIVIÈRE V; ALPERIN JP; MATTHIAS L; NORLANDER B; FARLEY A; WEST J; HAUSTEIN S. The state of OA: a large-scale analysis of the prevalence and impact of Open Access articles., Peer J., Fev. 2018. Disponível em: <https://peerj.com/articles/4375/>. Acesso em: 02 maio 2018.

PORTAL DE PERIÓDICOS FIOCRUZ. Eloy Rodrigues: pioneiro no debate sobre acesso aberto. 2015. Disponível em: <http://periodicos.fiocruz.br/pt-br/content/eloyrodrigues-pioneiro-no-debate-sobre-acesso-aberto>. Acesso em: 05 jun. 2017.

POYNDER, R. Six Questions About Openness in Science. Open and Shut? Blog. Disponível em: <https://poynder.blogspot.com.br/>. Acesso em: 20 maio 2018.

RONCEVIC, M. Directory of E-book platforms for libraries. Library Technology 
Reports, ALA, v.49, n. 3, p.12, 2013. Disponível em:

$<$ https://journals.ala.org/index.php/Itr/article/viewFile/4308/4957. Acesso em: 13 abr. 2017>.

RUMSEY, S. Open access: reflections on change. OUPblog - Oxford University Press's - Academic Insights for the Thinking World, Oxford,06 dez. 2017. Disponível em: <https://blog.oup.com/2017/12/open-access-reflections-change/>. Acesso em: 22 abr. 2018.

SCHMOLLING, R. Agents of the publishing chain: From Libraries as Academic Publishers to Libraries as Publishers in e-Science and Digital Humanities. Cape Town: International Federation of Library Associations IFLAWLIC, 2015. Disponível em: <http://library.ifla.org/1164/1/187-schmolling-en.pdf >. Acesso em: 08 jun. 2017.

SERRA, L.G. Os livros eletrônicos e as bibliotecas. 2015. 175p. Dissertação (Mestrado em Ciência da Informação) - Escola de Comunicações e Artes, Universidade de São Paulo, São Paulo, 2005. Disponível em: < http://www.teses.usp.br/teses/disponiveis/27/27151/tde-01122015-101516/pt-br.php >. Acesso em: 28 jan. 2018.

SIGIL EBOOK. Disponível em: <https://sigil-ebook.com/>. Acesso em: 12 jan. 2018.

SKINNER et al. Library-as-Publisher: Capacity Building for the Library Publishing Subfield. The Journal of Electronic Publishing, Ann Arbor, MI: Michigan Publishing, University of Michigan Library, v.17, n.2, Spring 2014. doi:10.3998/3336451.0017.207. Disponível em: <http://quod.lib.umich.edu/j/jep/3336451.0017.207?view=text;rgn=main >. Acesso em: 28 jun. 2017.

TRACY, D. G. Libraries as content producers: how library publishing services address the reading. College \& Research Libraries, v. 78, n. 2, p. 219-40, 2017. doi: 10.5860/crl.78.2.16583. Acesso em: 24 jan. 2018.

WITTENBERG, K. The Role of the Library in 21st-Century Scholarly Publishing. In: No brief candle : reconceiving research libraries for the 21 st century. Washington, D.C.: Council on Library and Information Resources; no. 142. p. 39. Disponível em: <http://www.clir.org/wp-content/uploads/sites/6/pub142.pdf>. Acesso em: 05 maio 2018.

. The Role of the Library in 21st-Century Scholarly Publishing. In: No brief candle : reconceiving research libraries for the 21 st century. Washington, D.C.: Council on Library and Information Resources; no. 142. p. 40. Disponível em: $<$ http://www.clir.org/wp-content/uploads/sites/6/pub142.pdf>. Acesso em: 05 maio 2018 
APÊNDICES 


\section{APÊNDICE A - Questões para Levantamento de Informações do MPS}

\section{How Michigan Publishing is structured for free digital books?}

We publish open access books under both the University of Michigan Press (UMP) imprint and the Michigan Publishing Services (MPS) imprint, but in different ways. The Press only publishes a few OA books per year, while MPS publishes nearly everything openly.

2. Librarians, editors and professors participate of the process? What are their tasks in the process?

UMP books, open or not, are acquired by editors who are specialists in particular fields. They work with authors to develop proposals and bring them to faculty review, and have a particular focus on sales revenue expectations. For MPS, I am a librarian and also an editor, in a way - I work directly with faculty at the University to meet their publication needs. I do not conduct independent peer review, but do bring all books MPS publishes to an internal review committee.

\section{How is the curatorship?} are not.

If you mean peer review, UMP titles are peer reviewed while most MPS titles

4. Human curatorship is more important than technology?

Yes.

\section{How autopublication is considered by Michigan Library Publishing?}

Do you mean self-publishing? In a way, Michigan Publishing Services is an assisted self-publishing model, where we don't have much of an editorial process and we charge back costs to our faculty for doing work like copyediting and typesetting. We also preserve publications on Library infrastructure. We think this is a more sustainable way of doing self-publishing at the University.

\section{Used softwares? Are OA platforms?}

We have our own platform that we built, called DLXS. We are building a new platform, Fulcrum. These platforms support both OA and non-OA books.

\section{Can you describe the publishing process itself?}

Book production here follows more or less a traditional process, except that it 
is faster than many academic presses. We typically can produce a book in about 3-4 months rather than 12 .

Here is a basic outline of the process:

- Acquisition/Consultation: we meet with the author to develop a proposal, and to determine the budget and services needed;

- Copyediting: we make the manuscript conform to a style guide, usually the Chicago Manual of Style. The author approves all changes;

- Typesetting: if we are producing a print and/or PDF version of the book, we design and lay out a typeset interior. The author approves this, too;

- XML/EPUB conversion: we create an XML or EPUB version of the book for hosting in our digital platform;

- Print proofs: we print one copy of the book on demand to make sure it passes our quality checks;

- Publication: we release all formats of the book (electronic, print, and Kindle/iBook) for reading and for sale;

- Assessment: we monitor sales, web analytics, and impact metrics to see whether the book is reaching its audience.

\section{Does Michigan Library Publishing only works with academic contents?}

Yes, except that we did a University of Michigan coloring book recently.

\section{What are the licenses used for open digital books?}

Standard copyright, and all varieties of Creative Commons licenses. CC-BYNC-ND is the most common, followed by CC-BY.

\section{What are the skills of editors?}

In MPS, we have two librarians and four regular staff. Our skills vary, but all have good project management experience.

11. In general librarians don't have editor's skills, and is necessary a cooperative work. How is the work between both of them?

Well, as a librarian acquiring books I have had to learn more about the editor's skill set. I would say the typical way that other librarians interact with UMP editors is by connecting them with faculty in their disciplines who may have interesting projects.

12. We know that open access has costs. can you tell me about the MU funds directed to the publication of digital books?

MPS receives $\$ 178,000 /$ year from our Provost to support open access publishing for University faculty, students, and staff. Other OA publications, particularly at the Press, are subsidized by programs like Knowledge Unlatched. 
13. Library Sciences need to get closer of the expertise of publishing courses? Library Sciences is a graduation course in Brasil; different of yours.

Library Science graduates don't tend to understand publishing very well, although they do understand the economics of the library world - and libraries are scholarly publishers' biggest customers. I think having more training in publishing in library education would be valuable as the library publishing world grows.

14. Can you say bad and good aspects of human curatorship related to selection of titles or some subject matter?

Well, I'm not quite sure how to answer that question. I can say that high standards of peer review are appropriate for some works, especially when they are being counted for tenure and promotion of faculty. But in other cases light curatorship is more useful, and in others (like an institutional repository) it is best to allow faculty to deposit whatever they feel appropriate. 


\section{APÊNDICE B - Processos de Desenvolvimento do Livro Digital}

Figura B-1 - Revisão de Fontes na diagramação do livro

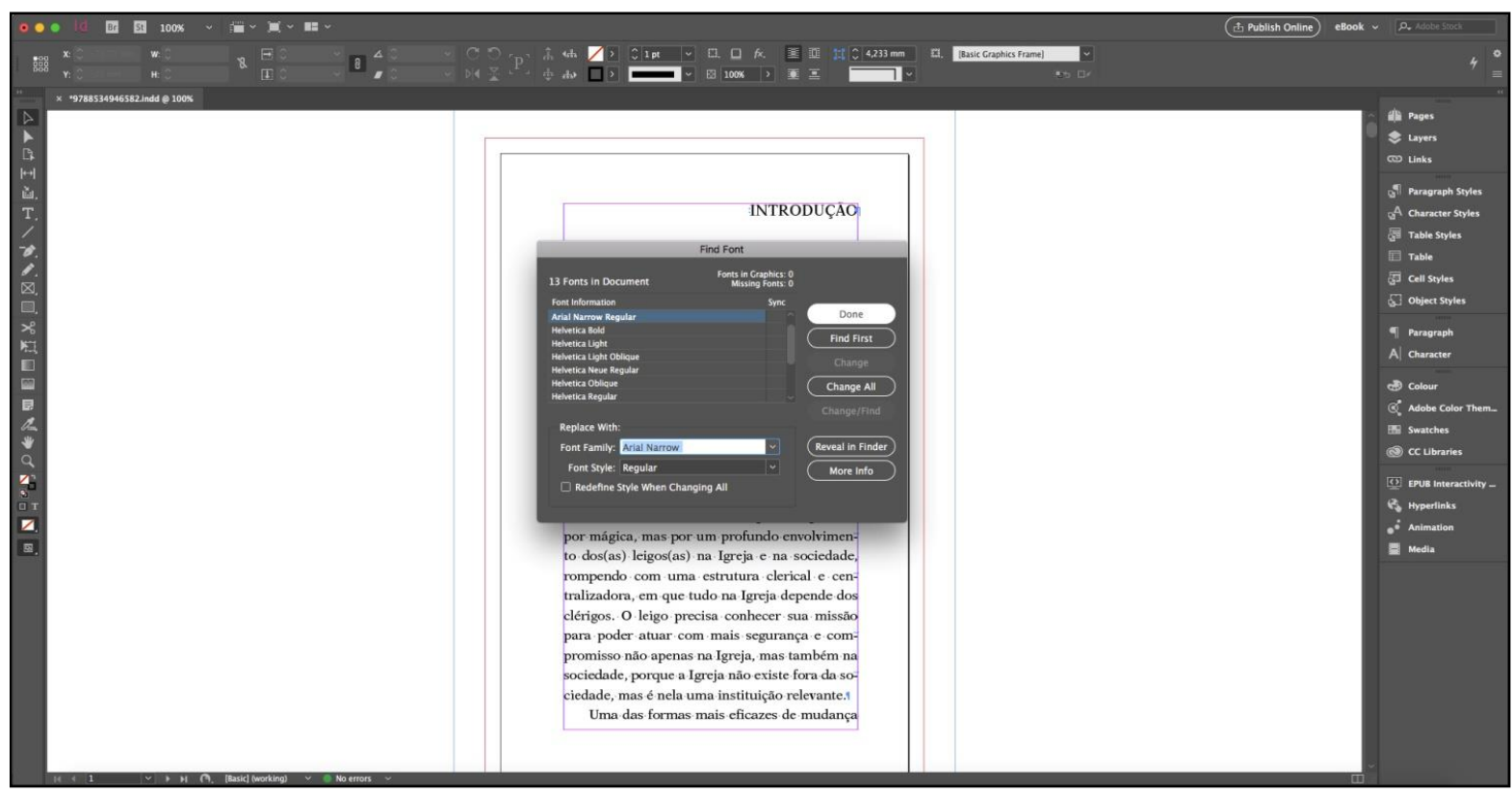

Figura B-2 - Criação de estilo de parágrafo

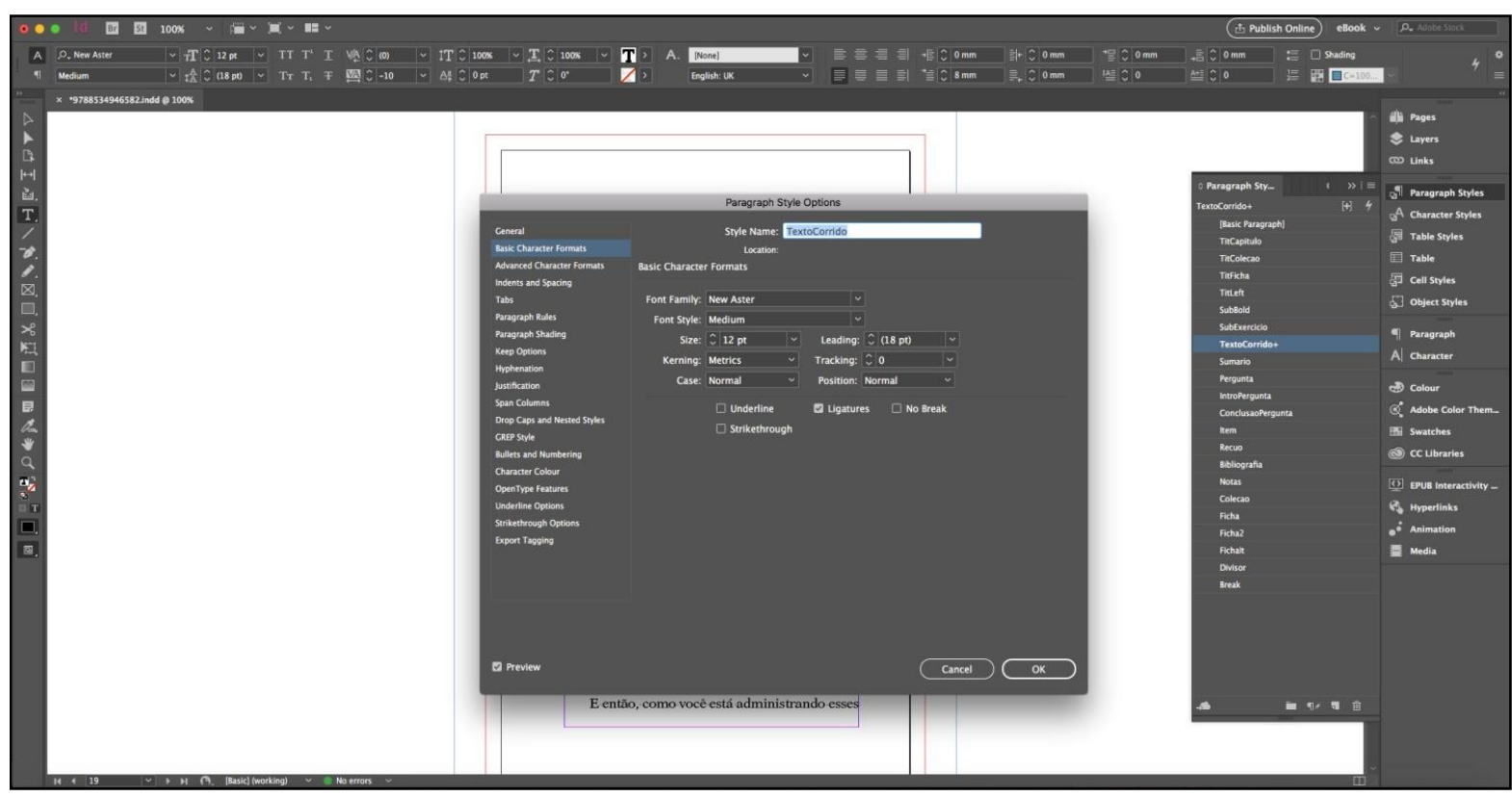


Figura B-3 - Configuração da tag de exportação

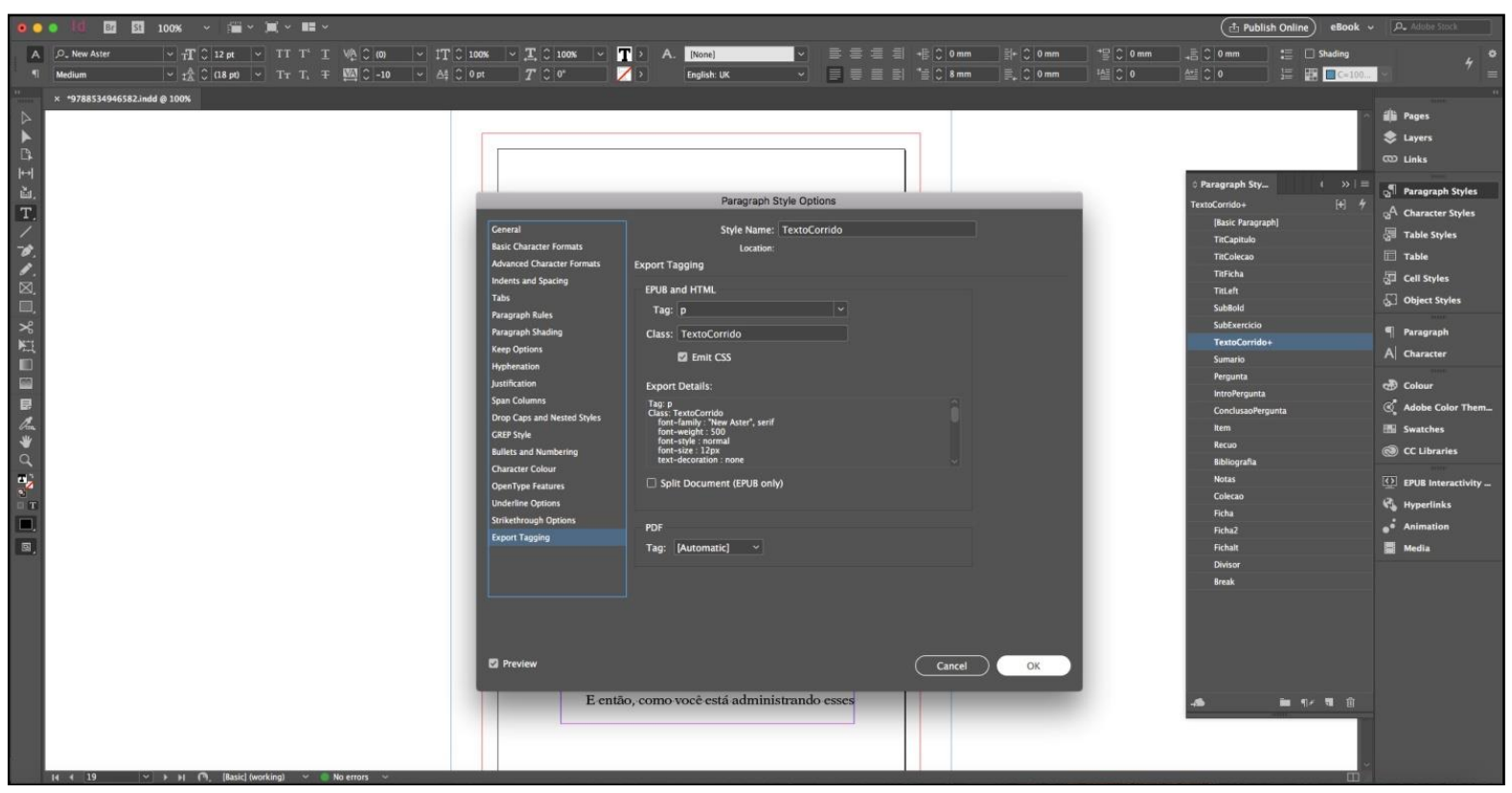

Figura B-4 - Estilo para títulos

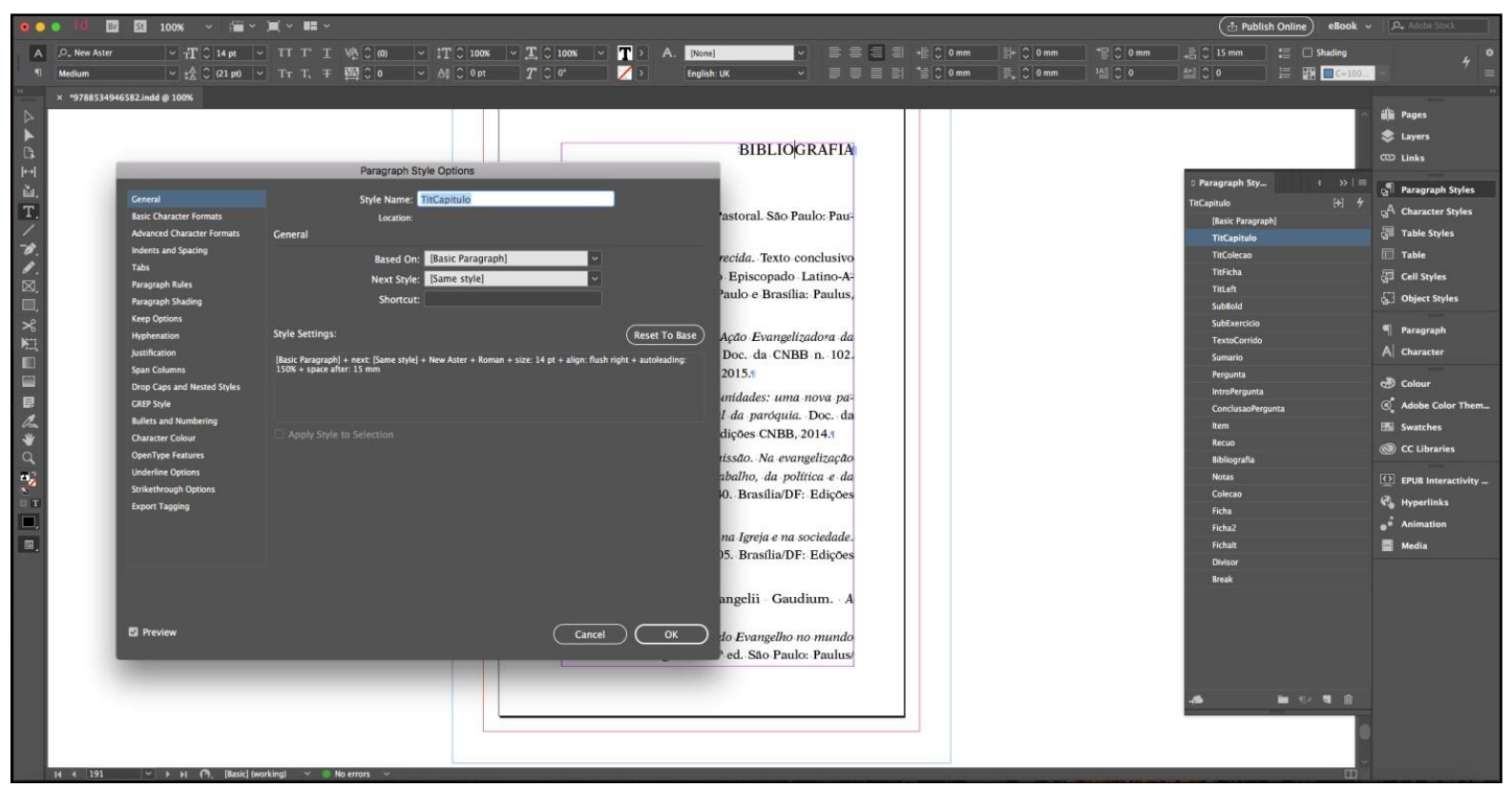


Figura B-5 - Estilo de caractere itálico

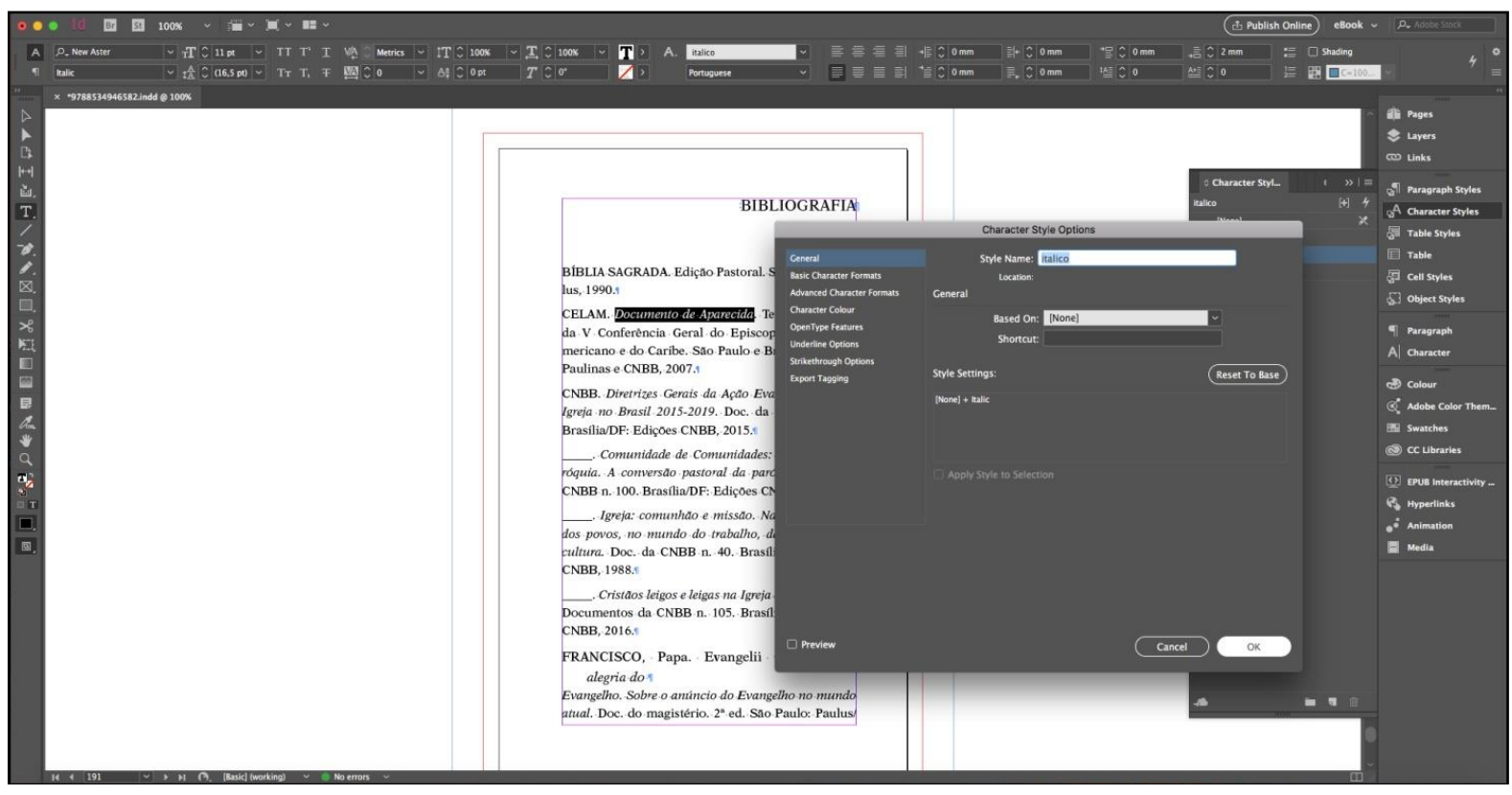

Figura B-6 - Configuração das notas de rodapé

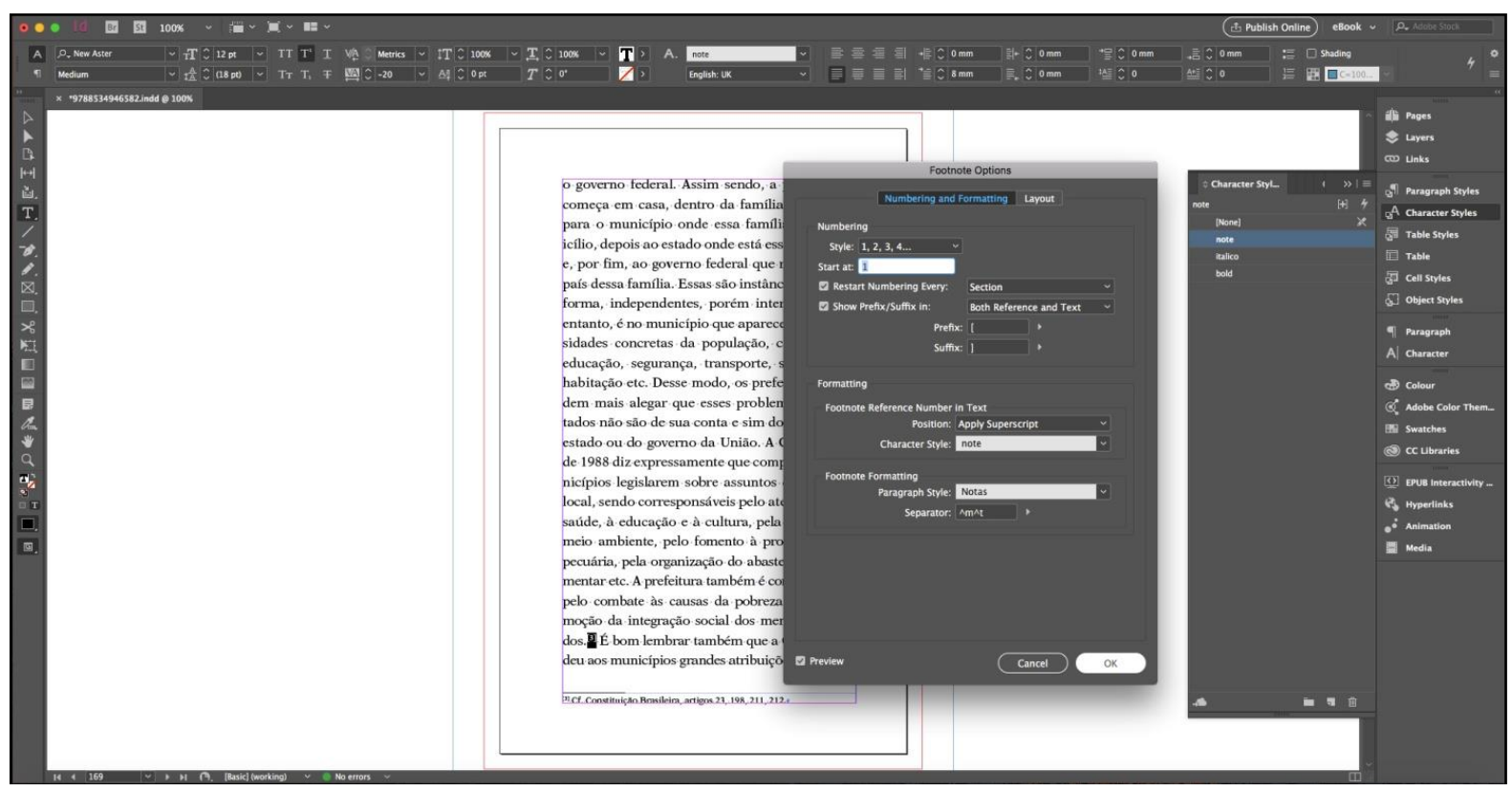


Figura B-7 - Exportação do arquivo EPUB

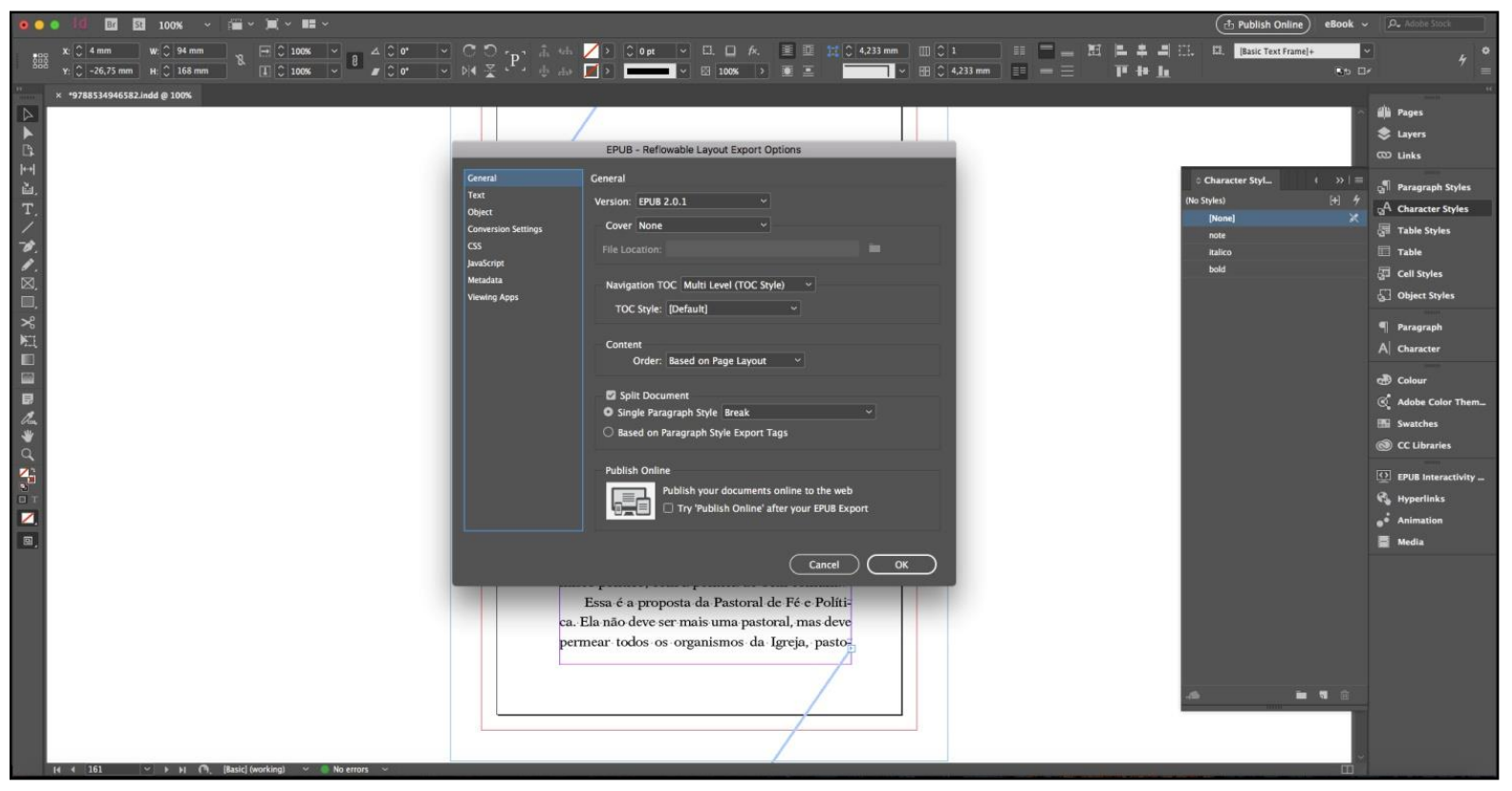

Figura B-8 - Definição dos metadados

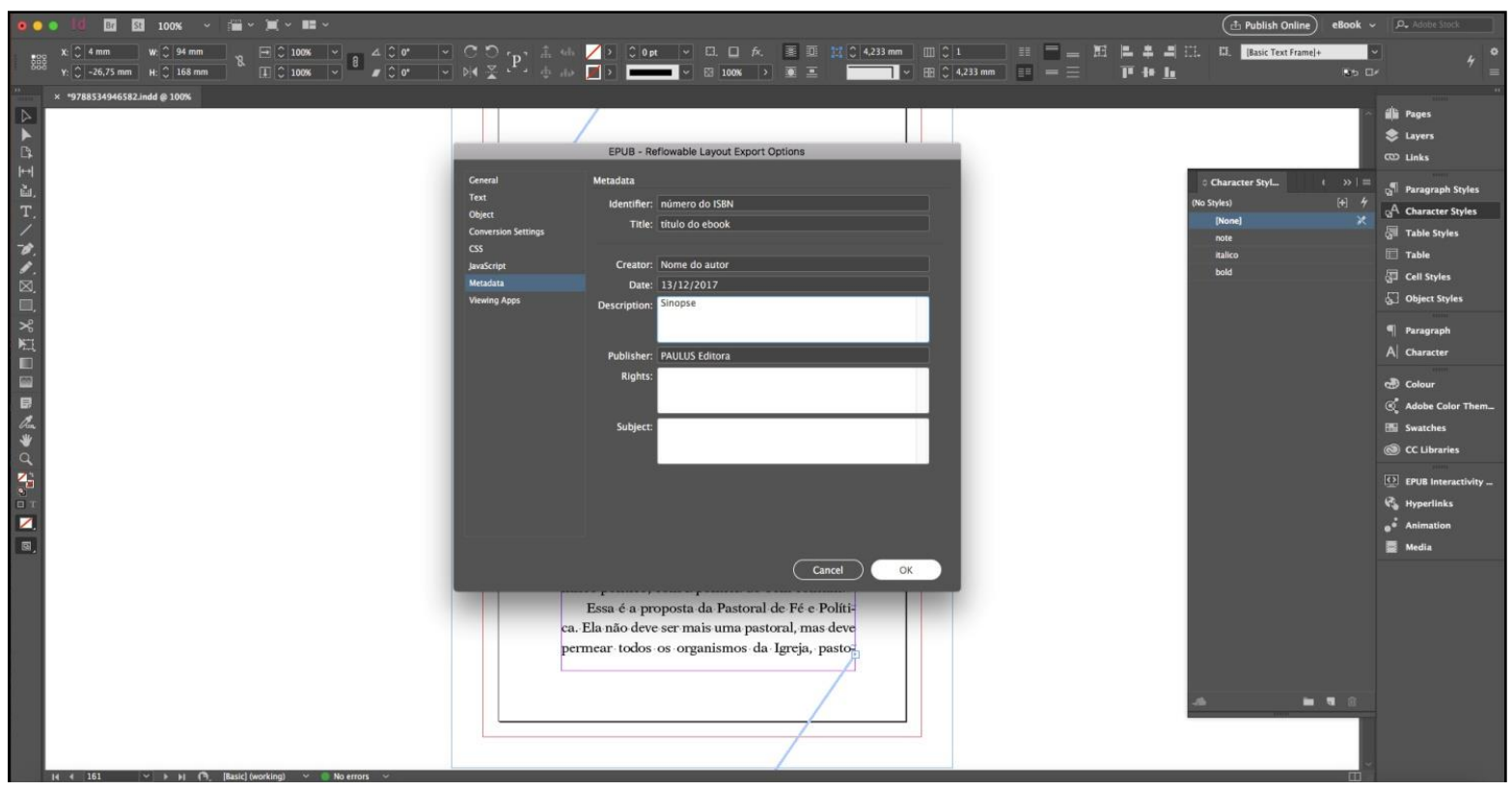


Figura B-9 - Folha de estilo

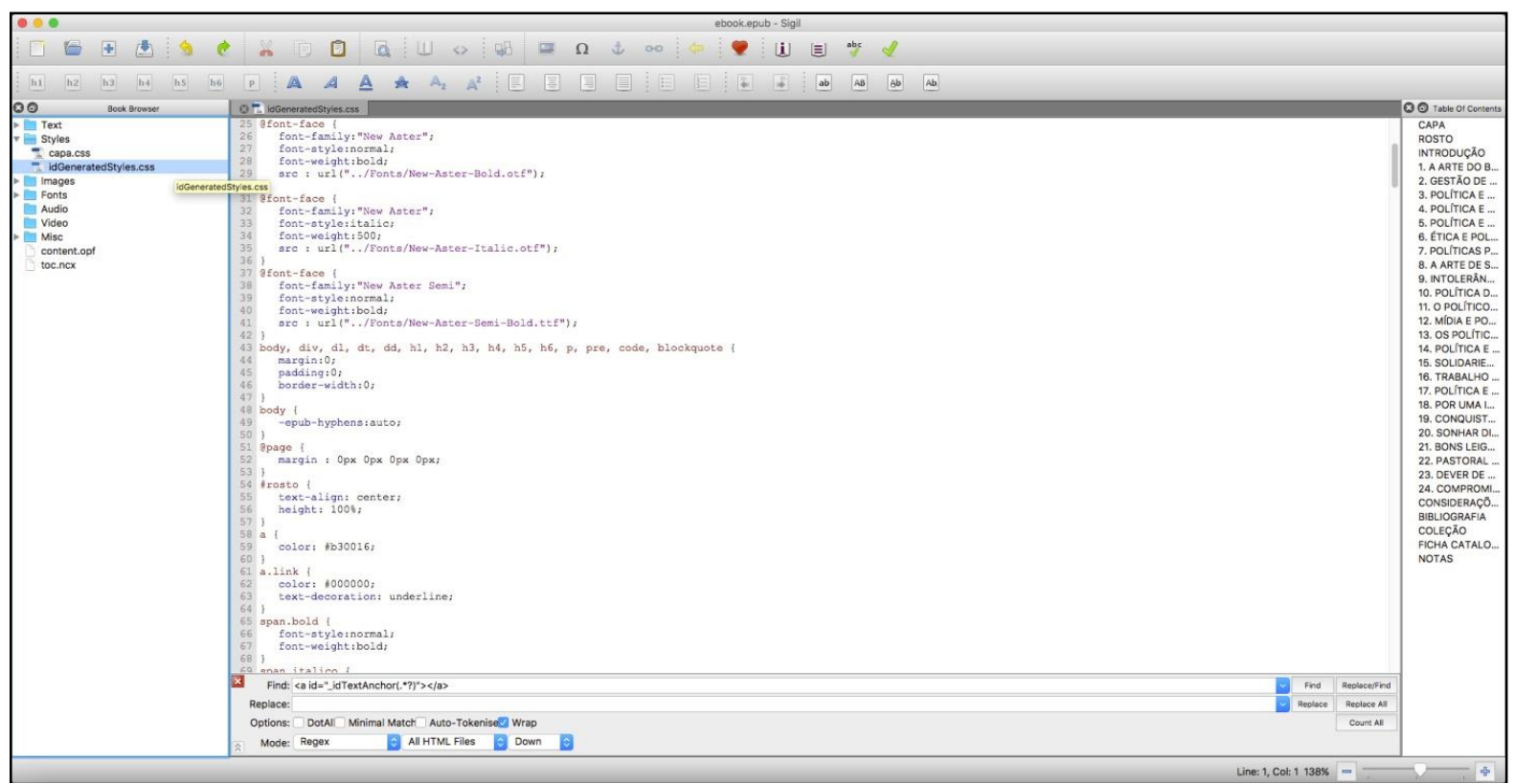

Figura B-10 - HTML da capa do livro digital com aplicação semântica na imagem de capa

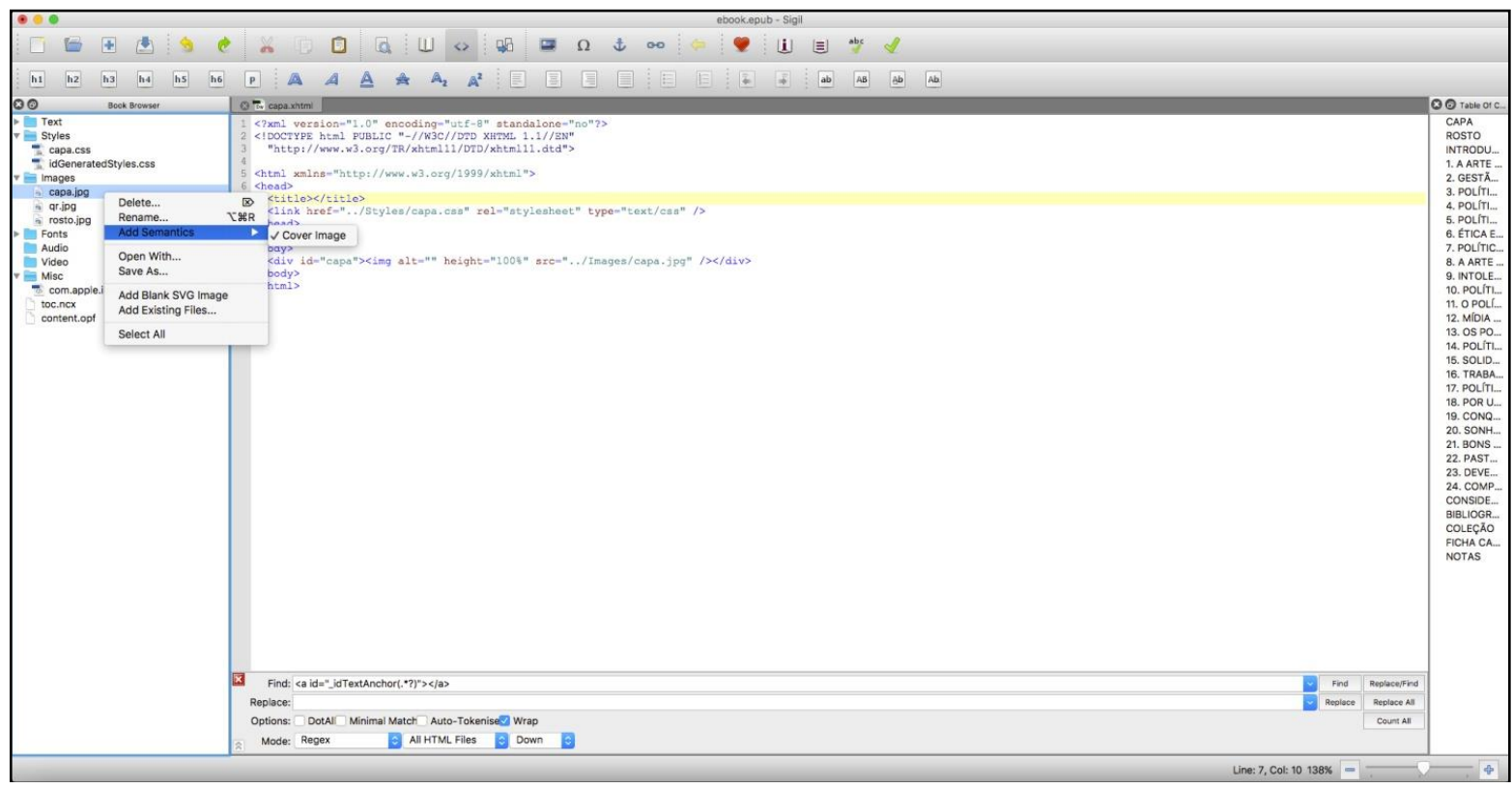


Figura B-11 - Aplicação semântica no arquivo HTML da folha de rosto

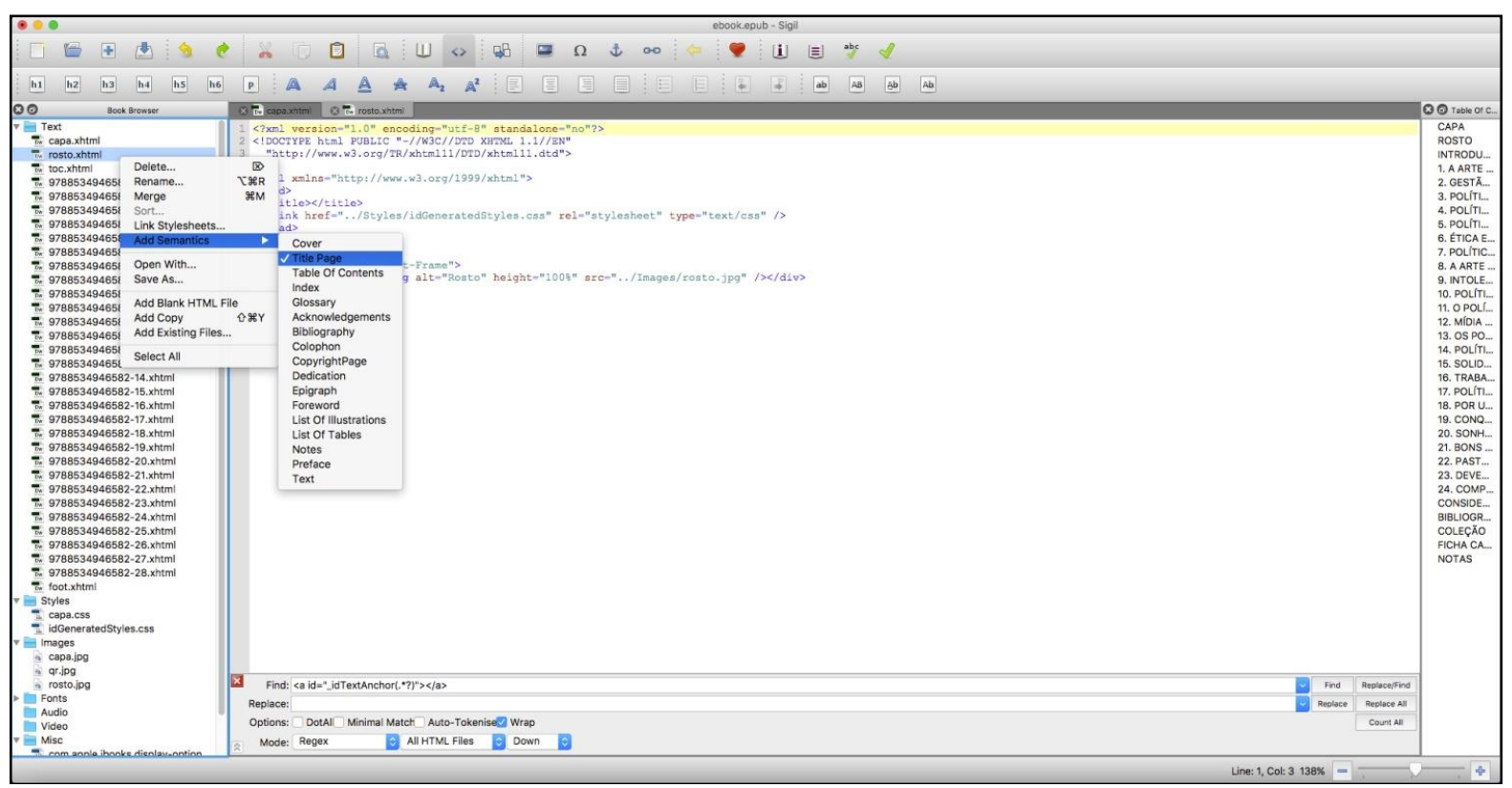

Figura B-12 - Edição do índice no Sigil

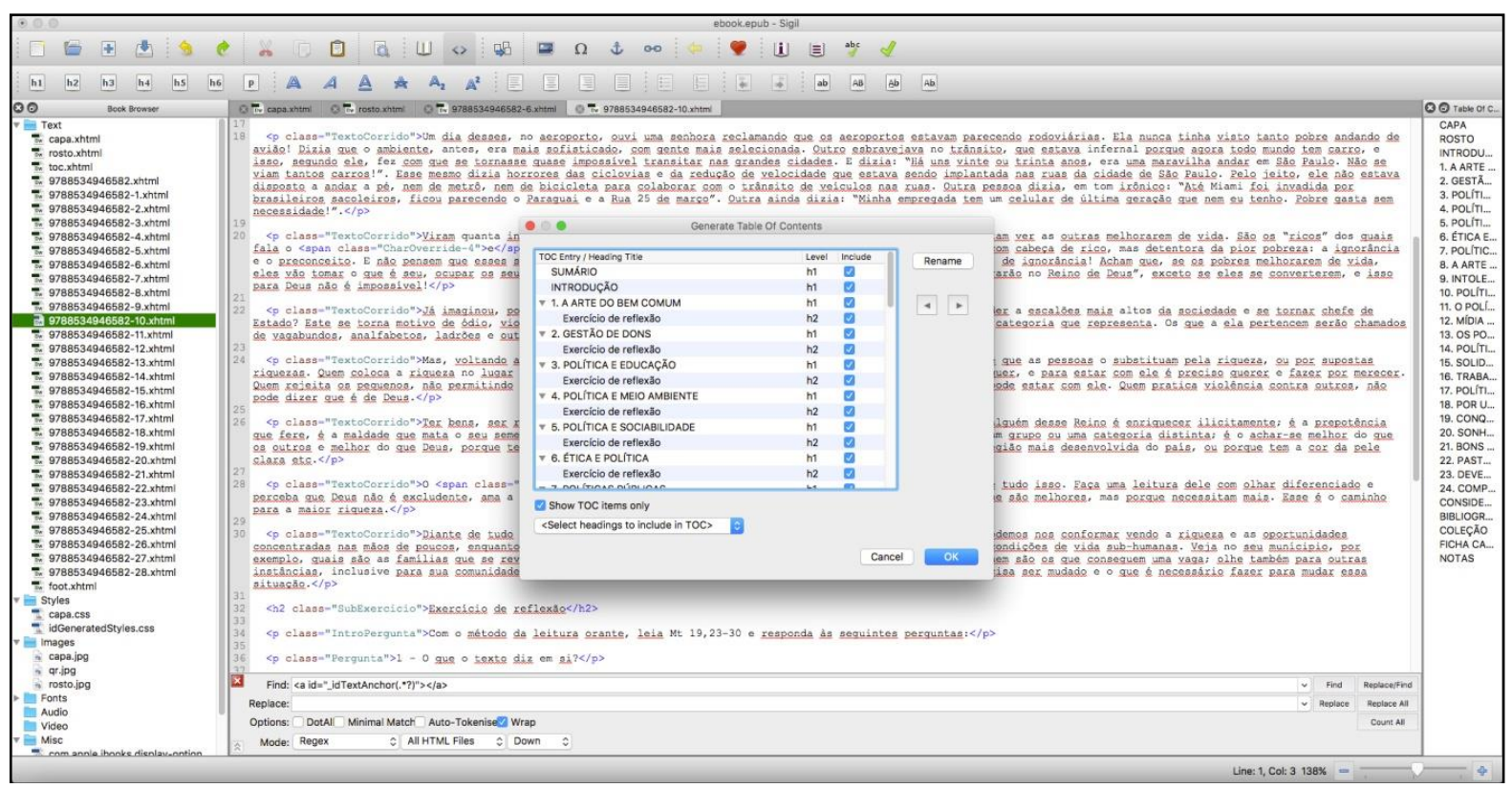


Figura B-13 - Índice HTML

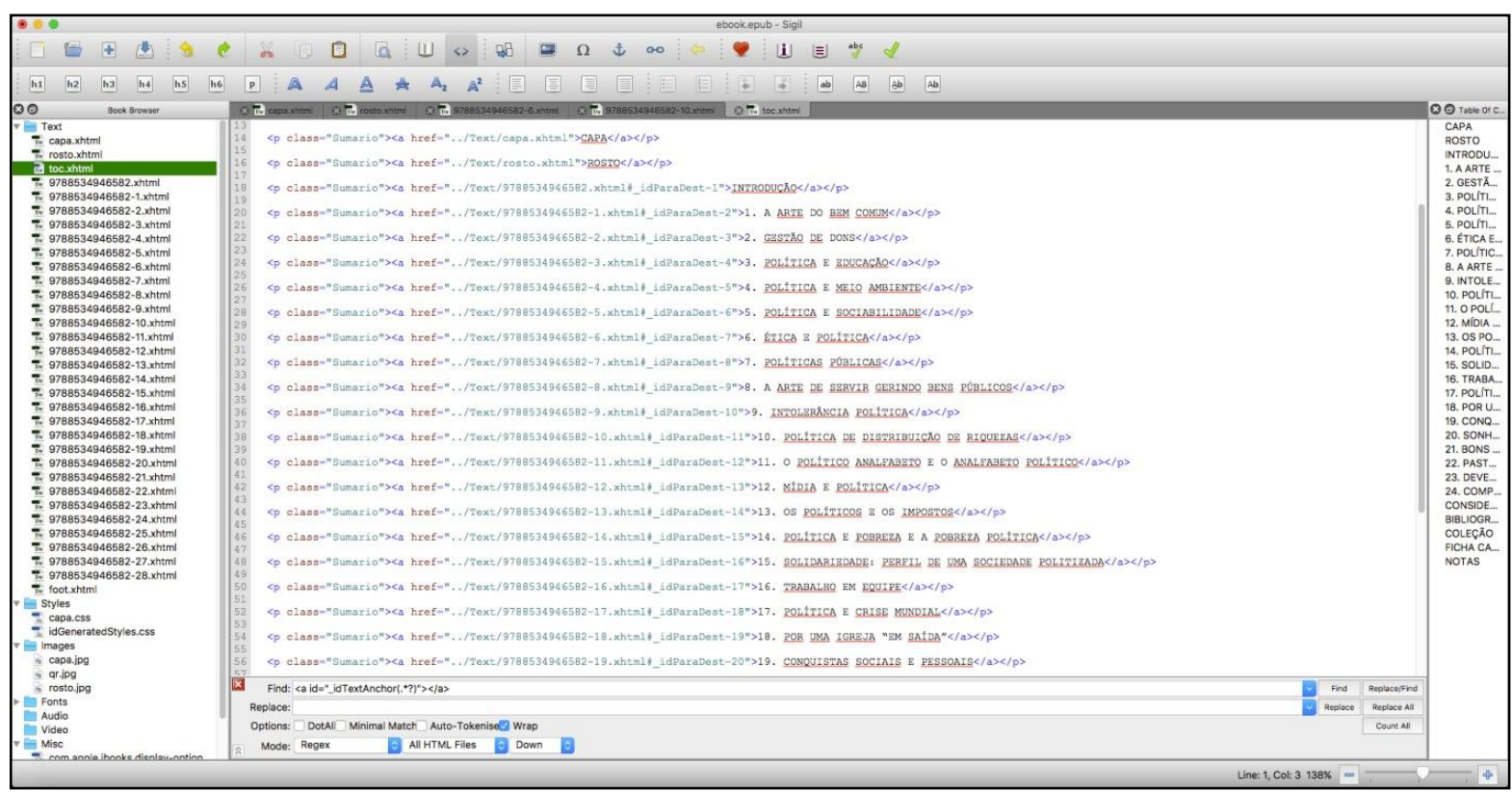

Figura B-14 - HTML do capítulo de notas

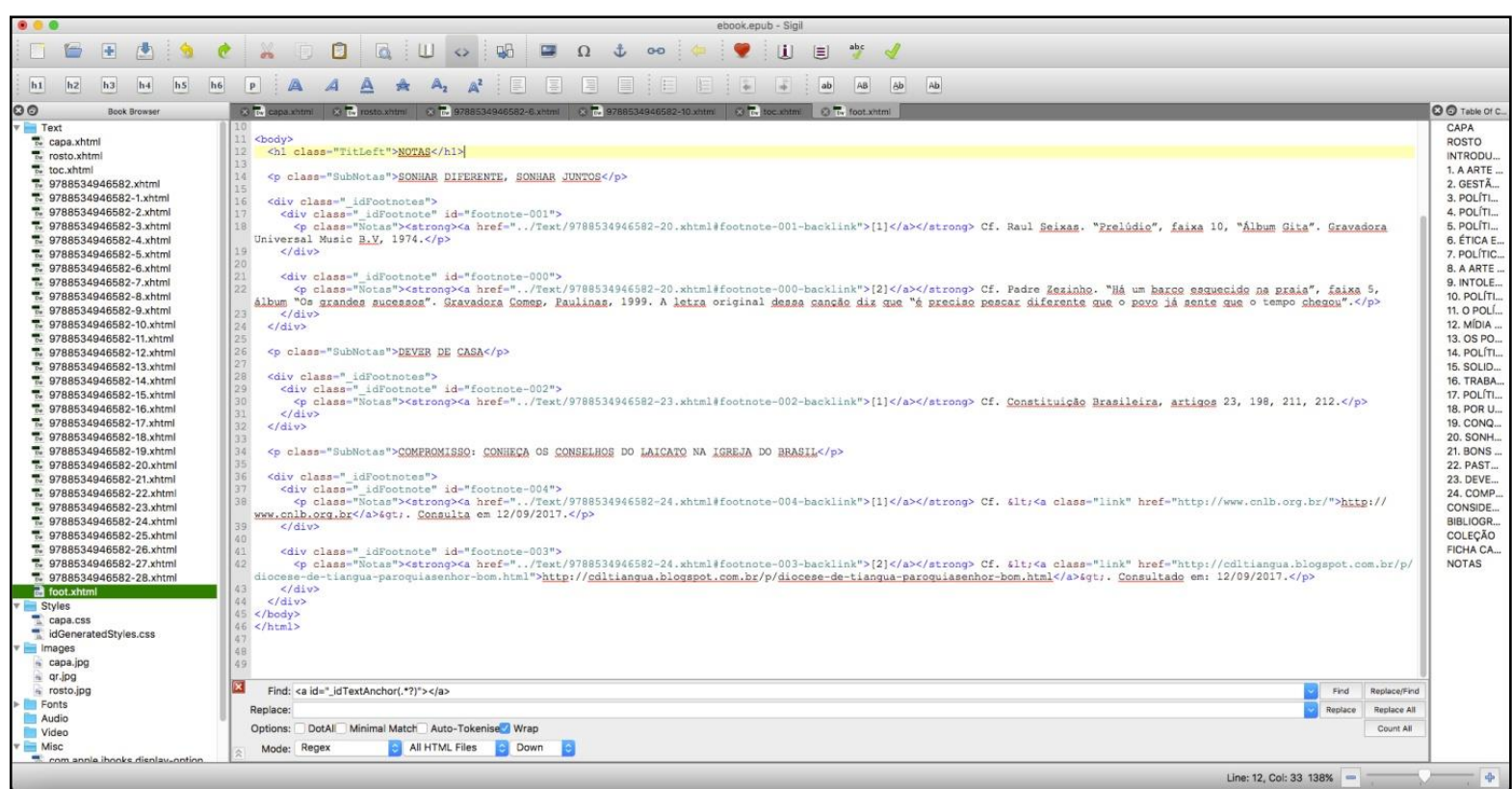


Figura B-15 - Edição de metadados no Sigil

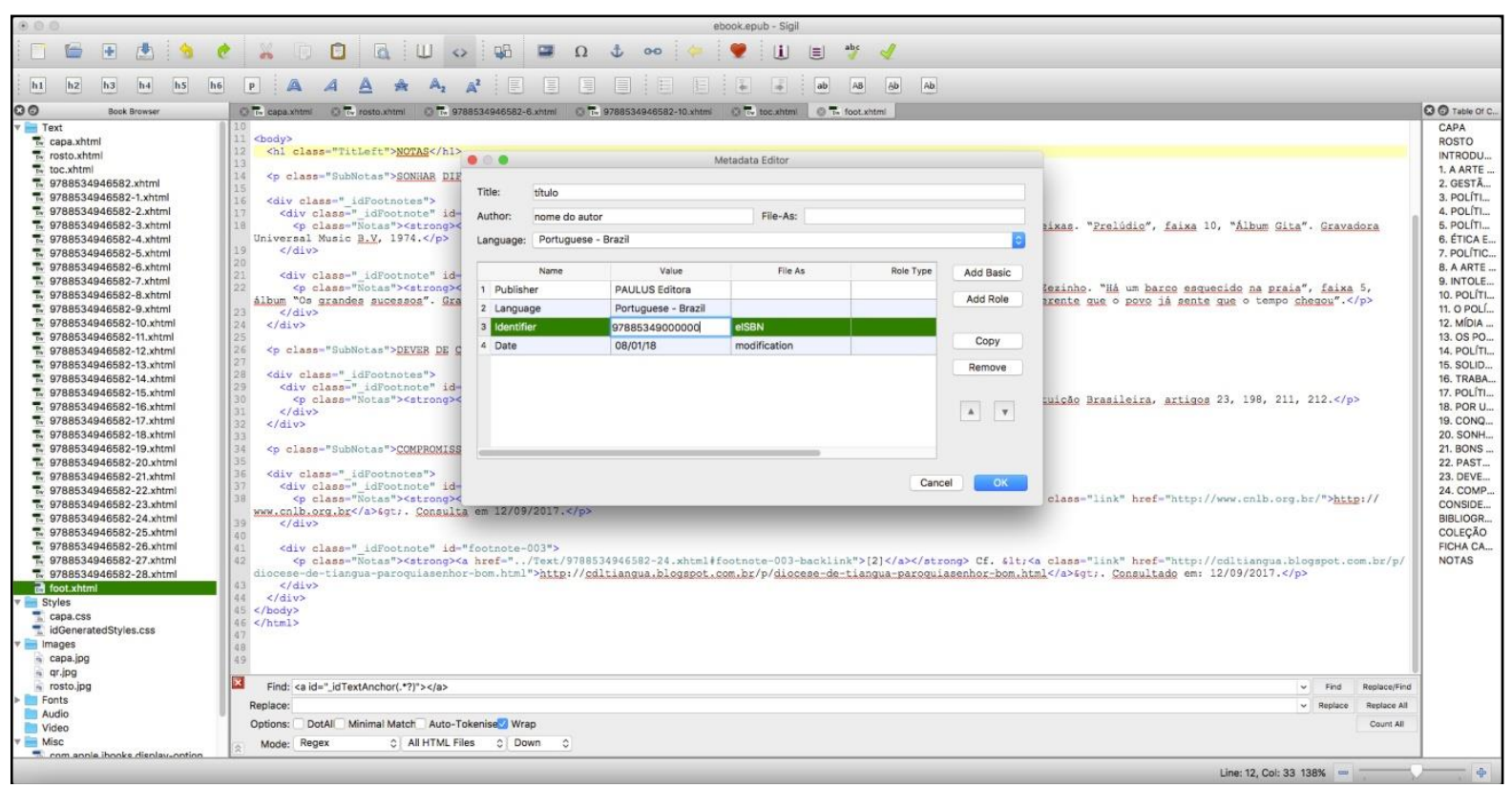

Figura B-16 - Verificação de erros final

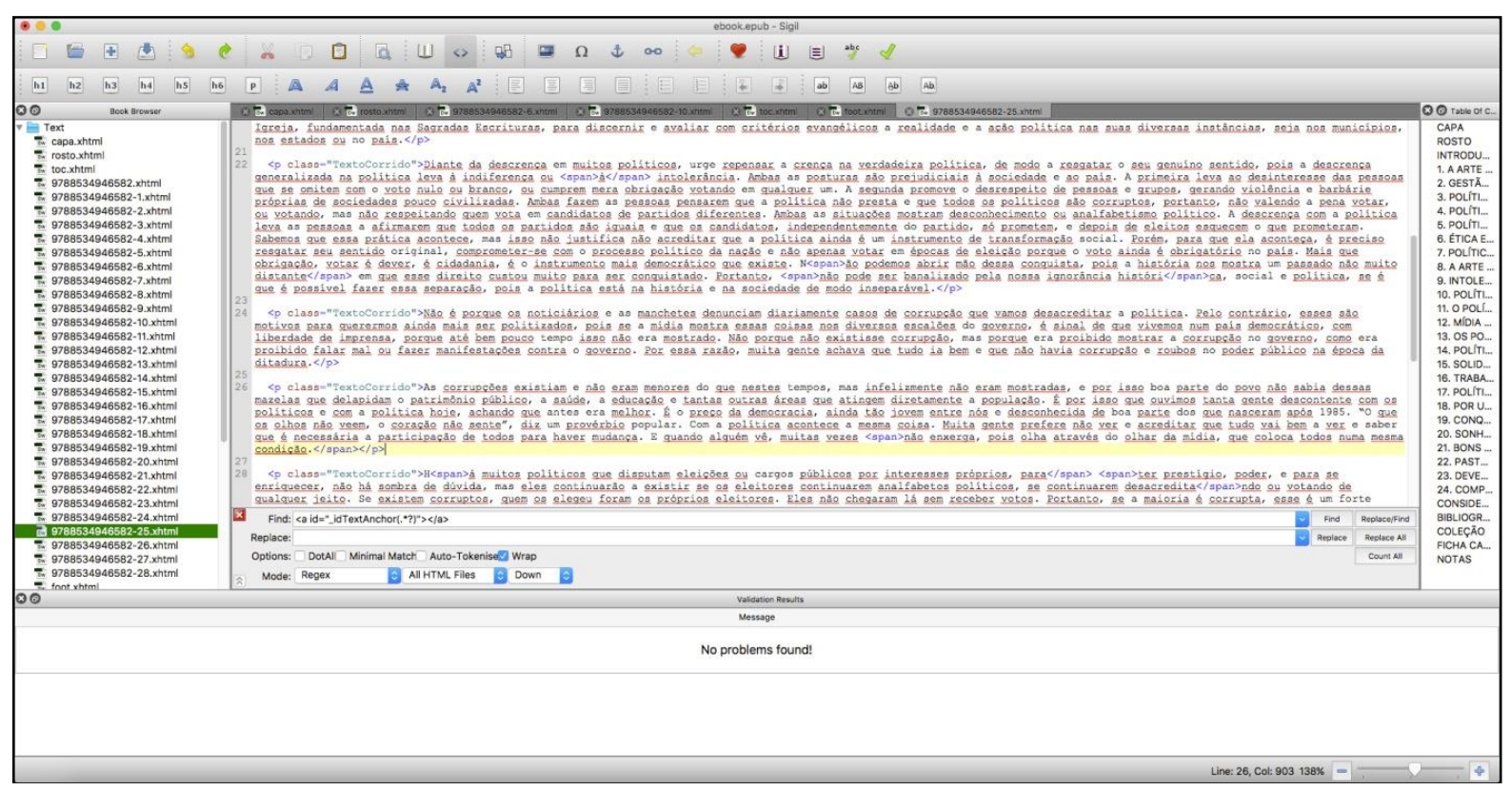


Figura B-17 - Plataforma Bookwire

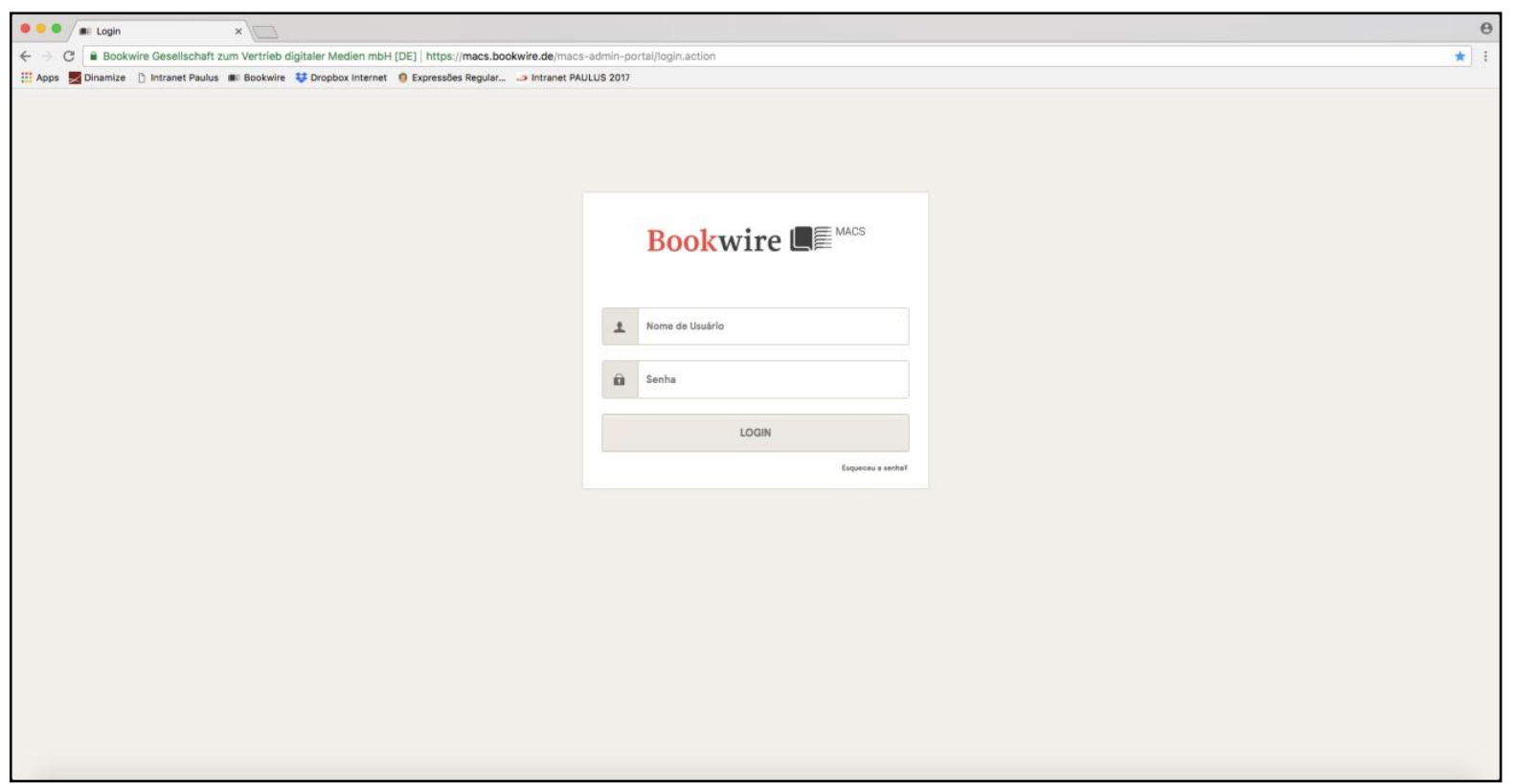

